\title{
1,1-BIS(3'-INDOLYL)-1-( $p$-SUBSTITUTEDPHENYL)METHANES INDUCE APOPTOSIS AND INHIBIT RENAL CELL CARCINOMA GROWTH
}

\author{
A Thesis \\ by \\ MELISSA DAWN YORK \\ Submitted to the Office of Graduate Studies of \\ Texas A\&M University \\ in partial fulfillment of the requirements for the degree of \\ MASTER OF SCIENCE
}

August 2007

Major Subject: Toxicology 


\title{
1,1-BIS(3'-INDOLYL)-1-(p-SUBSTITUTEDPHENYL)METHANES INDUCE APOPTOSIS AND INHIBIT RENAL CELL CARCINOMA GROWTH
}

\author{
A Thesis \\ by \\ MELISSA DAWN YORK \\ Submitted to the Office of Graduate Studies of \\ Texas A\&M University \\ in partial fulfillment of the requirements for the degree of \\ MASTER OF SCIENCE
}

Approved by:

Chair of Committee, Stephen Safe

Committee Members, Timothy Phillips

Robert Burghardt

Head of Department, Robert Burghardt

August 2007

Major Subject: Toxicology 


\section{ABSTRACT}

1,1-Bis(3'-indolyl)-1-( $p$-substitutedphenyl)methanes

Induce Apoptosis and Inhibit Renal Cell Carcinoma Growth. (August 2007)

Melissa Dawn York, B.S., Texas A\&M University

Chair of Advisory Committee: Dr. Stephen Safe

Renal cell carcinoma (RCC) accounts for $85 \%$ of kidney cancer incidence in the US. Since 1950 there has been a 126\% increase in kidney cancer incidence in the US. Thirty percent of new patients present with a localized easily treatable carcinoma while $30 \%$ of patients present with a high-grade metastatic carcinoma. Five-year survival rates for metastatic RCC is $6-12$ months (Lipworth et al, 2006). Current disease treatment options for metastasis include chemotherapy and radiation ( $8 \%$ response rate), immunotherapy (15-30\% response rate) and newly developed angiogenesis inhibitors which are in phase III trials (Staehler et el, 2005).

In RCC cells, it has been shown that PPARy agonists inhibit cell proliferation, induce apoptosis, and induce anti-angiogenic effects in vitro. Unlike most tumor types, PPARy is downregulated in tissue samples from $47 \mathrm{RCC}$ patients. However, in cell culture studies PPARy expression does not correlate with growth inhibitory or apoptotic effects of PPARy agonists in renal cell lines indicating that PPARy independent responses may play a large role in actions 
associated with the PPARy agonists (Yuan et al, 2006). 1,1-Bis(3'-indolyl)-1-(psubstitutedphenyl)methanes containing $p$-trifluoromethyl, $p$-t-butyl and $p$-phenyl substituents activate peroxisome proliferator-activated receptor $\gamma$ (PPAR $\gamma$ ) and inhibit growth of ACHN and 786-0 renal cell carcinoma cell lines. PPAR $\gamma$ is overexpressed in ACHN cells and barely detectable in 786-0 cells, and treatment with the $t$-butyl analog (DIM-C-pPhtBu) induces cell cyle inhibition. DIM-C-pPhtBu also induced several common PPAR $\gamma$-independent proapoptotic responses in $\mathrm{ACHN}$ and $786-0$ cells, including increased expression of nonsteroidal antiimflammatory drug-activated gene-1 (NAG-1) and endoplasmic reticulum stress which activates death receptor 5 and the extrinsic pathway of apoptosis. In addition, DIM-C-pPhtbu (40 mg/kg/d) also inhibited tumor growth in an orthotopic mouse model for renal carcinogenesis, and this was accompanied by induction of apoptosis in renal tumors treated with DIM-CpPhtBu but not in tumors treated with the corn oil vehicle (control). Thus, DIMC-pPhtBu and related compounds represent a novel class of mechanism-based drugs that have potential for treatment of renal adenocarcinoma for which there are currently limited options for successful chemotherapy. 


\section{DEDICATION}

"We have a hunger of the mind which asks for knowledge of all around us, and the more we gain, the more is our desire; the more we see, the more we are capable of seeing" - Maria Mitchell

To my husband and family who will always believe in me. 


\section{ACKNOWLEDGMENTS}

I would like to thank my committee chair, Dr. Safe and my committee members, Dr. Phillips, and Dr. Burghardt, for their guidance and support throughout the course of my research.

Thanks to Kim Daniels and all members of my laboratory for their friendship, support and teaching that has made this masters degree possible.

The financial assistance of the National Institutes of Health (ES09106 and CA112337) and the Texas Agricultural Experiment Station is gratefully acknowledged. 


\section{TABLE OF CONTENTS}

Page

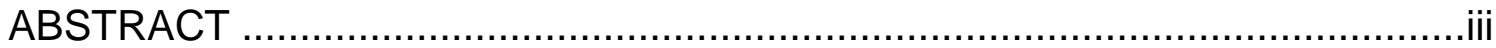

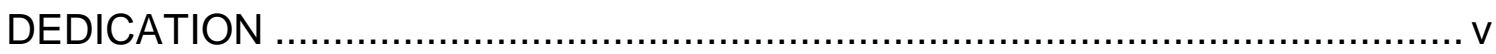

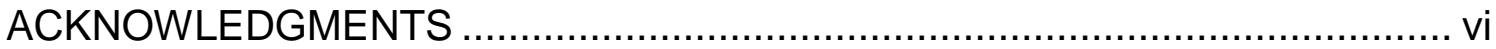

TABLE OF CONTENTS .............................................................................

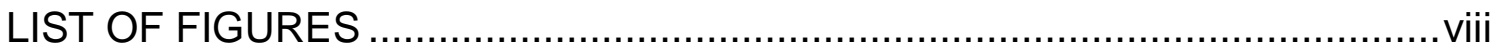

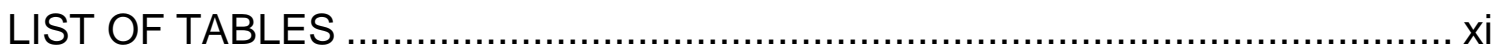

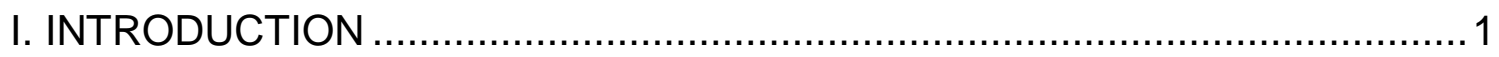

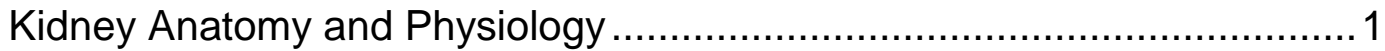

Chronic and Acute Kidney Disease................................................... 14

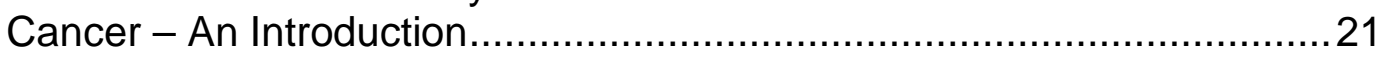

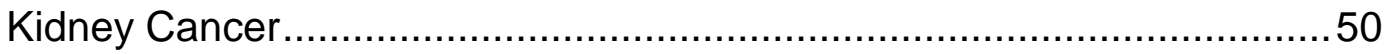

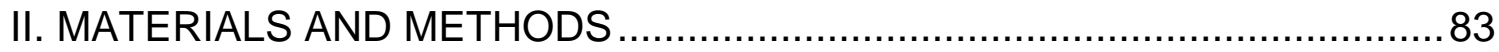

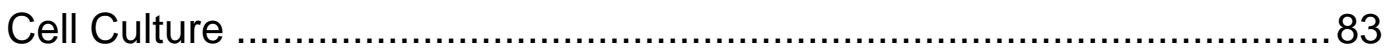

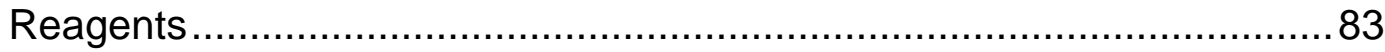

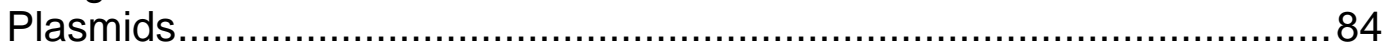

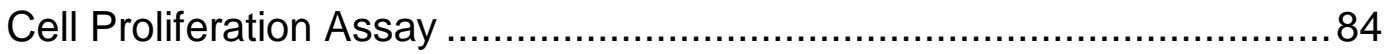

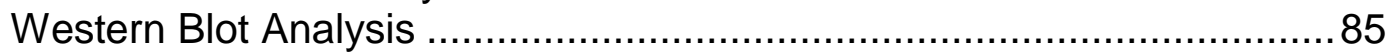

Transfection and Luciferase Assay ................................................. 86

Animals and Orthotopic Implantation of Tumor Cells ............................86

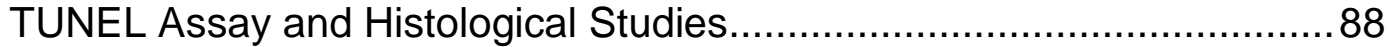

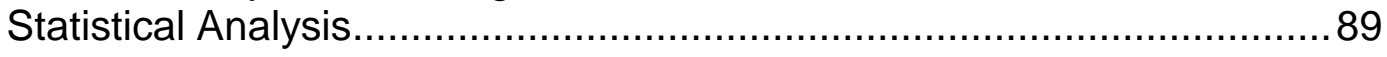

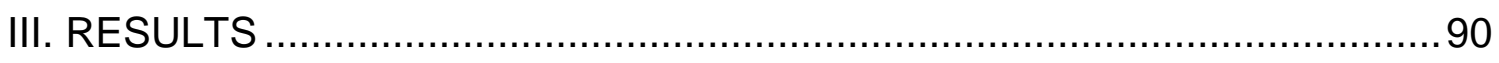

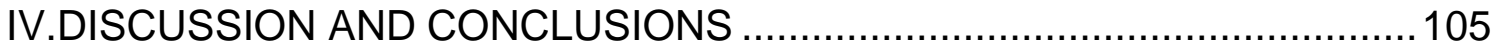

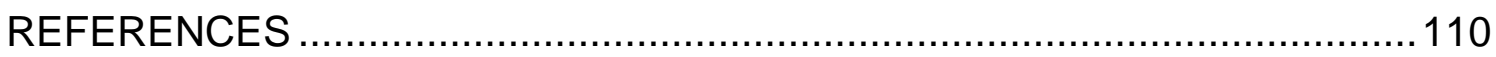

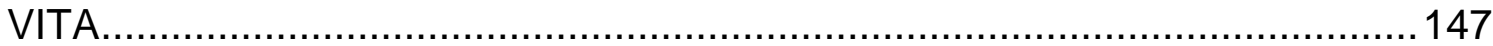




\section{LIST OF FIGURES}

Page

Fig. 1. Low magnification scanning electron micrography of renal

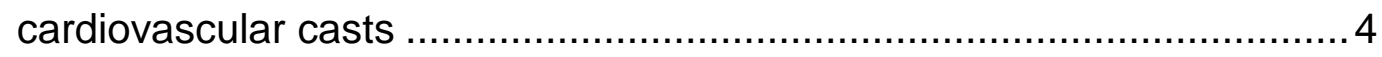

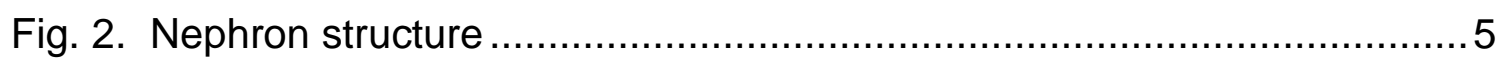

Fig. 3. Protective and restorative responses to volume loss ............................ 8

Fig. 4. Vitamin D synthesis and blood calcium regulation............................. 12

Fig. 5. Electron microscope picture of glomerular capillary wall .....................20

Fig. 6. Bioactivation of acetaminophen in the proximal renal tubule ................24

Fig. 7. p53 point mutations caused by mutagens …...................................26

Fig. 8. Biotransformation of S-(1,2-dichlorovinyl)-L-cysteine by

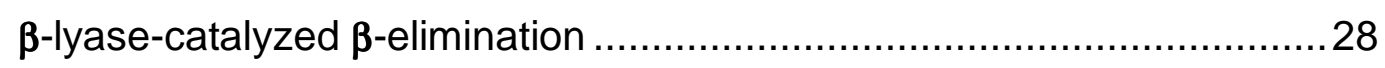

Fig. 9. Nicotine prevents apoptosis induced by methadione in human lung

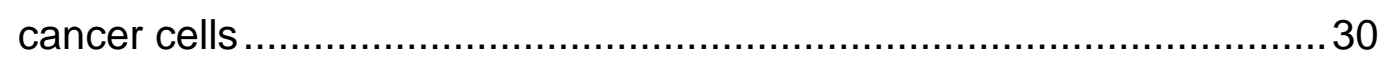

Fig. 10. Silencing of EGFR suppresses VHL -/- RCC tumor formation ..............32

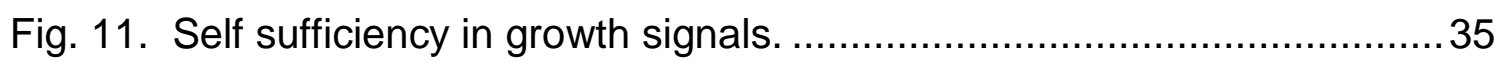

Fig. 12. Rescue of TGF- $\beta$ growth inhibition by overexpression of TBR 2 and

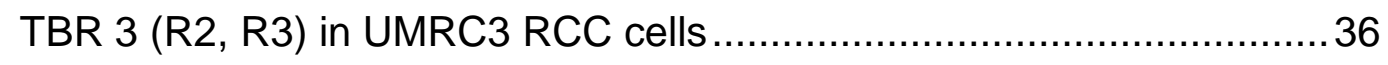

Fig. 13. Apoptosis evasion techniques found in RCC tissue samples .............40

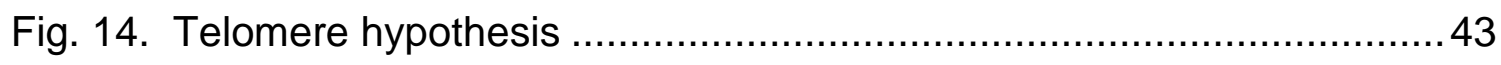

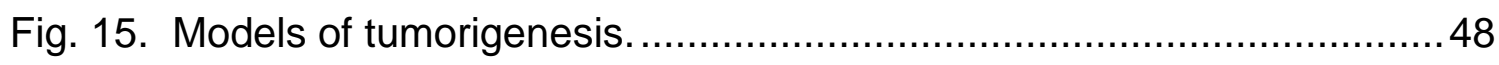


Fig. 16. Trends in 2000 United States standard age adjusted incidence of renal cell cancer by race and sex in 1973 to 2002 based on SEER data 51

Fig. 17. Age distribution of RCC diagnosis in occupationally TCE-exposed (black bars) and non-exposed patients (white bars) 56

Fig. 18. Immunotherapy against RCC using IFN- $\alpha$. 59

Fig. 19. Immunotherapy against RCC using IL-2 ....................................60

Fig. 20. Regulation of Hif $1 \alpha$ by $\mathrm{pVHL}$. 62

Fig. 21. Kaplan-Meier anaylsis of surivial free of tumor progression for patients receiving high dose bevazicumab 65

Fig. 22. Regulation of hypoxia induced metabolic switches by HIF-1 $\alpha$ 66

Fig. 23. Growth inhibitory effects of TFG- $\alpha$ antisense oligodeoxynucleotide on $\mathrm{VHL}^{-/-} \mathrm{RCC}$ cells 67

Fig. 24. Production of NAG-1 transgenic mice ........................................... 71

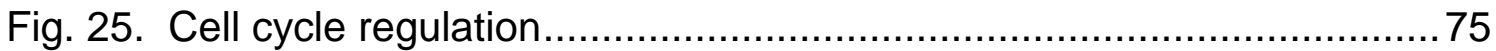

Fig. 26. ER stress-dependent apoptosis................................................. 78

Fig. 27. Rational for the targeting of ER stress-related apoptosis....................79

Fig. 28. Structures of PPAR $\gamma$-active C-substituted DIMs. ...............................80

Fig. 29. Inhibition of RCC growth by PPAR $\gamma$-active C-DIMs ...........................91

Fig. 30. Activation of PPAR $\gamma$ and cell cycle proteins by C-DIMs ......................94

Fig. 31. Effects of C-DIM compounds on caveolin-1 ..................................96 
Fig. 32. Activation of ER stress and apoptotic responses by C-DIMs in

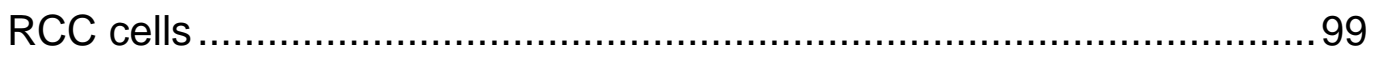

Fig. 33. Induction of apoptosis and role of PPAR $y$ in mediating effects

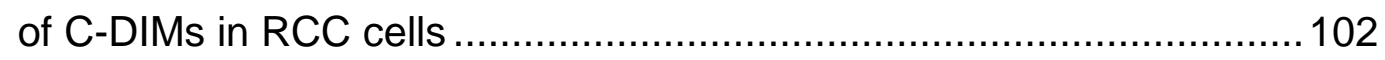

Fig. 34. DIM-C-pPhtBu inhibits tumor growth in an orthotopic model for renal adenocarcinoma. 103 


\section{LIST OF TABLES}

Page

Table 1. Reactivity of electrophiles and nucleophiles ..............................23

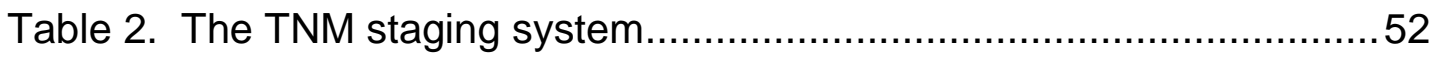

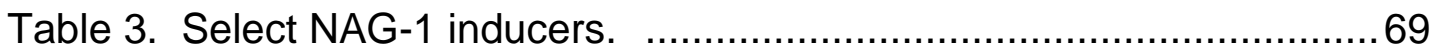




\section{INTRODUCTION}

\section{Kidney Anatomy and Physiology}

Kidney Physiology. The kidney has five main functions within the body, the regulation of body fluid osmolality and volume, electrolyte balance, the acid-base balance, the excretion of metabolic products and foreign substances, and the production and secretion of hormones. Fluid osmolality is important for the function of all organs, the kidney excretes and reabsorbs solutes based on water and solute intake. In the human body, the serum osmolality is maintained between the narrow range of $285-295$ mosm/l primarily by regulation of sodium levels (Tareen et al., 2005). Osmolality is controlled through the kidney by signals from the cardiovascular and central nervous systems. A second important function of the kidney is to maintain electrolyte and metabolite concentrations in equilibrium despite changes in dietary intake. Electrolytes controlled by kidney function include sodium, potassium, chloride, bicarbonate, calcium, and phosphate ions. Metabolic intermediates excreted through the kidney including citrate and succinate generated through the Krebs cycle (Tareen et al., 2005). Enzymes are active over a very narrow $\mathrm{pH}$ range and the lung and kidney are important for maintining $\mathrm{pH}$ within the 7.1-7.4 range.

This thesis follows the style of Molecular Pharmacology. 
The kidney serves to excrete acid products taken in through the diet or synthesized in the body as metabolic byproducts. In addition, kidneys also participate in regulation of the bicarbonate buffer system by selective reabsorption of $\mathrm{HCO}_{3}{ }^{-}$and production of new bicarbonate through ammonium production (Wagner et al., 2006). The kidney also has specialized transport and filtration mechanisms to ensure that toxicants and metabolic waste products are excreted through the kidney while selectively retaining proteins and other biochemicals. Natural waste products include urea from the metabolic breakdown of amino acids, uric acid generated from nucleic acid metabolism, and creatinine that is from muscle creatinine. In addition to natural waste products, the kidney also actively eliminates many foreign substances including drugs and pesticides and their metabolites. Patients with decreased renal function are unable to excrete these exogenous substances, thus changing the toxicological profile of the drug (Dekant and Vamvakas, 1996). In addition to secretion, the kidney is responsible for production of several important hormones including calcitriol, and erythropoietin. Renin is produced by the kidney to regulate blood pressure through activation of the rennin-angiotensinaldosterone system (Ruth and Wassner, 2006). Calcitriol secretion is important for regulation of calcium reabsorption in the Gl tract as well as calcium bone deposition (Hoenderop et al., 2005). Patients with chronic renal disease often develop bone abnormalities as a result of decreased bone deposition. Erythropoietin exhibits anti-inflammatory activity and secretion is necessary for 
red blood cell development in the bone marrow consequently, chronic renal failure patients often develop anemia and inflammation (Levin, 2006).

Renal Structure and Function. The kidney is symmetrically paired, located against the posterior wall of the abdomen behind the peritoneum and on either side of the vertebral column. The adult human kidney weighs between 115-170 grams and is $11 \mathrm{~cm}$ long, $6 \mathrm{~cm}$ wide and $3 \mathrm{~cm}$ thick. The kidney is divided into two strata, the medulla at the core and the cortex at the outer surface. Components of the kidney include blood vessels, nephrons, lymphatics and nerves (Stanton and Koeppen, 2001).

Twenty percent of total cardiac output of a kidney at rest is directed to the kidneys through the renal artery (O'Conner, 2006). The renal artery along with the renal vein and the pelvis make contact with the kidney through an invagination in one side, subsequently the vasculature branches in the cortex direction into interlobar arteries, arcuate arteries, and finally into afferent arterioles. Blood flow through the afferent arterioles is dispersed into the glomerular capillary network, and then combined again to form efferent arterioles (Fig. 1). The control of the afferent and efferent arterioles through vasodilatation and vasoconstriction control the resulting pressure of blood flow and filtration rate (Campese and Park, 2007). 


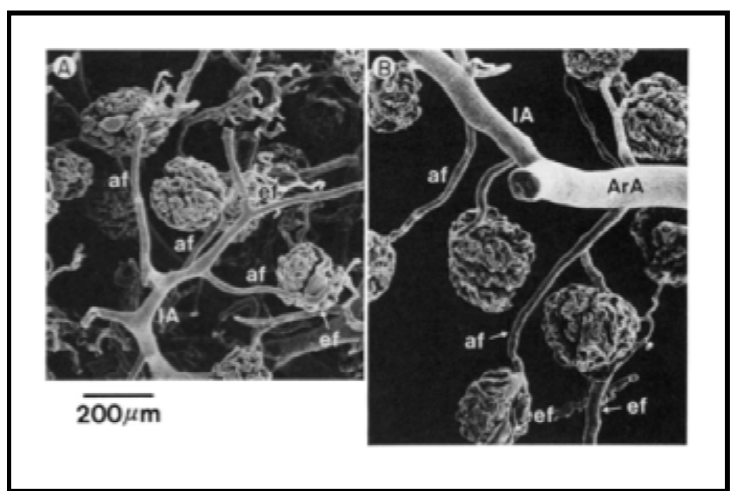

Fig. 1. Low magnification scanning electron micrography of renal cardiovascular casts. (af) afferent arteriole (ef) efferent arteriole (ArA) arcuate artery (AI) interlobular artery (Kimura et al., 1990).

Efferent arterioles branch into the vasa recta to supply blood to the outer and inner medulla. The efferent arterioles then divide to form the peritubular capillary bed to allow reabsorbtion of filtrate. The renal arteriole system runs opposed to the renal venous system that forms progressively the interlobular vein, arcuate vein, interlobar vein and finally the renal vein (Stanton and Koeppen, 2001).

Renal Filtration. Sixty percent of the adult body weight is water, two thirds existing as intracellular fluid and one third as extracellular fluid. Extracellular fluid consists of $75 \%$ interstitial fluid and $25 \%$ plasma (Verbalis, 2003). The downhill movement of sodium ions across the gradient is the main driving force for fluid and chemical reabsorption in the kidney. In bodily fluid, sodium is the major cation while chloride and bicarbonate are the major anions and the balance and composition of major ions is controlled by the kidneys filtration 
system. In order to maintain the stable ion concentrations in the blood, the kidney filters a three times the volume of the total body water every day (Ruth and Wassner, 2006).

Each human kidney consists of more than 1.2 million nephrons dispersed throughout the cortex and medulla. Nephrons are composed of cells constructed into a hollow tube of a single cell layer. Nephron structure consists of a renal corpuscle attached to a proximal tubule, which leads to a hairpin turn, called Henle's loop. The upturn in Henle's loop leads to the distal tubule and finally to the collecting duct system (Fig. 2). Each segment of a nephron is uniquely differentiated to play a unique role in filtration of substrate (Stanton and Koeppen, 2003).

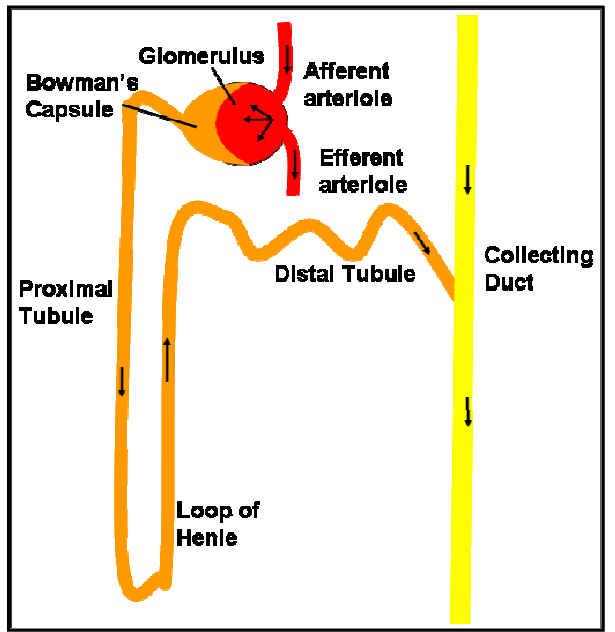

Fig. 2. Nephron structure. Filtrate flows into the glomerular apparatus through the afferent arteriole and then passes into the proximal tubule and then into the loop of Henle and the distal tubule. Final filtrate collection occurs in the collecting ducts. 
Glomerular Apparatus. The renal corpuscle that ultra concentrates molecules from the blood into the tubular space, is located in the cortex and is comprised of glomerular capillaries and the Bowman's capsule. Epithelial cells called podocytes cover the glomerular capillaries forming the filtration barrier (Kanwar, 1984). In addition to the capillaries and podocytes, mesangial cells are the active immune responsive elements and are similar to monocytes. The last important feature of the renal corpuscle is the juxtaglomerular apparatus, which is in contact with the afferent arteriole that actively controls renal blood flow.

To ultra concentrate substrates, hydrostatic pressure from the afferent arteriole in the glomerular capillaries forces water and filtrates to collect in the Bowman's space. The glomerular filtration barrier has a net negative charge resulting in reduced filtration of anionic proteins. Proteins and ions $<20$ angstroms pass easily through the negatively charged filtration barrier. However, proteins between 20-45 angstroms are selectively filtered based upon their cationic charge. Any molecule larger than 45 angstroms will not pass through the filtration barrier (Brenner, 1976; Kanwar, 1984).

The glomerular apparatus and associated juxtaglomerular apparatus are responsible for regulation of blood pressure via the renin, angiotensin system. Kidney regulation of blood pressure occurs during activation of the sympathetic nervous system or when blood pressure is low and is illustrated in Figure 1.3. In 
these situations, renin is produced in specialized cells that line the afferent arteriole and catalyzes the cleavage of circulating angiotensinogen to give angiotensin I. Angiotensin I is subsequently cleaved by angiotensin to give the final product, angiotensin II (Ang II). Ang II binds to G-protein coupled receptors to cause vasoconstriction (Campese and Park, 2007). In contrast to the release of renin, the glomerular apparatus is also affected by the release of NO from the proximal tubule and Henle's loop. NO has actions opposite to angiotensin II and acts as a vasodilator to reduce renal vascular resistance. In response to high blood pressure, NO is produced by the enzyme endothelial nitric oxide synthase (eNOS) in renal tubular epithelial cells (Fig. 3). NO expression reduces sodium reabsorption by inhibiting $\mathrm{Na}-\mathrm{K}-2 \mathrm{Cl}$ transporters that move $\mathrm{Na}$ from the tubule lumen into the blood (Herrera et al., 2006; Marin and Sessa, 2007).

The following nephron structures ensure that molecules that are either beneficial or of low availability are reabsorbed into the system. For example, although approximatly 8 grams of calcium ion are concentrated daily by the glomerulli, only 0.16 grams are excreted in the urine (Hoenderop et al., 2005). 


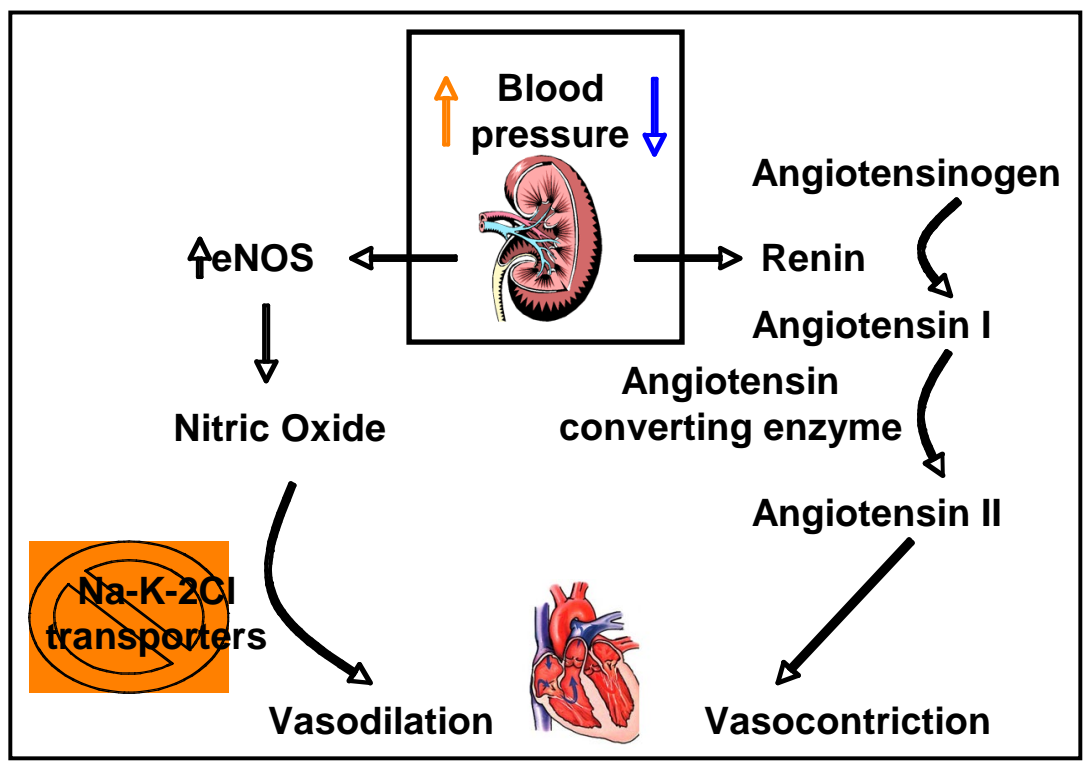

Fig. 3. Protective and restorative responses to volume loss. Renin is released from the kidney in response to a drop in blood pressure, resulting in activated angiotensin I that is converted to catalytically active angiotensin II that acts as a vasoconstrictor. If blood pressure increases eNOS expression is induced resulting in increased production of nitric oxide that inhibits the action of $\mathrm{Na}-\mathrm{K}-2 \mathrm{Cl}$ transporters leading to vasodilation.

Proximal Tubule. Once waste products and urine have been concentrated in the renal corpuscle, they flow into the proximal tubule. Proximal tubule cells have differential apical and basolateral a surface and the surface area of the apical, reabsorption side is increased though brush border surfaces (Kinne, 1975). Sodium potassium pumps maintain differential concentrations of major ions in the extracellular and intracellular fluids. For example in the extracellular fluid, sodium ion is actively maintained at $145 \mathrm{mEq} / \mathrm{L}$ while the intracellular fluid contains only $12 \mathrm{mEq} / \mathrm{L}$ of this ion. 
In the proximal tubule, $67 \%$ of the filtered water is passively reabsorbed along with soluble sodium, chloride, and potassium ions. The proximal tubules are responsible for the reabsorption of approximately $80 \%$ of filtered $\mathrm{HCO}_{3}{ }^{-}$by the action of two proton transporters, the $\mathrm{Na}^{+} / \mathrm{H}^{+}$exchanger NHE-3 and $\mathrm{H}^{+}$-ATPase (Nakamura, 2004). In proximal tubules, the passive, downhill movement of sodium across its concentration gradient through these transporters is coupled to the passive import of glucose, calcium as well as other molecules (Suki, 1979). Once inside the cell, glucose and other molecules move downhill from the basolateral membrane into the blood. In addition to the movement of solutes, charged metabolic proteins and nephrotoxic molecules such as cadmium bound to metallothionein can be endocytosed and broken down (or released) by lysosomes in the proximal tubule cells (Dekant and Vamvakas, 1996).

Large or highly charged particles often cannot pass through the filtration barrier because they bind strongly to plasma proteins such as albumin (Robertson and Rankin, 2006). In addition to the reabsorption of important electrolytes, proximal tubule cells are also important for the secretion of large organic anions and cations through nonspecific transporter systems. The activity and concentration of these transporters can determine xenobiotic-induced nephrotoxicity by controlling the excretion of charged nephrotoxic drugs and environmental toxicants. Organic cations that are excreted include many alkaloids, positively 
charged heterocyclic compounds from dietary sources, and recreational or therapeutic drugs including nicotine and cisplatin (Wright, 2005). The multidrug resistance transporter multidrug resistance transporter (MDR1) controls the efflux of both anionic glutathione A-conjugates, unmodified anionic chemotherapeutic agents as well as bulky, polyvalent organic cations (Miller, 1995; Cole et al., 1992). Smaller, positively charged monovalent compounds such as tetraethylammonium (TEA) move across the electrical potential gradient from the blood to the basolateral membrane by the passive action of organic cation transport (OCT) proteins (Inui et al., 2000). In contrast, organic ions are secreted uphill by the actions of organic anion transport (OAT) proteins. Organic anions that are excreted include cyclic nucleotides, prostaglandins, uric acid, and drugs such as B-lactam antibiotics, methotrexate and nonsteroidal antiinflammatory drugs (NSAIDs; Apiwattanakul et al., 1999; Uwai et al., 1998). Regulation of electrolyte reabsorption in the proximal tubule is controlled by aldosterone secretion. An increase in aldosterone results in increased sodium channel synthesis, particularly the epithelial sodium channel (ENaC), thus increasing sodium reabsorption into the blood (Ruth and Wassner, 2006).

Henle's Loop. Once through the proximal tubules and into the medulla, the substrate flows through Henle's loop through several consecutive structures termed the descending thin limb, the ascending thin limb and then a thick ascending limb. Unlike the highly differentiated proximal tubule cells, the cells 
composing the thin descending and ascending limbs of Henle's loop are poorly differentiated and contain few mitochondria. The thin ascending limb is impermeable to water and is highly invaginated with high concentrations of mitochondria. In the thick ascending limb of Henle's loop, $25 \%$ of the filtered potassium, calcium and bicarbonate are returned to the blood supply (Stanton and Koeppen, 2001).

One important function of Henle's loop is the activation and regulation of calcium levels in the blood through vitamin $D$ activation. Vitamin $D_{3}$ is synthesized by the action of UVB radiation (290-325 nm) on 7-dehydrocholesterol present in the plasma membrane of epidermal keratinocytes and dermal fibroblasts (Holick, 2003). Once generated, vitamin $D_{3}$ binds to vitamin $D$ binding protein that transports the structure to the liver for further processing by hydroxylation to generate 25-hydroxyvitamin $\mathrm{D}_{3}(25(\mathrm{OH}) \mathrm{D})$ (Fig. 4). 


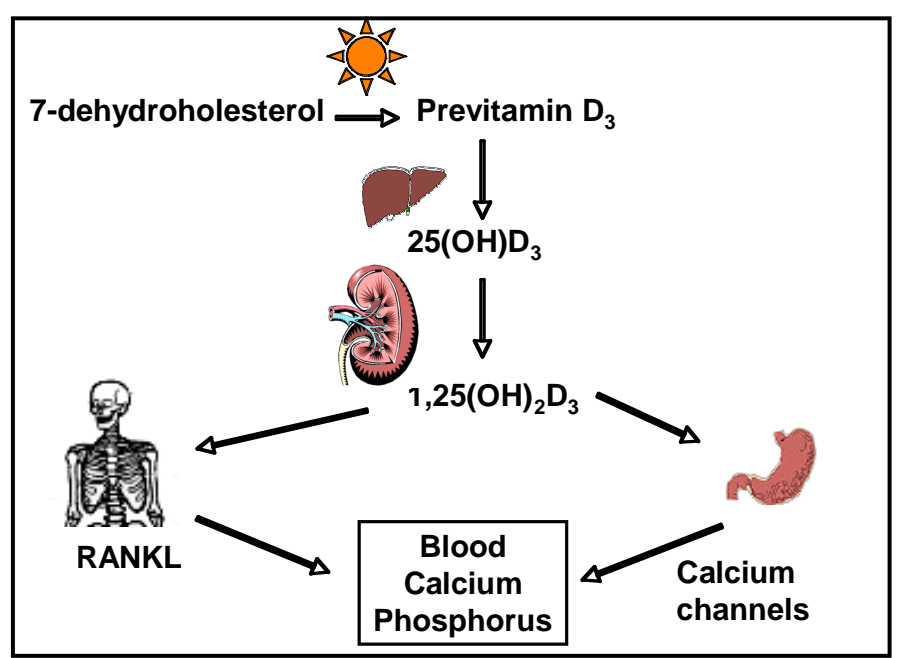

Fig. 4. Vitamin D synthesis and blood calcium regulation. The final step of vitamin $D$ synthesis occurs in the kidney and leads to increased RANKL activity and calcium channel espression in the gut resulting in increased calcium blood levels. Modified from Holik et al., 2003.

Hydroxylated vitamin $D$ is transported into the tubules and oxidized by cytochrome p450s specific to the kidney to generate the final product, 1,25 dihydroxyvitamin $\mathrm{D}_{3}$ (Nykjaer et al., 1999; Takeyama et al., 1997). The final product moves back into the blood where its primary action is upon the vitamin $D$ receptor (VDR) that enhances uptake of calcium in the diet and facilitates the release of calcium stored in bones. To increase calcium uptake the VDR mediates increased expression of epithelial calcium channel proteins and thereby enhanced calcium absorption in the intestines (Holick, 2004). In contrast, activation of VDR in osteoblasts increases expression of receptor activator of nuclear factor (NK)-KB (RANK) ligand (RANKL), which promotes maturation of preosteoclasts to osteoclasts. Mature osteoclasts release $\mathrm{HCl}$ and 
collagenases to destroy the bone matrix thus releasing calcium and phosphorus into circulation (Khosla, 2001).

Collecting Ducts. After leaving the thick ascending limb, substrates flow from a distal tube to the cortex, and into a cortical collecting duct. The collecting duct is a blend of two cell types, namely principal cells with low differentiation and intercalated cells that contain a high density of mitochondria. The cortical collecting duct is connected to the inner medullary collecting duct that contains poorly differentiated cells. The collecting duct is important for regulation of bodily fluid osmolality. An increase in body osmolality by as little as $1-4 \%$ can cause thirst by the release of arginine vasopressin, formally known as antidiuretic hormone (ADH) (Robertson, 1983; Thompson et al., 1986). ADH is synthesized in the hypothalamus and stored in neurosecretory granules in the pituitary until needed (Robertson, 1995). ADH in the kidney increases water retention through interaction with $\mathrm{AVP} \mathrm{V}_{2}$ receptors in the kidney. Activation of argenine vasopressin (AVP) $V_{2}$ receptors increases water permeability of the collecting duct by insertion of aquaporin-2 water channels (Knepper and Inoue, 1997). The final result is a decrease in urine volume and a reciprocal increase in urine osmolality. In contrast, when the blood becomes hypotonic to the intercellular fluid through salt loss, the kidneys respond by secretion of renin in the glomerular apparatus leading to the release of aldosterone. Aldosterone 
acts on the cortical collecting duct to reabsorb both salt and water returning the blood to proper osmotic levels (Ruth and Wassner 2006).

\section{Chronic and Acute Kidney Disease}

Patients can present with two general types of kidney disease, chronic renal disease and acute renal failure. The end stage for both diseases is end stage renal disease (ESRD) at which point all functions of the kidney are lost and the patient must consider dialysis or transplantation for survival.

Acute renal disease or acute renal failure (ARF) is the sudden and reversible loss of kidney function. In general, nephrotoxic substances of environmental origin or sudden changes in renal perfusion can cause ARF. Interestingly, 7.2\% of hospitalized patients develop ARF, the major causes being decreased renal perfusion 39\% (congestive heart failure, cardiac arrest, and volume contraction), nephrotoxin administration 16\%, contrast administration $11 \%$, and major surgery 9\% (Nash et al., 2002).

In the year 2000, it was estimated that $9.6 \%$ percent of Americans, corresponding to 19 million people had some form of chronic kidney disease (CKD) (Coresh et al., 2005). Unlike acute kidney disease, the nephrotic damage in chronic kidney disease is irreversible. CKD is strongly linked to cardiovascular disease and diabetes in the American population and is the 
leading cause of morbidity and mortality in CKD patients (Sarnak and Levey, 2000).

Interestingly, cardiovascular disease and CKD may be synergistic and even causal in their action. In some cases, mild undiagnosed CKD may be a precipitating factor in the development of cardiovascular disease due to mild kidney function dysregulation leading to volume overload, anemia, and hypertension. In contrast, cardiovascular disease may cause a blood volume or flow dysregulation producing chronic kidney disease (Jaradat and Molitoris, 2002). For example, diseased glomerular cells produce higher levels of renin compared to normal cells leading to vasoconstriction through increased levels of Ang II directly leading to hypertension. In addition to vasoconstriction, Ang II plays many roles in inflammation and increases levels of many inflammatory agents including IL-6, TNF- $\alpha$, NK-KB (Suzuki et al., 2003).

Renal Dysfunction. The development of chronic or acute kidney disease is linked to the dysregulation of body fluid osmolality, electrolyte maintenance, acid base regulation, and/or protein excretion.

The regulation of osmolality is important for cell and organ function. Changes in the osmolality of the blood or extracellular fluid results in the flow of into and out of the cell. Depending on the osmotic gradient, these shifts can cause 
significant swelling and contraction of organelles. For example, uncontrolled diabetes mellitus leads to hyperosmolality by solute movement against the increased cellular concentration of glucose (Ruth and Wassner, 2006).

Hyperosmotic blood causes water to flow from cells into the extracellular fluid and makes the cells lose volume. In the brain, membranous tethering allows only $15 \%$ shrinkage, leading to tearing of membrane-bound blood vessels and development of intracranial hemorrhages precipitating permanent neurological damage (Trachtman, 1991).

Hyperosmotic conditions can be generated by kidney dysregulation when congenital defects occur within the $A D H$ receptor pathway. $A D H$ insensitivity can occur within the defects in the $A \vee P V_{2}$ (X-linked recessive pattern of inheritance) receptor or the aquaporin-2 gene (autosomal recessive pattern of inheritance) (Fujiwara et al., 1995). Related decreases in AVP $V_{2}$ activation lead to decreased aquaporin-2 expression thus significantly reducing the body's ability to reabsorb water in the collecting duct (Verbalis, 2003).

In contrast, vomiting and diarrhea can lead to blood which is hypotonic to the cell resulting in water movement from the blood into cells which induces swelling. In the brain, cells cannot swell due to the presence of the bony skull and hypotonic blood can lead to intracellular cerebral edema, seizures and death (Trachtman, 1991). Interactions with the kidney can be a causal factor in the production of 
hypoosmotic blood, in the syndrome of inappropriate ADH secretion (SIADH) where $A D H$ secretion is upregulated causing the formation of high concentrations of aquaporin in the collecting duct. SIADH can be caused by drugs, infections, and is a common complication in lung carcinoma (Verbalis, 2003).

One of the major functions of the kidney is the regulation of calcium levels in the blood stream and dysregulation of this system can cause hyperkalemia (too much calcium) and hypocalcemia (too little calcium) leading to cardiac arrhythmia and altered myocardial contractility in acute cases (Commandeur and Vermeulen, 1990). As discussed above, in chronic kidney disease many patients have low circulating levels of activated vitamin $\mathrm{D}\left(1,25(\mathrm{OH})_{2} \mathrm{D}\right)$ and are unable to absorb calcium in the intestines leading to a net reduction in blood serum calcium levels (Christiansen et al., 1981; Takamoto et al., 1985). To compensate, PTH is released to enhance osteoclast activity in the bone matrix (Portale et al., 1984). In growing children, this condition can cause rickets due to normal circulating calcium but low circulating phosphate (Holick, 2004). In adult CKD patients, increased PTH causes destruction of the mineral and bone matrix of the skeleton causing osteoporosis. In addition, many CKD patients live in chronic pain caused by swelling in the inflamed bone matrix. To compensate, many doctors prescribe vitamin $D$ supplements to ease the pain and stop the loss of bone mass (Malabanan et al., 1998). 
Dysregulation of calcium levels by kidney disease can also lead to formation of atherosclerotic plaques. Atherosclerotic disease is defined as the fibrofatty plaque formation with late calcification leading to stiffening of arteries, or a circumferential lesion with calcification earlier in the course of the disease (Starry, 2000). Vascular smooth muscle cells differentiate from the same mesenchymal stem cells as osteoblasts. In CKD patients, high levels of circulating calcium generated as a result PTH derived bone loss, can cause vascular smooth muscle cells to transdifferentiate and take on osteoblastic character. In vitro calcium administration causes differentiated vascular smooth muscle cells to produce osteopontin, alkaline phosphatase and osteocalcin thus hypothetically causing mineralization of the vascular structure (Parhami et al., 1996).

The disruption of the acid base balance through renal tubular acidosis or metabolic alkalosis can be created or potentiated by many common disorders. Renal tubular acidosis is caused by disruption of the kidney's ability to regulate acid-base concentrations; this disease is seen in many hereditary and acquired conditions. For example a mutation in the gene encoding the $\mathrm{Na}^{+} / \mathrm{HCO}_{3}{ }^{-}$ cotransporter (SLC4A4) disrupts the ability of the proximal tubules to reabsorb bicarbonate resulting in excessive urinary bicarbonate wastage and severe metabolic acidosis (Alper, 2002; Dinour et al., 2004). Decreased bicarbonate in 
the blood leads to an increase in circulating acid byproducts, resulting in cerebral calcification, osteoporosis and glaucoma leading to blindness (Wagner et al., 2005).

Excess protein in the urine is a high predictor for the development of CKD. Proteinurea is always caused by structural defects in the glomerular apparatus. Glomerular apparatus damage can occur due to nephron damage caused by autoantigen generation or due to hereditary problems such as nephritic syndrome and Alport's syndrome.

Membranous nephropathy is the generation of glomerular subepithelial immunecomplex deposits resulting in decreased urinary protein excretion. It is estimated that $30-40 \%$ of patients reach end stage renal disease within $5-15$ years. The mechanism of immune complex generation in the disease is unknown but membranous nephropathy has been linked to toxicity generated by mercury, gold, and penicillamine (Nangaku and Couser, 2005). Current hypotheses describe either the release of antigens from damaged proximal tubules provoking an autoimmune response or the clumping of insoluble immune complexes in the glomerular apparatus filtration barrier (Edgington et al., 1968; Nagi et al 1971). In contrast, nephrotic syndrome is an increase in glomerular membrane permeability leading to net loss of essential protein from the bloodstream. An example is congenital nephritic syndrome of the Finnish type 
(NPHS1) that is caused by mutation in the NPHS1 gene that encodes for nephrin which is a major component of the glomerular filtration apparatus. In the absence of nephrin, filtration components such as the slit diaphragm and foot processes are missing (Fig. 5). Porteinuria develops during the fetal period leading to nephritic syndrome and death soon after birth (Kestila et al., 1998). There is no medical cure for NPHS1 and kidney transplantation is performed at the age of 1-2 years (Holmberg et al., 1995).

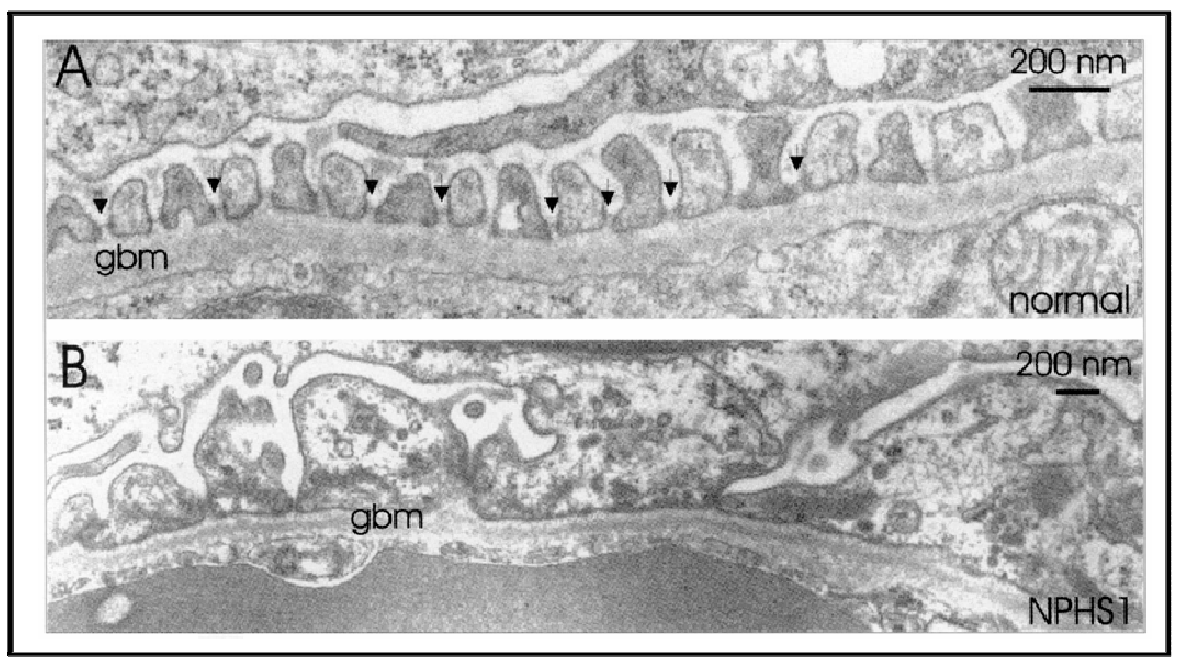

Fig. 5. Electron microscope picture of glomerular capillary wall. (A) Normal structure shows regular foot processes enclosing the glomerular basement membrane. (B) NPHS1 kidney, podocytes processes and slit diaphragm are missing (Jalanko et al., 2001).

Another common example of glomerular damage resulting in porteinuria is Alport's syndrome which is defined as the presence of blood in the urine linked to a defect in collagen matrix in the glomerular apparatus. Eighty-five percent of patients presenting with familial Alport's Syndrome have an X-linked mutation in 
type IV collagen (gene COL4A5) (Lemmink et al., 1997). In the absence of this collagen subtype, the glomerular basement membrane is exposed to proteases and oxidants and the glomerular membrane becomes thick, splitting, and deteriorating. This results in lack of size differential filtration (Kalluri et al., 1997). In this disease, blood in the urine can lead to inflammation of glomerular capillaries resulting in hypertension and renal failure (Dische et al., 1985).

\section{Cancer - An Introduction}

Statistics provided by the National Cancer Institute Surveillance Epidemiology and End Results (SEER) indicate that in the United States in the year 2007, $1,444,920$ will be diagnosed with and 559,650 people will die of cancer in 2007 (Mariotto et al., 2007). For all cancers, the median age at death was 73 years of age. Between their $50^{\text {th }}$ and $70^{\text {th }}$ birthdays, $21.26 \%$ of men and $15.56 \%$ of women will develop cancer at some site. Although total cancer mortality has been declining at a rate of $2.1 \%$ between the years of $2002-2004$, the overall five year relative survival rate is only $64.9 \%$ (Mariotto et al., 2007).

Tumor Development Model. Cancer development is a multi-step process with an estimated four to seven rate limiting events (Renan, 1993). In general, the stages are categorized as initiation, promotion and progression (Hursting et al., 1999). 
Initiation. Initiation involves mutations of critical DNA elements that allow selective growth advantage over normal cells and can occur due to DNA adduct formation by endogenous and exogenous carcinogens. Endogenous carcinogens include many types of reactive oxygen species (ROS) that are normal byproducts of oxidative metabolism and UV radiation.

Exogenous toxins are ubiquitous and can cause carcinogenesis by covalent adduct formation with DNA bases (Weinstein, 1988). Xenobiotic metabolizing enzymes are present in many organs of the body including the liver and kidney. The liver is the main site of xenobiotic metabolism via phase I enzymes called cytochrome p450s (CYPs). CYP enzymes account for $70-80 \%$ of all xenobiotic metabolizing enzymes and are primarily located in the endoplasmic reticulum (ER), mitochondria, and plasma membrane (Evans and Relling, 1999). CYP acts as a hemoethiolate monooxygenase in which the conserved peptide motif Phe- $\mathrm{X}_{(6-9)}$-Cys- $\mathrm{X}$-Gly ( $\mathrm{X}$ denotes any amino acid) binds octahedral iron and transfers one atom of atmospheric oxygen to a substrate (Bachschmid et al., 2005). CYPs catalyze the oxidation or epoxidation of $\mathrm{C}-\mathrm{H}$ and carbon-carbon double bonds to give more hydrophilic metabolites (Anders, 1980). Phase II enzymes conjugate reactive electrophilic species with polar intermediates for secretion in the bile. It is estimated that only $25 \%$ of all carcinogenic compounds create adducts in their natural form, the other $75 \%$ must first undergo metabolic activation by CYP oxidative enzymes to generate reactive intermediates (Nebert 
and Dalton, 2006). Metabolic activation of procarcinogens creates an electrophilic compound capable of binding to nucleophilic sites. Selectivity of binding targets is based on the relative "hardness" of the electrophile and nucleophile, thus hard electrophiles will selectively bind hard nucleophiles (Table 1; Commandeur and Vermeulen, 1990).

Table 1: Reactivity of electrophiles and nucleophiles. In order of increasing hardness (Commandeur and Vermeulen, 1990).

\author{
Electrophiles \\ aldehydes \\ polarized double bonds \\ epoxides \\ strained ring lactones \\ alkyl sulfates \\ alkyl halides \\ aryl carbonium ions \\ benzylic carbonium ions \\ nitrenium ions \\ alkyl carbonium ions
}

\title{
Target Nucleophiles
}

thiol groups (cisteinyl residues in protiens and glutathione) sulfur atoms (methionyl residues)

primary and secondary amino groups in protien

amino groups and purine bases in DNA and RNA

oxygens of purines and pyrimidines in DNA and RNA

phosphate oxygen of RNA and DNA

The kidney also contains significant CYP450 levels, however, most p450 activity in the kidney is involved in synthesis of endogenous sterols and hormones such as vitamin D (Dekant and Vamvakas, 1996). Nevertheless, select compounds can cause nephrotoxicity and tumorigenesis by metabolic activation in the kidney. For example, high doses of acetaminophen result in renal necrosis by 
two mechanisms involving either direct oxidation catalyzed by CYPs or deacetylation followed by CYP-dependent oxidation. Direct CYP450 oxidation results in the reactive intermediate $\mathrm{N}$-acetylbenzoquinonimine, an intermediate with little renal toxicity. However, primary deacetylation creates $\rho$-aminophenol which is oxidized to the final electrophilic product benzoquinoneamine that is capable of creating adducts to nucelophilic species (Fig. 6; Commandeur and Vermeulen, 1990).

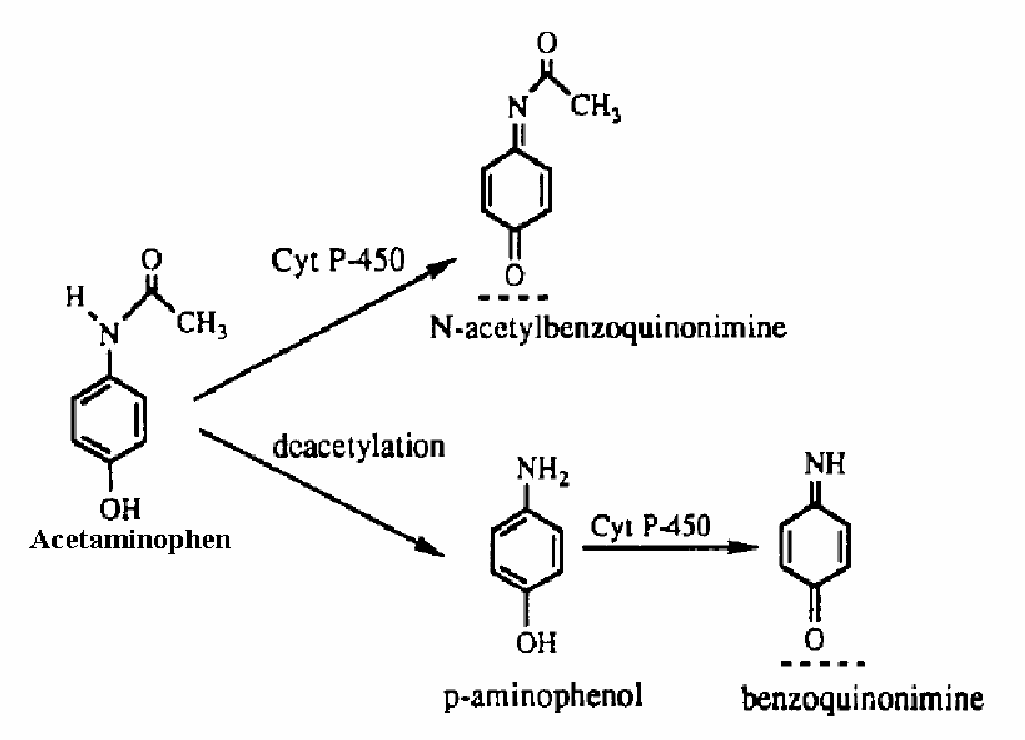

Fig. 6. Bioactivation of acetaminophen in the proximal renal tubule. Reactive intermediates capable of covalent binding to macromolecules are underlined by dashed lines (Commandeur and Vermeulen, 1990).

CYP450-dependent metabolic activation can also cause DNA adduct formation at distant sites and cigarette smoke is a good example of this type of activity. Sixty-five percent of all cancers have been linked to carcinogen exposure due to 
diet and the environment (Koide et al., 1999). US cancer deaths attributable to cigarette smoking are as high as 30\% (Doll and Peto, 1981). Skin exposure to cigarette smoke condensate can cause nearly 50,000 stable DNA adducts for every 24 hours of exposure (Melendez-Colon et al., 1999). The most carcinogenic compound identified in smoke is a polycyclic aromatic hydrocarbon (PAH) called benzo(a)pyrene (BaP). BaP is metabolically activated by cytochrome p450 and epoxide hydrolase in cells to generate BaP-7,8dihydrodiol-9,10-epoxide (BPDE).

Electrophilic diol epoxides such as BPDE form covalent adducts at the N2 of guanine. Upon DNA replication, bulky adducts at guanine N2 create a unique $\mathrm{G} \rightarrow \mathrm{T}$ transversion in the p53 gene (Ruggeri et al., 1993). Consequently, in smokers p53 mutations are most often found in areas associated with $G \rightarrow T$ transversions (Fig. 7; Rubin, 2002). 


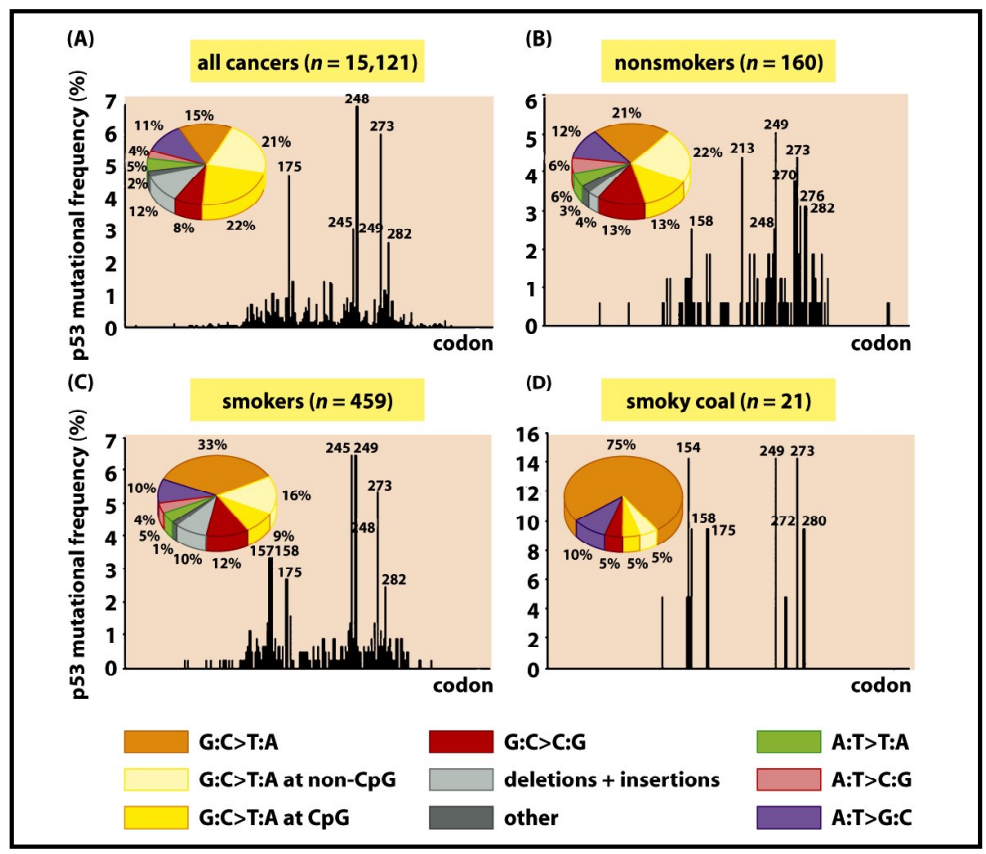

Fig. 7. p53 point mutations caused by mutagens. (A) All cancers (B) lung cancer in nonsmokers (C) lung cancer in smokers (D) lung cancer in nonsmokers exposed to smoky coal emissions (Weinberg et al., 2007).

Proximal tubule cells have low concentrations of activating CYPs, however, kidney cells have the highest levels of $\beta$-lyase activity and this is an alternative bioactivation pathway (Boogard et al., 1989; Commandeur et al., 1989). The phase II enzyme GST catalyzes the conjugation of electrophilic compounds and glutathione for subsequent secretion in the bile (Anders, 2004). In the proximal tubule $\gamma$-glutamyltransferase (GGT) catalyzes a salvage pathway resulting in hydrolysis of glutathione S-conjugates to cysteine S-conjugates that are removed from the plasma by active transporters in the kidney (Lash and Anders, 1989). Once concentrated in the nephron, bioactivation to cytotoxic metabolites is catalyzed by pyridoxal-phosphate-dependent $\beta$-lyase and bioactivation of 
haloalkanes can also occur after addition of glutathione follwed by $\beta$-lyasedependent-bioactivation (Cooper et al., 2002).

Glutathione dependent activation is implicated in the tumorgenicity of select dihalomethanes such as dichloromethane. Dichloromethane is used as a solvent, degreaser, paint remover, and the manufacture of photographic film. In the liver CYP-dependent biotransformation generates carbon monoxide as the final product, however, in the kidney GST-dependent conjugation is catalyzed by theta-class GST giving S-(chloromethyl)glutathione and formaldehyde as products (Kubic and Anders, 1978; Ahmed and Anders, 1978; Reitz et al., 1989). Historically, formaldehyde has been implicated in the tumorgenicity of dichloromethane, however, it was demonstrated by Wheeler et al. (2002) that glutathione conjugates of dihalomethanes are genotoxic in bacterial assays while formaldehyde generates no mutations. Downstream metabolic activation can occur in $\beta$-lyase-catalyzed $\beta$-elimination reactions of 1,1 -dichloalkene derived cysteine S-conjugates. For example, bioactivation of S-(1,2dichlorovinyl)-L-cysteine yields pyruvate, ammonia and 1,2 dichloroethenethiolate that can lose chloride to give chlorothioketone or tautomerize to give the chlorothioacetyl chloride (Cooper et al., 2005). Thioketenes are highly reactive and chlorothioketone can give DNA adducts to cytosine in organic solvents (Volkel and Dekant, 1998). Evidence for thioketene 
formation in the reaction was obtained by Fourier-transform ion cyclotron resonance mass spectrometry (Fig. 8; Zhang et al., 1995).

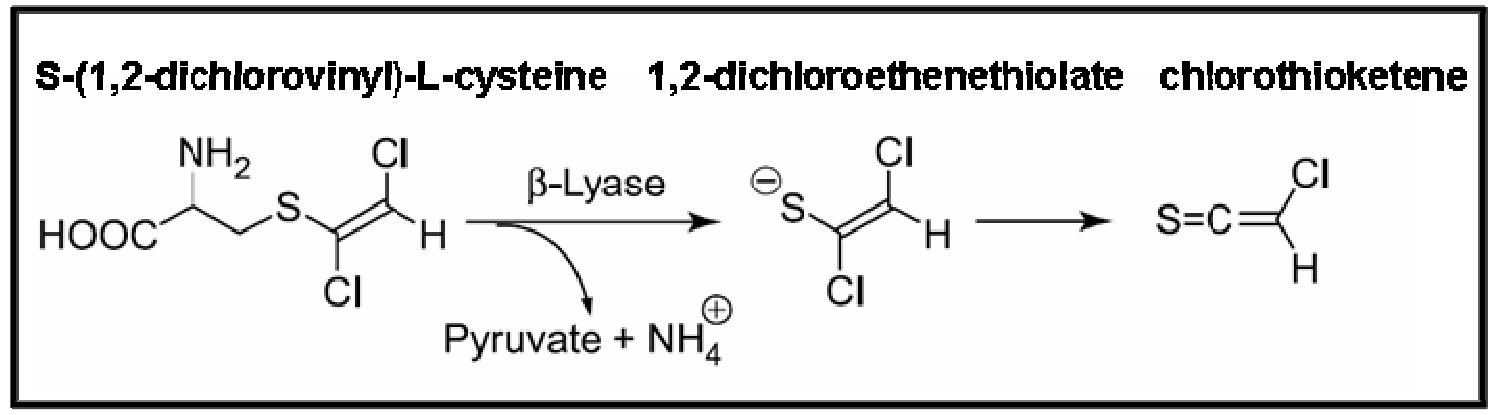

Fig. 8. Biotransformation of S-(1,2-dichlorovinyl)-L-cysteine by $\beta$-lyase-catalyzed $\beta$ elimination (Anders, 2004).

Not all initiating events result in tumorigenesis due to the action of specialized DNA repair enzymes. Base excision repair enzymes repair alkylated bases by removal of the damaged base and replacement with the corresponding WatsonCrick complement. Methyltransferases repair methylation at the $\mathrm{O}^{6}$ or $\mathrm{O}^{4}$ of guanine or thymine respectively. Long strands of mismatched bases (27-29 nucleotides) can be generated by DNA adducts or UV light photodimers and these are repaired by nucleotide excision repair enzymes (Hursting et al., 1999).

Promotion. Once initiation has occurred, selective pressure by various promoters allow clonal expansion of initiated cells. Promoting agents themselves are not carcinogenic but provide selective pressure through the expression of genes for hyperproliferation, tissue remodeling, and inflammation 
(Hursting et al., 1999). In effect, tumor promoters increase proliferation at the expense of regulatory apoptosis.

The concentration of BPDE in cigarettes has been estimated to be only $2 \%$ of the concentration necessary for development of cancer based on results of studies with $\mathrm{BaP}$ alone. However, cigarettes enhance inflammation and cell proliferation through many pathways. First, the repeated cytotoxic insults offered by the caustic chemical milieu can result in rapid and widespread cell death mediated by necrosis and apoptosis. High selective pressure can lead to the selective proliferation of resistant cells that are insensitive to immune system surveillance or necrotic signals (Rubin, 2002). Second, promoters can act directly on epithelial cells to favor cancer cell growth by stimulating proliferation, altering gene expression, generating free radicals, and inhibiting cellular communication and apoptotic signals (Wright et al, 1994). Cigarette smoke contains high concentrations of the tumor promoter catechol, a phenolic compound with two adjacent hydroxyl groups (Hecht et al., 1981). Other chemical promoters in cigarette smoke include other phenols, non-aromatic hydrocarbons (decane, undecane, tetradecane) and non-carcinogenic aromatic hydrocarbons such as $(\mathrm{B}(\mathrm{e}) \mathrm{P})$, benzo $(\mathrm{g}, \mathrm{h}, \mathrm{i})$ perylene and long chain alcohols and acids (lauryl alcohol, stearic acid) as well as cocarcinogens with action weaker than BaP (Van Duuren and Goldschmidt, 1976). Cigarretes also contain high concentrations of the promoter nicotine and the average pack-per-day smoker 
absorbs $20-40 \mathrm{mg}$ of nicotine each day resulting in plasma concentrations of 23$35 \mathrm{ng} / \mathrm{ml}$ by the afternoon (Zhang et al, 2006). Nicotine in the plasma interacts with nicotinic acetylcholine receptors (nAChRs) found in many endothelial and vascular smooth muscle cell types (Macklin et al., 1998). Zhang et al. (2006) demonstrated that pretreatment of human lung cancer cells with $100 \mu \mathrm{M}$ nicotine for 6 hours followed by treatment with $100 \mu \mathrm{M}$ menadione, an apoptosis inducer, significantly reduced the percentage of cells undergoing late stage apoptosis from $52 \%$ to $30 \%$ (Fig. 9 )

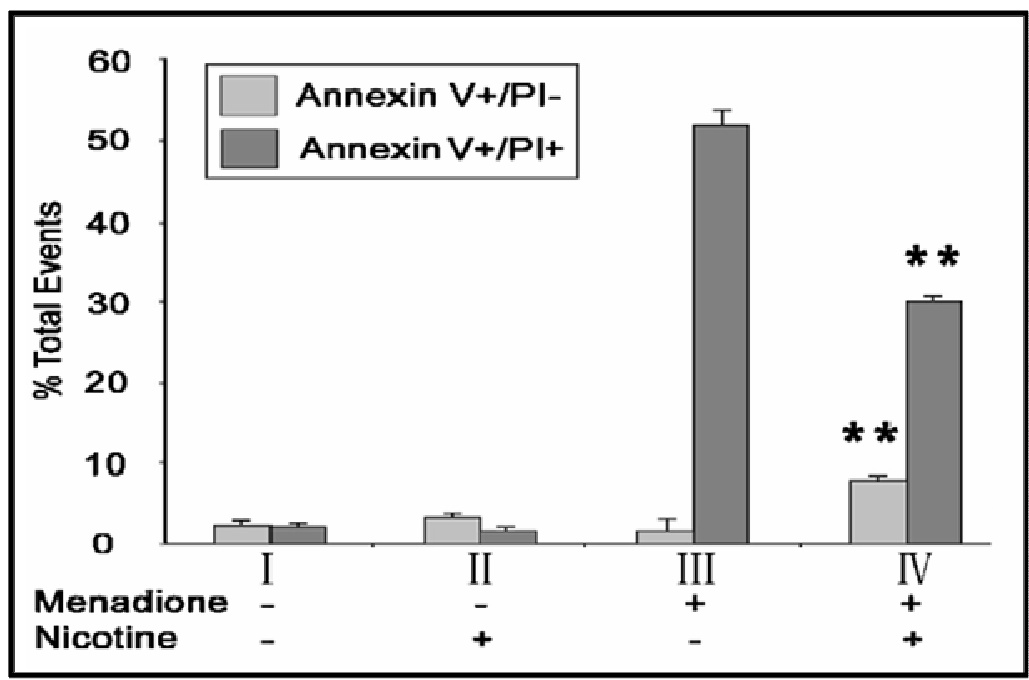

Fig. 9. Nicotine prevents apoptosis induced by methadione in human lung cancer cells. Early apoptotic cells exhibit Annexin $\mathrm{V}+$ /propidium iodide (PI)- and late apoptotic cells exhibit Annexin $\mathrm{V}+\mathrm{Pl}+$ signatures in flow cytometric analysis.

It has been suggested that nicotine inhibits apoptosis induction by several mechanisms, including activation of the mitogen activated protein kinase 
(MAPK) and protein kinase $\mathrm{C}(\mathrm{PKC})$ pathways as well as overexpression of antiapoptotic Bcl-2 proteins (Zhang et al, 2006).

Progression. Progression is a series of genetic changes that result in clonal expansion in the absence of promoters (Pilot, 1989). In Hanahan's Hallmarks of Cancer, six essential steps are defined in tumorigenesis: self-sufficiency in growth signals, insensitivity to growth-inhibitory (antigrowth) signals, evasion of programmed cell death, limitless replicative potential, sustained angiogenesis, and tissue invasion and metastasis (Hanahan and Weinberg, 2000). In kidney tumor development, mutations of the "gate keeper" gene von-Hippel-Lindau $(\mathrm{VHL})$ can contribute too many of these traits, making it an essential target during progression (Kopper and Timar, 2006).

Self Sufficiency in Growth Signals. Nontransfromed cells require positive interactions with growth signals for proliferation whereas cancer cells lose dependence on outside signals. For example, normal propogation of cells in culture requires addition of mitogenic factors and matrix proteins for integrin adhesion; in contrast tumor cells can grow in the absence of matrix proteins and at low serum levels (Hanahan and Weinberg, 2000). Growth signals can be transduced through interactions with members of the diffusible growth factors, extracellular matrix proteins, and cell-to-cell adhesion molecules. Cancer cells often engage in two types of signaling; normal heterotypic signaling in which 
cells generate growth factors that interact with neighboring cells and autocrine signaling an unusual adaptation allowing cancer cells to provide their own signaling molecules in a feedback loop. Examples of heterotypic signaling in tumorigenesis are growth stimulatory factors generated by immune cells in response to inflammation (Cordon-Cardo and Prives, 1999). In kidney cancer, the loss of the gatekeeper VHL gene creates overexpression of both EGFR and its growth stimulatory ligand, TNF $\alpha$ that generate an autocrine feedback loop. Smith et al. (2005) demonstrated growth of tumor tissue in mice could be completely inhibited by silecing this autocrine loop by inhibition of EGFR by inhibitory RNA (Fig. 10; Smith et al., 2005).

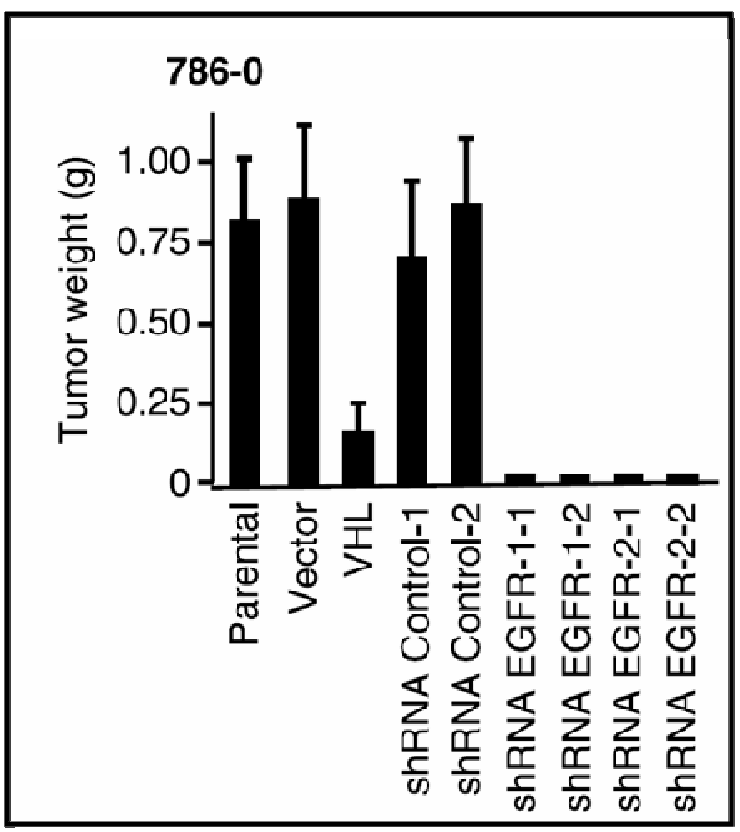

Fig. 10. Silencing of EGFR suppresses VHL -/- RCC tumor formation. Average tumor mass 9-weeks post injection. In all cases they failed to detect any tumor formation following shRNA injection into EGFR expressing VHL -/- RCC cells (Smith et al., 2005). 
The EGFR autocrine loop is important in many cancer types including stomach, brain and breast cancer (Yarden and Ulrich, 1988). Many cancers receive growth signals independent of ligands through the use of mutated or overexpressed growth factor receptors. In addition to the regulation of growth factor receptors, most cancer cells also gain the ability to switch cell-cell adhesion molecules to favor proliferation.

Integrins are highly conserved cell surface receptors composed of two subunits, $\alpha$ and $\beta$, and each $\alpha \beta$ combination has a unique ligand specificity for different extracellular matrix (ECM) components. ECM activation is transduced through adaptor proteins to many receptors including protein tyrosine kinases such as focal adhesion kinase (FAK), Src family kinases and Integrin-linked kinases. As an example, FAK signaling is activated by many $\alpha \beta$ combinations and results in FAK autophosphorylation to create a binding site for Src homology 2 (SH2) domains of Src (Schaller et al., 1994). Signal transduction occurs through activation of phosphoinositide-3 kinase (PI3K) which then phosphorylates phosphatidylinositol-4,5-bisphosphate $\left(\mathrm{PIP}_{2}\right)$ at the 3' position of the inositol ring to generate $\mathrm{PIP}_{3}$. Phosphoinositide-dependent kinase 1 (PDK1) is recruited to the plasma membrane by $\mathrm{PIP}_{3}$ action through its plekstrin homology domain where it phosphorylates and activates AKT (Dillon et al., 2007). AKT translocates to the nucleus where its phosphorylation activity is implicated in the production of positive growth signals by mammalian target of rapamycin (mTOR) 
among others (Mita et al., 2003). mTOR is overexpressed in many kidney cancers and is implicated in the induction of VHL targets (Staehler et al., 2005). Activity of PI3K is regulated by phosphatase and tensin homolog deleted on chromosome 10 (PTEN), which removes 3' phosphate of $\mathrm{PIP}_{3}$ to abrogate the signal (Dillon et al., 2007). Consequently, the PTEN gene is often downregulated in RCC (Steahler et al., 2005). In addition to PI3K activation, SrC phosphorylates FAK a second time resulting in an exposed binding site for the adaptor proteins Grb2 and Ras guanosine 5'-triphosphate exchange factor mSOS (Schlaepfer et al., 1994). Ras is a membrane associated GTP-ase that cycles between GTP-bound active and GDP-bound inactive states through the activating action of guanine-nucleotide exchange factors (Giehl, 2005). Activated Ras recruits the serine/threonine kinase Raf to the plasma membrane for activation and subsequent phosphorylation of MEK-1 and 2 also known as mitogen-avtivated protein kinase (MAPK) that itself phosphorylates ERK 1 and 2. Phosphorylated ERK translocates to the nucleus and interacts with transcription factors to promote cell proliferation (Giehl, 2005). Ras is also located downstream of many autocrine growth factor receptors including EGFR, vascular endothelial growth factor receptor (VEGFR), and platelet-derived growth factor receptor (PDGFR; Fig. 11; Staehler et al., 2005). 


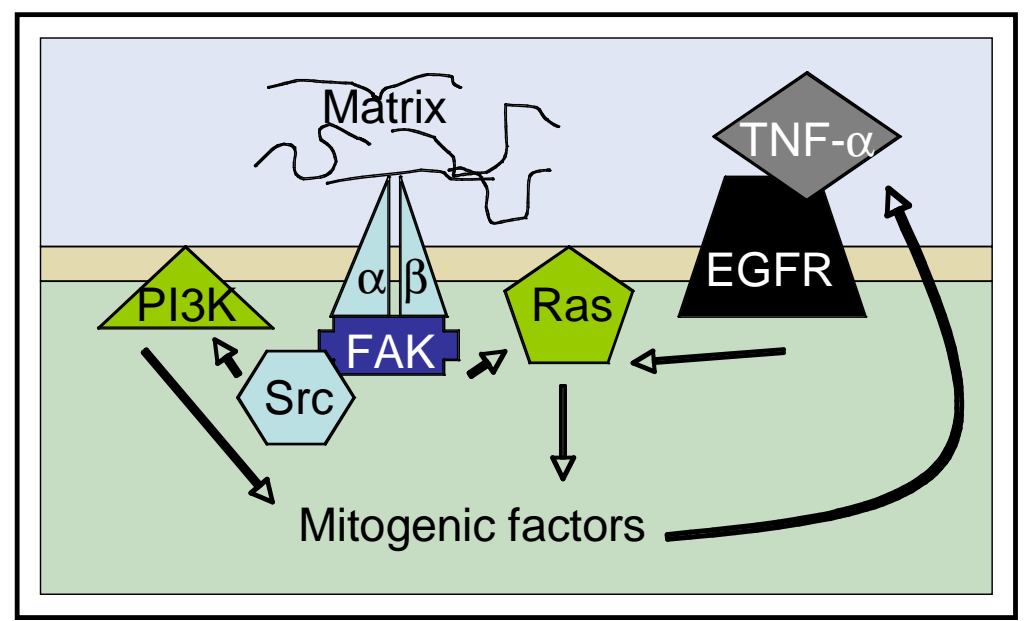

Fig. 11. Self sufficiency in growth signals. Integrin signaling through FAK kinase results in signal transduction through the PI3K/AKT and Raf/MEK/ERK signaling pathways. Ras can also be activated through receptor binding of growth factors.

The Raf/MEK/ERK signaling pathway is constitutively activated in kidney cancer cell lines. Mechanisms of constitutive activation of Ras specific to renal carcinoma are unknown but $25 \%$ of all tumors express a mutated form of Ras that is constitutively activated (Medema and Bos, 1993).

Insensitivity to Growth Inhibitory Signals. The second hallmark for cancer is insensitivity to growth inhibitory signals that generate quiescence or differentiation. Cancer cells proliferating in culture can be forced to exit the proliferative cycle into a quiescent state termed $\mathrm{G}_{0}$ (Hanahan and Weinberg, 2000). An example of this action in renal cell carcinoma is insensitivity to transforming growth factor- $\beta$ (TGF- $\beta$ ) signaling. TGF- $\beta$ is a potent cytokine that interacts with 3 receptors, Type I, II and III (TBR-1,2 and 3) and activates mediator Smad proteins that inhibit proliferation, promote cellular differentiation 
and regulate interactions with the ECM (Moustakas et al., 2001). Surprisingly, many studies of human renal cell carcinoma $(R C C)$ demonstrate that RCC cells overexpress TGF- $\beta$ and patients have high serum levels of the growth inhibitory cytokine (Cardillo et al., 2001; Hegele et al., 2003). In contrast, overexpression of TGF- $\beta$ in normal cells has been implicated in development of chronic renal disease resulting in renal fibrosis and apoptosis (Bottinger and Bitzer, 2002). It has been hypothesized that TGF- $\beta$ overexpression generates immunosuppressive effects and provides the insensitive tumor with a favorable growth environment (Hegele et al., 2003). Copland et al. (2003) demonstrated that in order to evade TGF- $\beta$-dependent growth inhibition, RCC cells sequentially lose TBR 3 and 2 expression correlating with localized and metastatic progression respectively (Fig. 12). Interestingly, in RCC cells transfection with TBR 2 and 3 rescue the growth inhibitory phenotype (Copland et al., 2003).

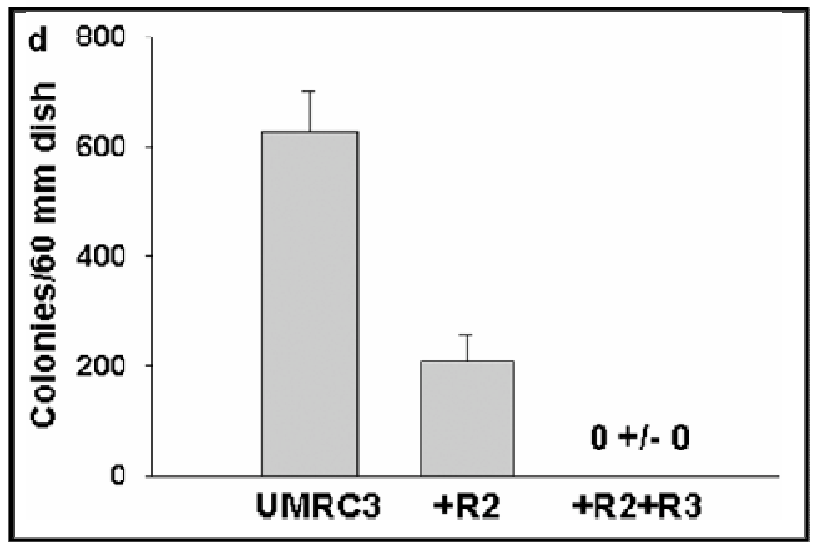

Fig. 12. Rescue of TGF- $\beta$ growth inhibition by overexpression of TBR 2 and TBR 3 (R2, R3) in UMRC3 RCC cells (Copland et al., 2003). 
Many human tumors develop strategies to evade cell growth inhibition by TGF- $\beta$. For example, hereditary nopolyposis colorectal carcinoma produces loss-offunction mutations in TBR2 and $85 \%$ of all colon carcinoma cells have complete loss of TBR2 (Akhurst and Derynck, 2001; Markowitz et al., 1995).

Evading Apoptosis. Classically, there are two recognized mechanisms of cell death, necrosis, and apoptosis. Necrosis is generated by environmental perturbations, severe hypoxia/ischemia, temperature extremes, and mechanical trauma (Farber and Mofty, 1975). Generally, necrosis is regarded as being an unplanned event that results in regional inflammation. In contrast, apoptosis or programmed cell death is a highly conserved and tightly regulated event involved in regulated cell death during development, immune surveillance, and by many anti-cancer drugs. Apoptosis is defined by morphological characteristics incuding; cell shrinkage, membrane blebbing, nuclear chromatin condensation, and fragmentation resulting in the production of a tight ball of membrane bound fragments exposed for phagocytosis by phagocytes (macrophages and dendritic cells). Many different pathways regulate apoptotic activity including activation of death receptors, endoplasmic reticulum stress and mitochondrial pertubations (Vermeulen et al., 2005). 
Death receptor induced (extrinsic) apoptosis is coordinated by the action of membrane bound receptors that are activated by extracellular signals. The death receptor family includes Fas (Apo-1, CD95), TNF-receptor-1 (TNF-R1), death receptor 3 (DR3 or TFN-receptor related apoptosis-mediating protein (TRAMP) or APO-3), TNF-related apoptosis inducing ligand receptor-1 (TRAILR1 or DR4), TRAIL-R2 (DR5 or Apo-2) and DR6 (Ashkenazi and Dixit, 1998). For example, the Fas receptor has a death domain (DD) that interacts with adaptor protein's Fas-associated death domain protein (FADD) upon Fas ligand binding to form a death receptor-induced signaling complex (DISC) (Nagata, 1997). FADD in turn recruits caspase 8 through its death effector domain to activate the caspase cascade.

Caspases are enzymes that are expressed as inactive proenzymes and activated by proteolytic and active caspases recognize and hydrolyze tetrapeptide sequences at an Asp residue (Nicholson and Thornberry, 1997). Targets of caspase activity include poly-(ADP)-ribose polymerase (PARP) used for DNA repair and inhibitor of caspase-activated DNAse (ICAD) that inhibits CAD or DNA fragmentation factor (DFF) (Duriez and Shah, 1997; Sakahira et al., 1998). Upon ICAD cleavage, DFF translocates to the nucleus and catalyzes nucleosomal DNA cleavage to generate oligonucleosomal DNA fragments (Liu et al., 1997). In addition, caspase cleavage of the cytoskeleton proteins fodrin and actin result in cytoskeletal disorganization (Mashima et al., 1995). 
In mitochondrial-dependent apoptosis (intrinsic), regulation of the balance of proapoptotic (Bax, Bak) and anti-apoptotic (Bcl-2, Bcl-XI) bcl-2 protein family members leads to opening of the permeability transition pore (PTP) in the mitochondrial membrane (Burlacu, 2003). The PTP is composed of two proteins, the adenine translocator (ANT) at the inner membrane and the voltagedependent anion channel (VDAC) at the outer membrane as well as accessory proteins that regulate the release of cytochrome $\mathrm{c}$ into the cytosol. Once released, cytochrome $\mathrm{c}$ interacts with apoptotic protease activating factor 1 (Apaf-1) that can bind and activate procaspase 9 to generate the mitochondrial DISC (or apoptosome) that activates the caspase cascade (Vermeulen et al., 2005). Mitochondrial-dependent apoptosis can be activated by many stimuli, for example p53 is stabilized in the presence of DNA damage resulting in cytochrome c release and apoptosis (Hanahan and Weinberg, 2000).

Tumors use a number of different mechanisms to avoid apoptosis. For example, more than $50 \%$ of cancers have a loss-of-function mutation in the p53 gene (Harris, 1996). Mechanisms of evasion of apoptosis in renal cell carcinoma have only recently been elucidated. Sejima et al. ( 2003) reported that RCC tissue samples had significantly reduced Fas protein and mRNA expression compared to normal tissue. Interestingly, similar to TGF- $\beta$, Fas ligand (FasL) expression is increased in RCC cancer tissue compared to normal tissue, a 
feature shared with hepatocellular carcinoma, melanoma, and colon adenocarcinomas. It has been suggested that overexpression of FasL induces apoptosis in tumor infiltrating lymphocytes thus protecting the cells from the immune system (Strand et al., 1996). In addition to the reduction in Fas receptors, RCC cell lines are also characterized by heavy methylation on the APAF-1 gene thus allowing evasion of both the extrinsic and intrinsic apoptotic pathways (Christoph et al., 2006). Apoptosis evasion techniques used in RCC are illustrated in Figure 13.

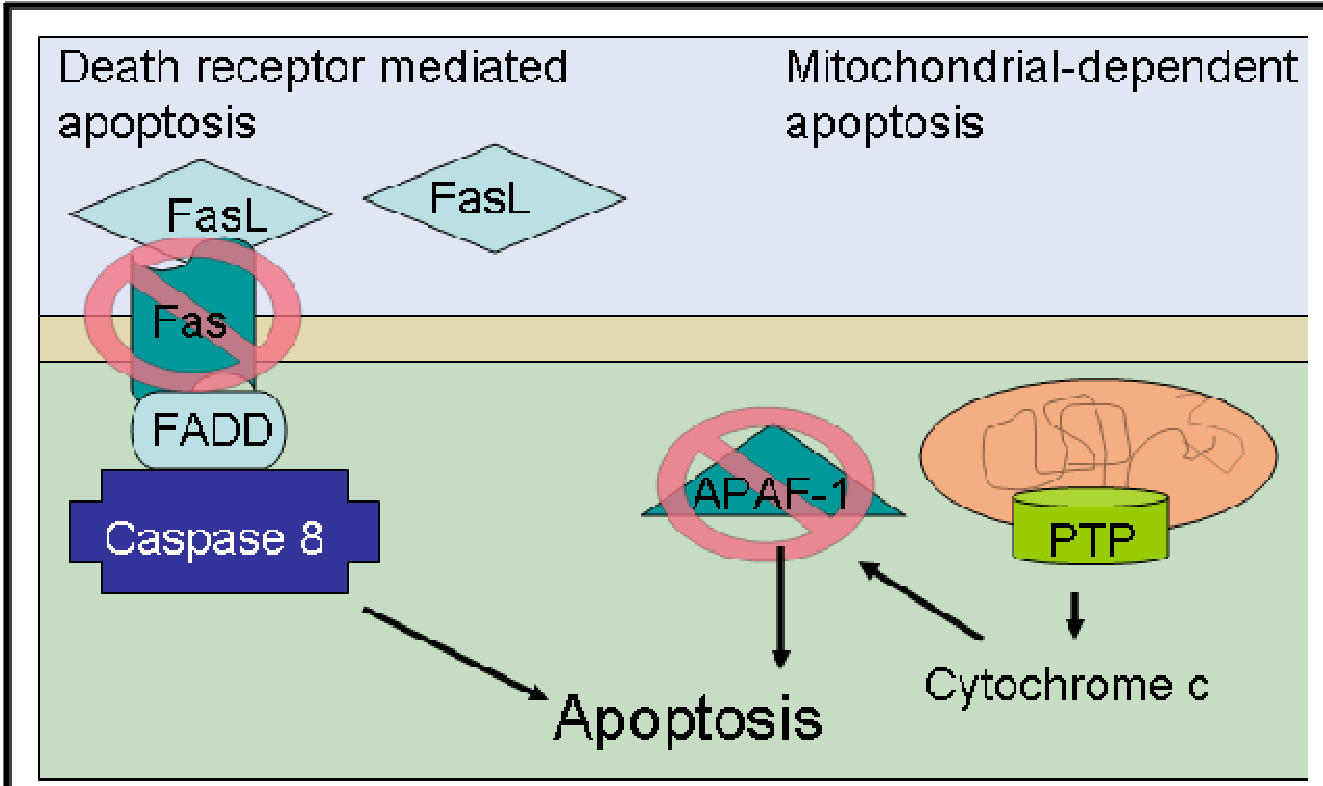

Fig. 13. Apoptosis evasion techniques found in RCC tissue samples. Death receptor mediated apoptosis is inhibited by decreased expression of Fas ligand on the cell surface. Mitochondrial-dependent pathway of apoptosis is inhibited by methylation of APAF-1. Decreased expression is marked by the red cross-through symbol. 
Limitless Replicative Potential. In the 1960's Leonard Hayflick demonstrated that isolated fibroblasts had finite replicative potential correlating with a certain number of cellular divisions. As the cells reached this allowable number, they ceased to proliferate and entered a phase termed senescence. Morphologically, senescent cells are metabolically active and characterized by a flat, extended shape with no proliferative activity. These observations led to the hypothesis that cells are subject to the actions of an internal clock that tracks the number of cell divisions and stops this process after a predetermined number of cell divisions (Hayfilck, 1965). In the 1970's, Watson and Olovnikov proposed a possible mechanism for the internal clock namely, the end replication problem, in which linear chromosomes are unable to replicate the extreme 3' ends of chromosomes (Olovnikov, 1973, Watson, 1972). It is now known that senescence is triggered by the exposure and interference of the structural integrity of the telomere nucleoprotein (Shay and Wright, 2005). The 3' end of every normal chromosome is capped by a telomere nucleoprotein that contains single and double stranded DNA in a higher ordered structure in which the overhanging, single tail of the G-rich strand binds to complementary upstream telomere sequences creating a displacement loop known as the T-loop (Griffith et al., 1999). Loss of T-loop structure can be induced in vitro by the overexpression of a telomere nucleoprotein termed TRF2 and this results in DNA damage and downstream activation of p53 (Karlseder et al., 2002). Consequently, Shay et al. (1991) demonstrated that in human cells, induction of 
senescence could be bypassed by the loss of only p53 (DNA damage signaling protein) and $\mathrm{Rb}$ (replication suppressive proteins).

Cells that bypass senescence continue to replicate until the telomeres are completely degraded and cannot protect exposed chromosome ends from DNA regulatory mechanisms that detect and repair strand breaks. At this point cells enter the crisis phase characterized by end-to-end chromosomal fusions, anaphase bridges (chromosomes pulled in opposite directions by centromeres), and apoptotic cell death (Shay and Wright, 2005). It was observed that 1 in every $10^{7}$ human cells will survive and exhibit no telomere shortening due to the induction of full-length telomerase reverse transcriptase (hTERT) enzyme or the activation of a telomere maintenance system termed alternative lengthening of telomeres (ALT; Fig. 14; Stewart and Weinberg, 2006). hTERT catalyses a reverse transcriptase reaction and acts on a telomerase RNA template to add a TTAGGG repeat to lengthen and stabilize the telomere. Mechanistically, ALT is thought to proceed through homologous recombination, a theory strengthened by the finding that the addition of a unique DNA sequence in the subtelomeric region of a chromosome will result in its subsequent redistribution to all telomeres in the cell (Dunham et al., 2004).

Research on renal cell carcinoma has demonstrated genetic alterations that bypass senescence and the crisis point. Roe et al. (2006) demonstrated that 
p53 signal for DNA damage is stabilized by the "RCC gatekeeper" tumor suppressor protein, VHL. Specifically, p53 binds to pVHL to block Mdm2 mediated ubiquitination, nuclear export, and subsequent proteasomal degradation of p53. Thus, when VHL is lost p53 is destabilized and unable to transmit apoptotic signals to the mitochondria.

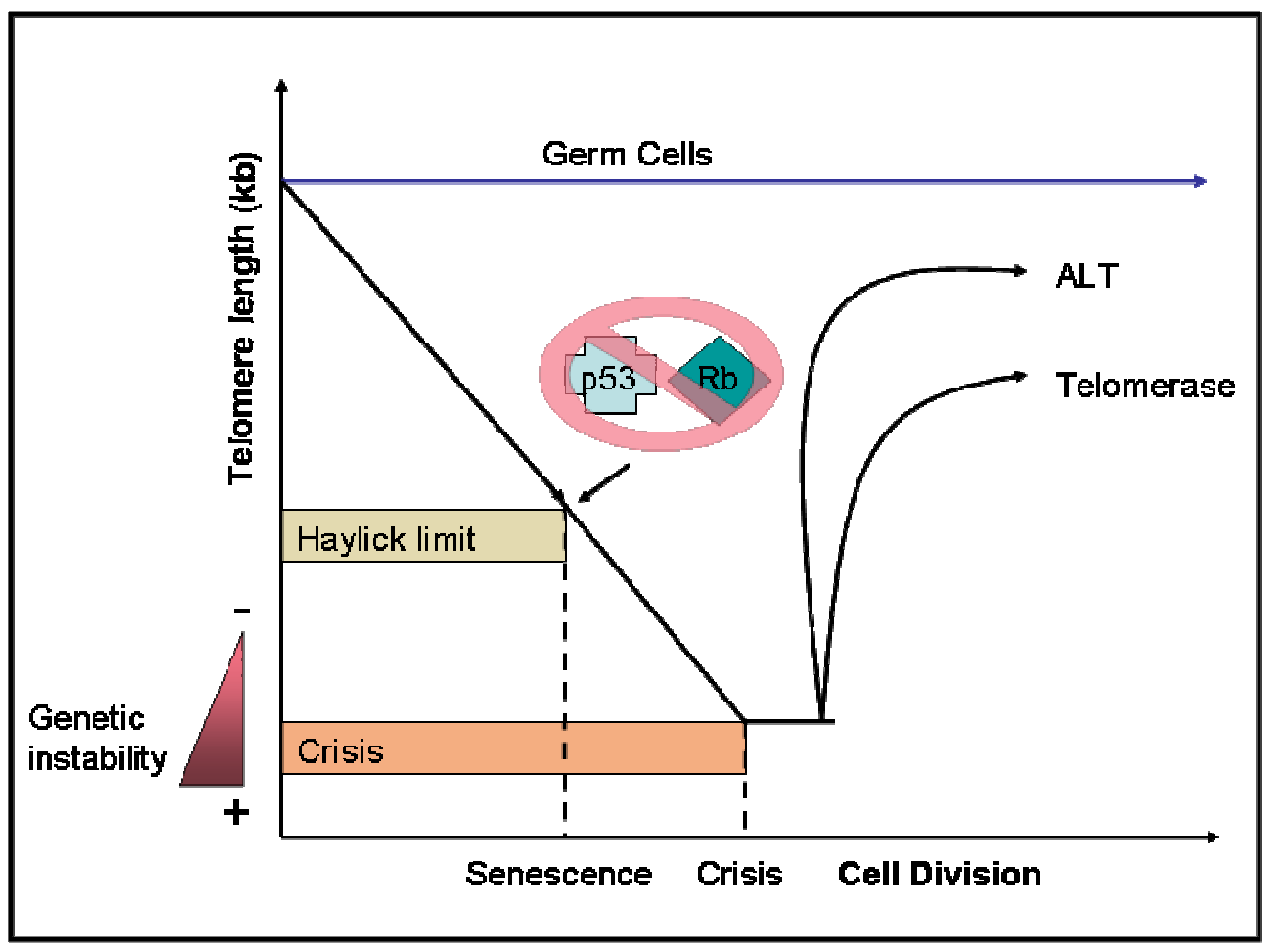

Fig. 14. Telomere hypothesis. Telomere length (y axis) is gradually lost during cell division (x axis), leading to p53 and $\mathrm{Rb}$ dependent growth arrest called senescence. Inactivation of p53 and $\mathrm{Rb}$ allows further cell division but does not abrogate telomere shortening. Telomeres erode until a crisis point is reached at which the DNA ends are no longer protected resulting in apoptosis. Some clones will emerge with stable telomere lengths by the actions of telomerase or ALT (Stewart and Weinberg, 2006).

The $\mathrm{Rb}$ protein controls progression through the cell cycle and is found at unaltered levels in RCC tissue, however, tumor progression correlates with 
increasing $\mathrm{Rb}$ deactivation through phosphorylation (Hedberg et al., 2004). To bypass the crisis point, it was demonstrated that $80 \%$ of RCC tissues express full length and functional hTERT whereas, $71 \%$ of normal tissues express an alternatively spliced hTERT with nonfunctional or dominant negative characteristics (Fan et al., 2005).

Sustained Angiogenesis. In solid tumors, oxygen and nutrients can passively diffuse only $100 \mu \mathrm{m}$ from a capillary blood vessel, thus allowing only a finite tumor size (Hanahan and Weinberg, 2000). In order to progress, tumors must develop the ability to recruit and sustain angiogenic growth. A balance of soluble or membrane bound, pro and apoptotic factors regulate angiogenesis. Proapoptotic soluble factors include vascular endothelial growth factor (VEGF) and acidic and basic fibroblast growth factors (FGF1/2) that bind transmembrane kinase receptors presented by vascular cells for directional recruitment (Presta et al., 2005). An example of an antiangiogenic soluble factor is thrombospondin1 that binds Src-like CD36 (Bull et al., 1994). Membrane bound proteins that regulate angiogenesis include the integrins. Research has shown that angiogenesis can be suppressed by inhibition of particular integrins expressed only on membranes of growing vasculature (Giancotti and Ruoslahti, 1999). $\mathrm{RCC}$ is known for its high level of vascularization, a characteristic that will be discussed in the next section. 
Tumor Invasion and Metastasis. Metastasis is the capacity of cancer cells to escape a primary tumor and colonize other areas in the body. Ninety percent of all cancer deaths are directly linked to metastasis (Sporn, 1996). Steps associated with metastasis include, escape from the primary tumor, translocation of tumor cells across extracellular matrix barriers, and colonization of secondary tumors (Woodhouse et al., 1997).

The first step in metastasis is the escape of cells from the primary tumor through the vascular or lymph systems (intravasation) and subsequent cellular arrest in capillary beds of metastatic sites. For intravasation, a tumor cell must lose adhesive junctions connecting it to the ECM and neighboring cells at the primary tumor site. Intercellular junctions use desmosomes, gap junctions, and adherens junctions to mediate epithelial cell adhesion. Cadherins are the main component of the adherens junction and are often lost during cancer progression (Esteban et al., 2006). Once in the vasculature, three mechanisms have been proposed for tumor selection of metastatic targets and these include, selective growth, selective adhesion, and selective chemotaxis. The selective growth hypothesis states that cancer cells can invade (extravasate) into every site equally but that growth is favored in some sites over others. Selective adhesion proponents theorize that tumor cells select targets by the same mechanisms as white blood cells that selectively attach blood vessel walls by interactions of integrins, selectin and their integrins. Selective chemotaxis is the 
term used for the expression of certain cytokines by cancer cells and complementary receptors on metastasis sites (Woodhouse et al., 1997).

Extravasation of the tumor cell into the new growth site requires the coordinated activities of ECM attachment and proteolysis proteins and occurs in only $0.05 \%$ of all circulating tumor cells (Liotta et al., 1974). Invasive mechanisms are not unique to tumor cells and in fact, tumors use the same techniques used in angiogenesis, morphogenesis, and trophoblast implantation (Folkman, 1971; Talhouk et al., 1992; Lola and Graham, 1990). Invasion mechanics involve the protrusion of a cylindrical psuedopod that expresses activated proteinases that lyse impeding ECM followed by adhesion at the leading edge and movement of the cell forward through detachment at the rear (Woodhouse et al., 1997). Proteolysis is carried out by a family of proteins termed the matrix metalloproteinases that catalyze the degradation of ECM components (Deryugina and Quigley, 2006). At the new site, tumor cells must take advantage of local expression of growth stimulatory cytokines. For example, Yoneda et al. compared the sensitivity of original tumor cells and bone metastatic tumor cells to insulin-like growth factor (IGF) that is expressed at high levels in the bone and found that only secondary site tumors were sensitive to IGF-dependent promotion (Yoneda et al., 2001). 
Kidney cancer has high metastatic potential with the main sites being the bone and the lung. In RCC, loss of the tumor suppressor protein VHL results in decreased expression of E-cadherin and increased expression of membrane type-1 matrix metalloproteinase and this is a deadly combination (Estaban et al., 2006; Petrella and Brinckerhoff, 2006).

Stem Cell Theory of Tumorigenesis. Recently, the classical theory of tumor initiation, promotion, and progression has been contested by an alternate theory described as the stem cell pathway for carcinogenesis (Gudjonsson and Magnusson, 2005). There are three groups of stem cells: embryonic (progenitor of all cells in the body), germinal (produce egg and sperm) and somatic stem cells (tissue renewal) (Sell, 2004). Evidence for the somatic stem cell type is evident in tissue with rapid cell turnover such as skin, colon, and blood. Characteristics of somatic stem cells include self-renewal through asymmetric cell division generating differentiated progeny with a long life span (Sell, 2004). The principal difference between the classical and stem cell models of carcinogenesis is that instead of normal differentiated cells undergoing mutations that give them stem cell characteristics, somatic stem cells are mutated and become independent of inhibitory regulation, but continue to generate mutant partially differentiated cells. Figure 15 provides an illustrated comparison between three-step carcinogenesis and stem cell carcinogenesis. 


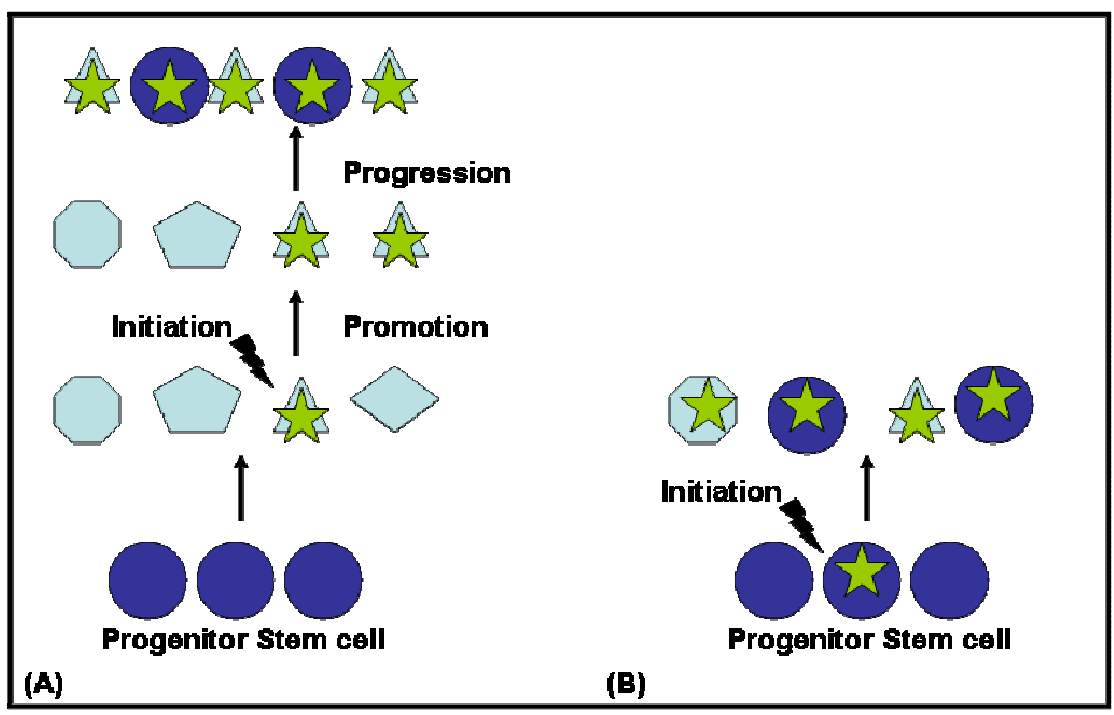

Fig. 15. Models of tumorigenesis. (A) Three-step carcinogenesis, normal differentiated cells undergo initiation at a DNA element that allows for selective growth advantage. Promotion allows selective clonal expansion and progression allows expansion in the absence of the promoter, final progressive targets are stem cell like in nature (B). Stem cell carcinogenesis, stem cells are initiated and form cancer cells with complete differential heterogeneity. Cells with stem cell like characteristics are represented by circles, differentiated cells are represented by angular shapes. Stars represent mutations in tumor suppressor genes or oncogenes that give cells selective growth advantage.

If this model proves correct, modern therapies that have been developed for treating differentiated cells may not affect critical stem cells. Thus, new therapies must target the affected stem cell populations to promote differentiation and maturation. Breast cancer is a good illustration of the stem cell theory. Breast cancer stem cells are hypothesized to be located in the luminal epithelial compartment that is singularly important for cell transformation (Gudjonsson et al., 2002; Sainsbury et al., 2000). It has been observed that there is an exponential increase in breast cancer incidence with increasing age. It is argued that the long life span of stem cells would permit accumulation of 
mutations over the course of a life time compared to the relatively short life span of differentiated cells. Candidate stem cells expressing CD44 in the absence of CD24 (CD44+/CD24-) isolated from breast tumors are 10-50X more tumorgenic as the surrounding partially differentiated cells. Interestingly, as few as 100 CD44+/CD24- cells were capable of forming tumors that presented the same phenotypic heterogeneity as the primary tumor (Gudjonsson and Magnusson, 2005).

In summary, tumorigenesis is initiated by changes to DNA that create a mutated cell with selective growth advantages. Promotion creates positive selective pressures that allow the tumorgenic cell to grow at a higher rate than surrounding cells. Progression then changes DNA expression and allows cells undergoing progression promoter-independent growth. After progression, a non-diferentiated tumor cell emerges and this cell is capable of self-renewal and long life. The stem cell carcinogenesis theory allows for initiation and progression to occur at the level of the stem cell, thus producing differentiated tumor cells. 


\section{$\underline{\text { Kidney Cancer }}$}

Epidemiology. In 2006, 38,890 people will be diagnosed with kidney cancer and 2,840 will die of this disease in the United States (Jemal et al., 2006). Some argue that kidney cancer mortality statistics are underestimated due to the fact that few RCC patients die of tumor metastasis but instead die of related complications affecting the heart and body homeostasis. Kidney cancer has classically been divided into 3 large categories: renal cell carcinoma (RCC), renal pelvis cancer, and rare malignancies. RCC is classified as adenocarcinoma that grows from primary tubule epithelium while renal pelvis cancers are transitional cell carcinomas. RCC accounts for $85 \%$ of kidney cancer incidence in the U.S. and is the subject of our studies (Lipworth et al., 2006). Three different varieties of RCC are observed: clear cell RCC (75\%), type 1 papillary RCC (5\%), and chromophobe RCC and oncocyoma (1\%; Lipworth et al., 2006). All cell lines used in our study are clear cell renal carcinoma cells. Since 1950 , there has been a $126 \%$ increase in kidney cancer incidences in the U.S. (Volpe and Jewett, 2005). In the past, renal cell carcinoma has occurred twice as often in men as in women with an average age of diagnosis at 60 years. However, recently rates have been increasing more rapidly for females than males. Some argue that the increase in cancer incidence is a direct result of improved imaging and diagnostic equipment but increased incidence rates have been reported for all stages of RCC (Fig. 16; Lipworth et al., 2006). 


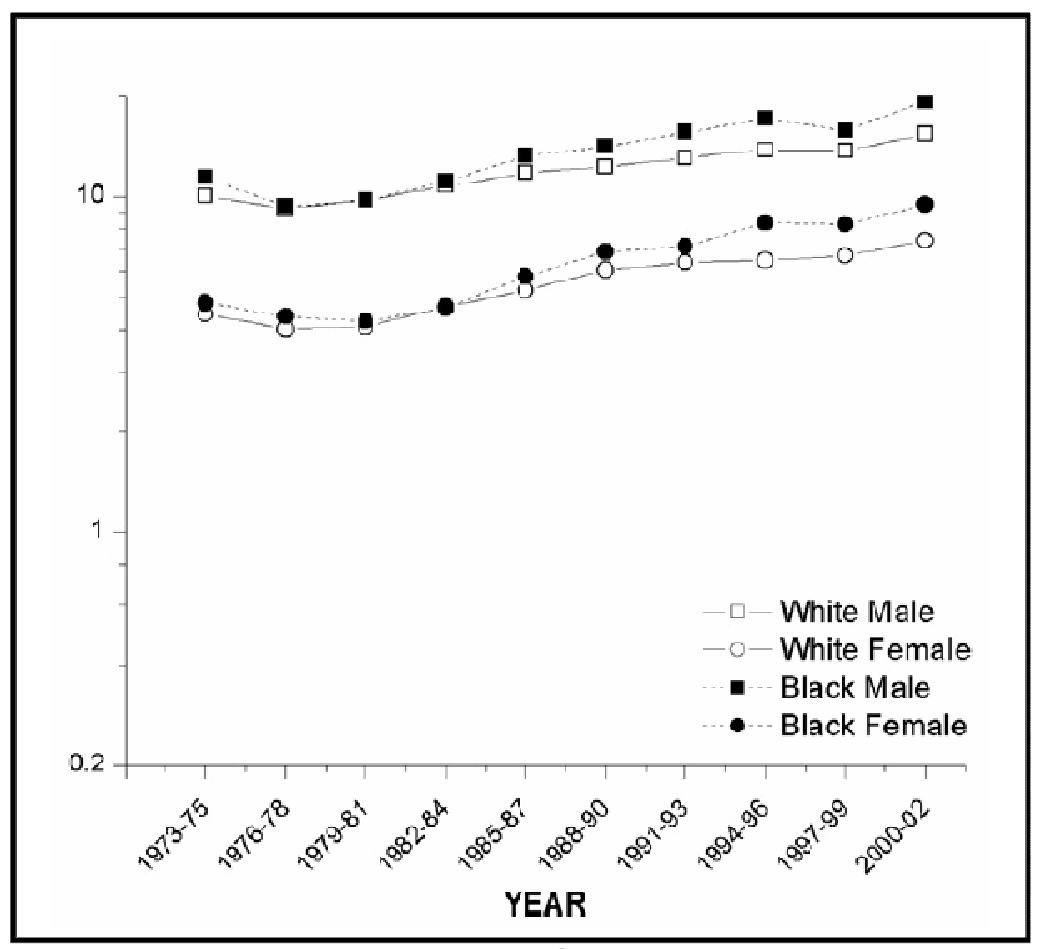

Fig. 16. Trends in 2000 United States standard age adjusted incidence of renal cell cancer by race and sex in 1973 to 2002 based on SEER data (Lipworth et al., 2006).

Fifteen to forty-eight percent of kidney cancers are discovered incidentally during diagnosis for unrelated abdominal pain (Tsui et al., 2000). Kidney cancer does not have any distinctive symptoms, and the classic triad of RCC symptoms, "flank pain, haematuria and a palpable mass", are rarely seen the in clinic and indicate high grade, metastatic tumors. Symptoms of early stage RCC include a grouping of variable symptoms such that RCC has taken the nickname of "internists cancer". Symptoms include hypertension, anemia, weight loss, fever, elevated alkaline phosphatase, hypercalcemia, and hepatic necrosis (Wotkowicz and Libertino, 2007). RCC prognosis and staging is determined using definitions in the 2002 TNM Classification based on clinical manifestations (Table 2). 
Table 2. The TNM staging system.

\section{Primary Tumor}

TX Primary tumor cannot be assessed

TO No evidence of primary tumor

T1 Tumor $7 \mathrm{~cm}$ or less in greatest dimension, limited to the kidney

T1a Tumor $4 \mathrm{~cm}$ or less in greatest dimension, limited to the kidney

T1b Tumor more than $4 \mathrm{~cm}$ but not more than $7 \mathrm{~cm}$ in greatest dimension,

limited to the kidney

T2 Tumor more than $4 \mathrm{~cm}$ in greatest dimension, limiten to the kidney

T3 Tumor extends into major veins or invades adrenal gland or perinephroc tissue but not beyond Gerota's fascia

T3a Tumor directly invades adrenal gland or perirenal and/or renal sinus fat but not beyond Gerota's fascia

T3b Tumor grossly extends into the renal vein or its segmental (muscle containing) branches, or vena cava below the diaphragm

T3c Tumor grossly extends into the renal cava above diaphragm or invades the wall of the vena cava

T4 Tumor invades beyond Gerota's fascia

\section{Regional Lymph Nodes (N)}

NX Regional lymph node cannot be assessed

No regional lymph node metastasis

Metastasis in a single regional lympph node

Metastasis in more than one regional lymph node

\section{Distant Metastasis (M)}

MX Distant metastasis cannot be assessed

M0 No distant metastasis

M1 Distant metastasis

Stage Grouping

Stage I

Stage II

Stage III

\begin{tabular}{|c|c|c|c|}
\hline \multirow[t]{10}{*}{ Stage III } & $\mathrm{T} 1$ & N1 & MO \\
\hline & T2 & N1 & Mo \\
\hline & T3 & NO & Mo \\
\hline & T3 & N1 & Mo \\
\hline & T3a & NO & Mo \\
\hline & T3a & N1 & Mo \\
\hline & T3b & NO & Mo \\
\hline & T3b & N1 & MO \\
\hline & T3c & NO & Mo \\
\hline & T3c & N1 & Mo \\
\hline \multirow[t]{4}{*}{ Stage IV } & T4 & No & MO \\
\hline & T4 & N1 & M0 \\
\hline & Any $\mathrm{T}$ & N2 & Mo \\
\hline & Any $T$ & Any $\mathrm{N}$ & M1 \\
\hline
\end{tabular}

Risk Factors. Rates for kidney cancer vary by more than 10 -fold between regions/countries suggesting that environmental factors may be important for this cancer. Highest incidence rates for RCC are observed in Western and Eastern European countries while lowest rates are observed in Asia and Africa (Lipworth et al., 2006). Factors implicated in this disease include cigarette 
smoking, obesity, hypertension, analgesic usage, diet, alcohol, hormonal and reproductive factors, occupation, and kidney disease.

Estimates of RCC incidence due to cigarette smoking are as high as $20-30 \%$ in men and $10-20 \%$ in women (McLaughlin et al., 1995). A recent meta-analysis of 24 trials, found a relative risk of RCC development for smokers at 1.54 for males and 1.22 for females. The relationship between RCC and smoking is complicated by the finding that current smokers with RCC have an increased risk of death compared to non-smokers with RCC (hazard ratio 1.7) (Sweeney and Farrow, 2000). Heavy smokers (21+ cigarettes daily) have a relative risk of 2.03 in males and 1.54 in females. RCC risk decreases substantially (15-30\%) with within 10-15 years after smoking cessation in men and women (Hunt et al., 2005).

Obesity can be considered as both a cancer initiator by increased lipid peroxidation leading to endogenous ROS generation and cancer promotion by hypertension and increased glomerular filtration resulting in inflammation. Forty percent of RCC incidence every year is directly linked to obesity. Recent analysis indicated that a relative risk for RCC of $1.07 / \mathrm{U}$ increase in body mass index (Bergstrom et al., 2001). RCC will often result in the dysregulation of body osmolality and volume control augmenting the effects of obesity and increasing hypertension. Hydrochlorothiazide and furosemide are commonly used diuretics 
prescribed for treatment of hypertension and interestingly both have been linked with renal tubule cancers in rats (McLaughlin and Lipworth, 2000). However, parallel increases in risk for human patients have not been documented. Patients undergoing long-term dialysis for end stage renal disease have an increased risk of RCC compared to the general population (Lipworth et al., 2006).

Since the introduction of phenacetin, analgesics have long been postulated to cause kidney cancer. Phenacetin caused cancers of the renal pelvis but was withdrawn from the market for 25 years ago. Today, although the analgesics aspirin, acetaminophen as well as other NSAIDS have been investigated, no correlation between their use and RCC has been found (McCredie et al., 1995). Large studies have found no increased risk associated with increased exposure to these drugs.

A study by Hemminki and Xinjan (2002) found that second generation immigrants to Sweden had kidney cancer risk profiles more closely linked to the host country than their ancestral origin implicating dietary and environmental factors in RCC tumorigenesis (Hemminki and Xinjun, 2002). Consequently, in 2005 a Swedish study found high consumption of fruits and vegetables and alcohol consumption to be protective against RCC (Rashidkhani et al., 2005). 
Although high protein diets are a known risk factor for kidney disease, no correlation has been found for RCC incidence (Lipworth et al., 2006).

Environmental toxicants implicated in RCC include asbestos, gasoline, and trichloroethylene (TCE). Epidemiology studies on the role of environmental factors are problematic due to the numerous confounders including smoking and obesity. Studies on asbestos have not conclusively linked exposure to RCC risk; three studies have found a correlation while one meta-analysis has found no increased risk (Lipworth et al., 2006). Gasoline involvement in RCC has been suspected since the early 1980 s when exposed male rats developed renal cancer. However, epidemiological studies have found no correlation between gasoline exposure and RCC risk. A possible explanation for the discrepancy was reported in 1993 with the discovery of male rat specific expression of $\alpha 2$ microglobulin. Androgen control leads to the synthesis of $\alpha 2$-microglobulin in the liver of male rats and $\alpha 2$-microglobulin binds to chemicals in gasoline that make it resistant to protease hydrolysis. Unable to degrade $\alpha 2$-microglobulin, the cell accumulates high concentrations in lysosomes of the proximal tubule leading to lysosomal disruption and cell necrosis resulting in increased compensatory cell proliferation. Interestingly, a similar protein was extracted from the urine of human males with renal disease but it does not have the capability to bind to gasoline extracts and is found at very low concentrations. In summary, the renal carcinogenicity of gasoline in humans is limited by the 
absence of the $\alpha 2$-microglobulin protein (Dekant and Vamvakas, 1996). TCE has been implicated in RCC carcinogenesis in both animal models and human studies. Brauch et al. (2004) found a significant (8 year) difference between age at diagnosis for TCE exposed and non-exposed RCC patients (Fig. 17). However, the correlation between RCC and TCE exposure has not been confirmed and will be the subject of future studies (Lipworth et al., 2006).

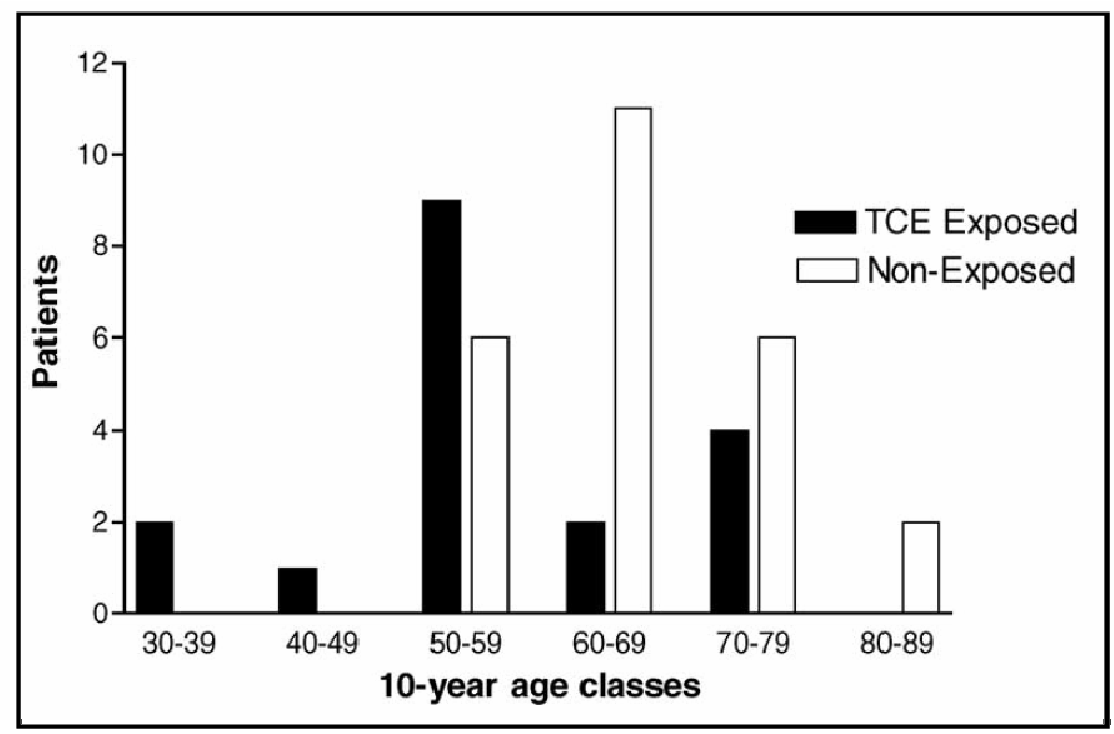

Fig. 17. Age distribution of RCC diagnosis in occupationally TCE-exposed (black bars) and non-exposed patients (white bars) (Brauch et al., 2004).

Presentation. Thirty percent of all RCC patients present with localized noninvasive disease that is easily controlled by radical nephrectomy or tumor enucleation (Bichler and Wechsel, 1999). However, another 30\% of all RCC patients seem to present with localized disease, but then progress into metastatic disease within 5 years of diagnosis (Sabo et al., 1997). Incidental 
diagnosis of patients with invasive metastatic disease occurs in forty percent of all RCC diagnosis. RCC metastasis is very difficult to treat and the median survival time for patients presenting with metastatic disease is $6-12$ months (Staehler et al., 2005). Common sites of metastasis include the lung and lymph nodes with bone and brain as secondary sites of invasion (Tomita, 2006). In $\mathrm{RCC}$, high native concentrations of multi-drug resistance protein as well high activity of regional glutathione systems confer resistance to both chemotherapy and radiation (Gurova et al., 2004). In addition, RCC is known for having high intratumoral heterogeneity with both diploid and aneuploid cells within the same tumor (Bichler and Wechsel, 1999).

Treatment Options. FDA approved treatment options have changed little since the 1980s and localized RCC is best treated with surgical methods that remove the primary tumor. Classical surgical methods include radical nephrectomy with regional lymphadenectomy and ipsilateral adrenalectomy to decrease chances of unresecteed metastasis (Wotcowicz and Libertino, 2007). New nephronsparing techniques are gaining popularity due to increased risk of kidney disease in RCC patients. Nephron sparing techniques include laparascopic partial nephrectomy, cyroablation, and energy-ablative therapy (Wotkowicz and Libertino, 2007). Surgery of primary or secondary tumors has little therapeutic value except to decrease pain, malaise, and hypercalcemia (Staehler et al., 2005). As late as 2005 , immune therapy was the only treatment for metastasis. 
Immune targeted therapies developed in the early 1990 s allowed partial control of metastasis for the first time. It had been observed that $6-7 \%$ of placebo treated patients undergo spontaneous regression after immune challenging nephrectomy, inflammation, or infectious insults (Young, 1998). Immunoediting is the regulation and control of tumor cells by the immune system (Dunn et al., 2002). A characteristic of RCC is the compromise of the immune system. For example, RCC tumor infiltration by dendritic cells is decreased compared to normal cells. Second, T cell reactions to tumor associated antigens are inhibited so that instead of the release of effector cytokines (interleukin-2 (IL-2), interferon- $\alpha(\mathrm{IFN} \alpha)$ ) that would promote apoptosis, compromised T cells instead secrete immunosuppressive cytokines (Michael and Pandha, 2003). New immune therapies attempt to stimulate the natural immune system by the introduction of exogenous IL-2 and IFN- $\alpha$.

IFN- $\alpha$ is a glycoprotein secreted in response to viral infections and foreign antigens that promotes expression of major histocompatibility complex (MHC) I molecules on the surface of the molecule. MHC class I antigen presenting cells interact with T-cell receptor for T-cell activation and target cell lysis (Fig. 18; Dembic et al., 1986; Clevers et al., 1988). Ten to fifteen percent of RCC patients treated with IFN- $\alpha$ have some response, $2 \%$ present with complete 
regression while most have only a delay of 6-7 months in progression (McDermott and Rini, 2007).

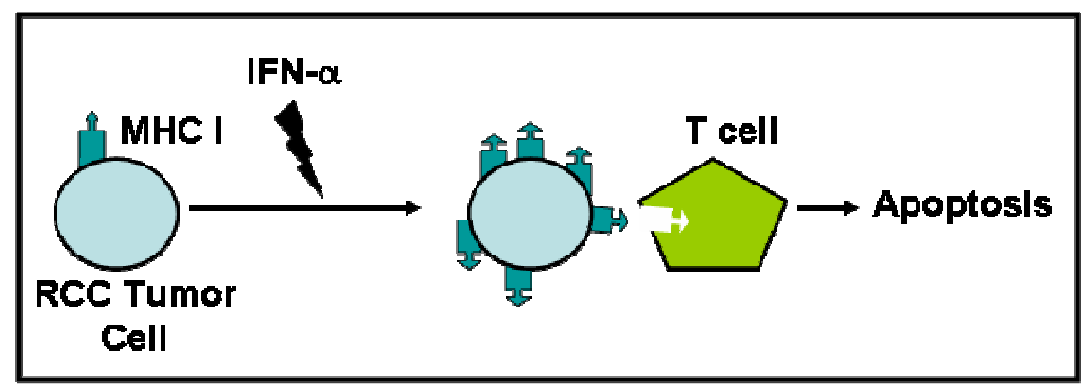

Fig. 18. Immunotherapy against RCC using IFN- $\alpha$. IFN- $\alpha$ therapy promotes expression of MHC-1 of cell surface of RCC tumor cells making it a target for cytotoxic T cells.

IL-2 glycoprotein is produced in response to infection and is necessary for regular lymphocyte function and growth. Specific functions include the discrimination between self and foreign antigens. IL-2 stimulates natural killer cells to secrete IFN- $\alpha$, granulocyte-macrophage colony stimulating factor (GMCSF) and tumor necrosis factor $\alpha$ (TNF- $\alpha$ ) that activates macrophages and causes maturation of antigen presenting cells (APC) for increased T cell activity and subsequent apoptosis (Fig. 19; Bleumer et al., 2003). 


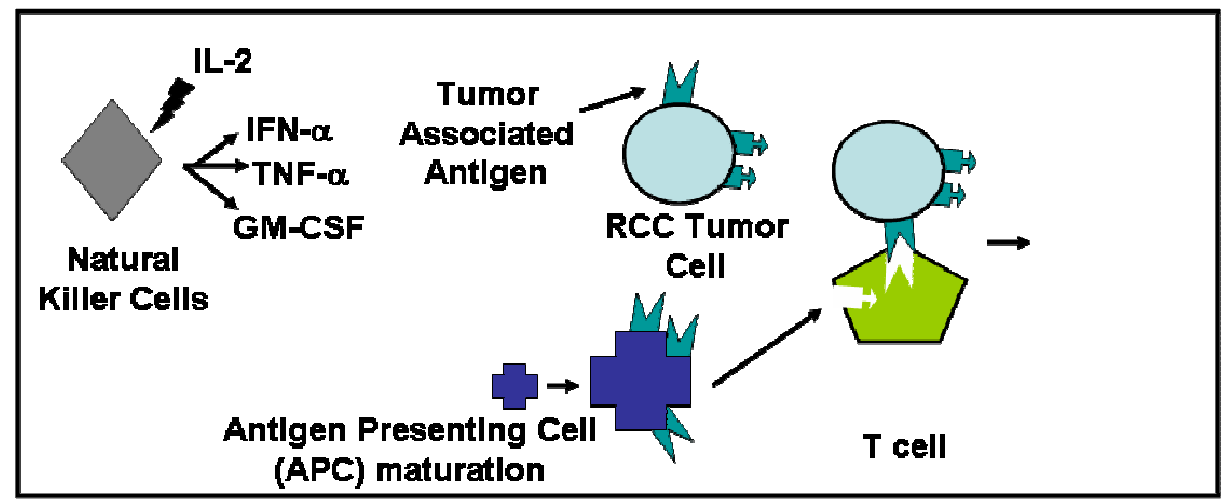

Fig. 19. Immunotherapy against RCC using IL-2. IL-1 stimulates natural killer cells to secrete TNF- $\alpha$ that activates macrophages, increases MHC-1 expression on surface of tumor cells and causes maturation of APC cells resulting in increased T-cell activity.

The response of RCC patients to IL-2 is correlated with the expression of the carbonic anhydrase IX (CAIX) antigen presentation on cellular surfaces. CAIX is overexpressed in $>90 \%$ of RCC cases due to ubiquitous loss of the von HippelLindau allele (Kim et al., 2004; McDermott and Rini, 2007). CAIX expression is particularly high in primary or low stage tumors but decreases with advancing stage (Bui et al., 2003). Response rates for IL-2 therapy in metastatic disease vary from 3-39\% depending on the differentiation characteristics of the tumor cells. For example, good predictive features include morphological features allowing for $>50 \%$ alveolar and no granular or papillary features. Conversely, only $3 \%$ of patients with bad predictive features $(>50 \%$ granular or papillary features) will respond to IL-2 therapy (McDermott and Rini, 2007).

Von-Hippel Lindau. New treatment options using molecular targets specific to RCC for antitumor activity have been reported. The Von-Hippel Lindau (VHL) 
allele is considered the gate-keeper of RCC. In mice, reintroduction of VHL will completely suppress RCC formation in VHL-/- cell line (Virtanen and Lehto, 2004). It is estimated that 1 in 35000 people in the US are affected by inheritance of a mutation at one VHL allele in an autosomal dominant pattern of inheritance (Vira et al., 2007). The VHL gene is found at chromosome 3p25-26 and expression patterns are highest in the kidney, eye and lung (Mukhopadhyay et al., 1997). Loss of VHL presents as a silent disease whose symptoms first appear as tumors of the CNS, kidney, adrenal gland, pancreas and retina. Sixty percent of VHL patients develop RCC making it the primary cause of death (Mukhopadhyay et al., 1997; Staehler et al., 2005). VHL patients that develop RCC present with numerous solid and cystic lesions and one estimate gave an average of 1100 cysts and 600 clear cell neoplasms per kidney (Vira et al., 2007).

Eighty-four to ninety-eight percent of sporadic (noninherited) RCC has loss of heterozygocity at the VHL allele. Forty percent of patients have mutations in the remaining allele while another $10 \%$ have silencing methylation at the $\mathrm{VHL}$ allele (Rini and Rathmell, 2007). The product of the VHL gene (pVHL) forms a complex that ubiquitinates protein kinase $\mathrm{C}$, decreases expression of matrix metalloproteases (MMPs), and increases expression of MMP inhibitors (Kopper and TImar, 2006). In addition to MMP regulation, one primary target is hypoxia inducible factor (HIF) that regulates hypoxia-responsive genes. 
In normoxic conditions, HIF is expressed at low levels in the cytoplasm. Without hypoxic stimulus, HIF is hydroxylated on conserved prolyl and arginyl residues by oxygen dependent prolyl and arginyl hydroxylases. pVHL is synthesized and forms a multiprotein complex (VEC) along with elongins $\mathrm{B}$ and $\mathrm{C}$, cullin 2, and rbx1 at the hydroxylated $\alpha$ domain of the HIF molecule (Leung and Ohh, 2002). In hypoxic conditions, HIF is not hydroxylated and is not bound by pVHL for targeted degradation. HIF $\alpha$ binds to its constitutively expressed partner, HIF $\beta$ to initiate transcription of genes containing the DNA sequence 5'-RCGTG-3' that regulate angiogenic, metabolic, and proliferative factors (Fig. 20; Staehler et al., 2005)

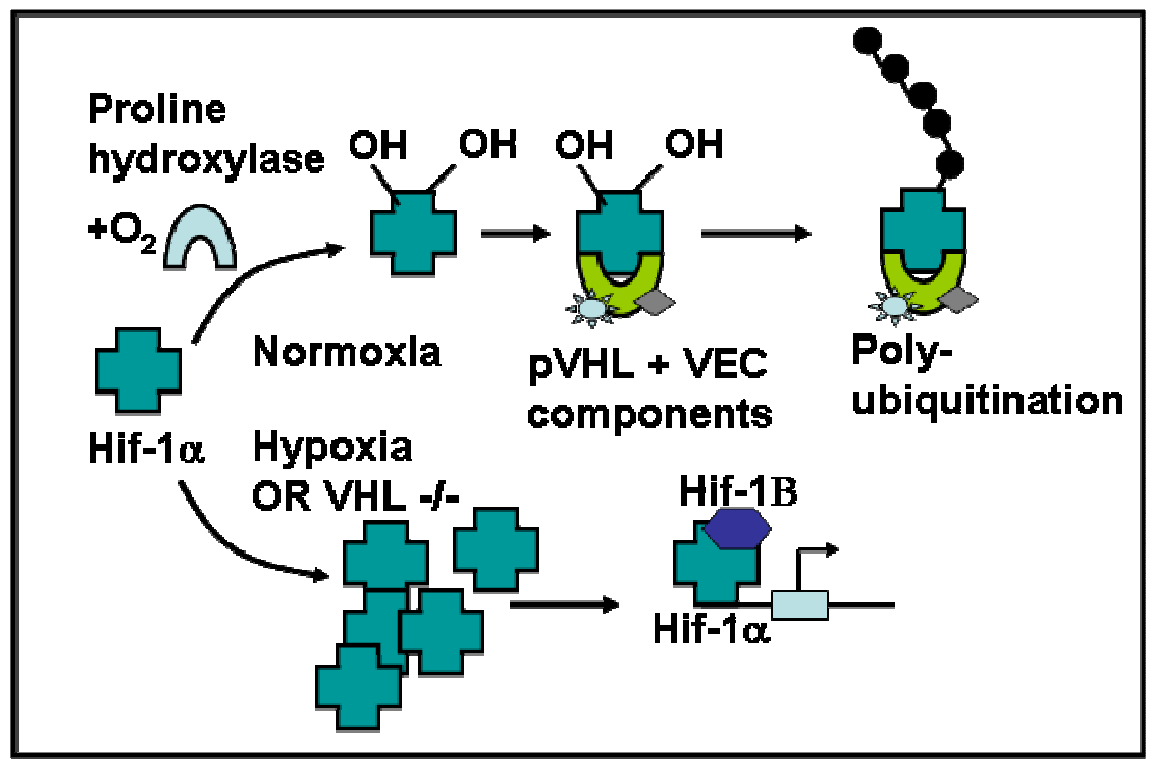

Fig. 20. Regulation of Hif $1 \alpha$ by pVHL. In normoxic conditions, Hif $1 \alpha$ is hydroxylated on prolyl and arginyl residues to allow pVHL binding and ubiquitin-mediated degradation. In hypoxic or VHL-/- conditions, VHL is unable to bind Hif $1 \alpha$ for its degradation resulting in translation of angiogenic, metabolic, and proliferative proteins. 
Angiogenic factors induced by HIF action include a high number of angiogenic genes including vascular endothelial growth factor (VEGF) as well as plateletderived growth factor (PDGF). RCC tumor cells secrete high levels of VEGF that interacts with three different transmembrane tyrosine kinase receptors: VEGFR-1, VEGFR-2, and VEGF-R3 (Staehler et al., 2005). VEGFR ligand binding results in autophosphorylation of transmembrane tyrosine kinase receptors and activation of downstream signaling pathways involving phospholipase $\mathrm{C} \gamma$, PI3K, Ras GTPase-activating protein and MAPK among others (Zeng et al., 2001). RCC tumors overexpress VEGF type VEGFA that binds to similarly overexpressed VEGFR-1 (FIt-1), VEGFR2 (KDR/Flk-1) and the nonkinase receptor neropilin (NRP-1) (Mukhopadhyay et al., 1997). VEGFA is a powerful vascular permeability agent and acts at a concentration of $1 \mathrm{mmol} / \mathrm{L}$, nearly 50,000 times equivalent acting concentration for histamine (Senger et al., 1983). The increase in vascular permeability results in leakage of plasma proteins including clotting proteins and fibrinogen into the tumor site. Subsequent activation of the clotting proteins results in deposition of fibrin in tumor stroma. Fibrin leakage converts stroma with antiangiogenic character into highly angiogenic provisional stroma (Dvorak et al., 1985). Downstream effectors of VEGF activity include induction of MMPs, nitric oxide synthase, mitogens, and antiapoptotic factors including bcl-2, survivin, and X-linked mammalian inhibitor of apoptosis (XIAP) (Dvorak, 2002). PDGF interacts with 
PDGR receptor (PDGFR) expressed on endothelial cell structural and support cells called pericytes. PDGFR expression is important for later stages of blood vessel formation (Steahler et al., 2005).

New therapies in phase III clinical trials are targeted against RCC overexpression of VEGF. Mature vasculature endothelium is coated with periendothelial cells that secrete growth factors necessary to maintain angiogenic growth. However, immature vasculature is dependent on VEGF signal for survival (Benjamin et al., 1999). Therapy options for RCC were increased when it was discovered that established solid tumors had a high number of immature vessels still sensitive to VEGF inhibition. Massive hemorrhage and necrosis result from VEGF withdrawal in glioma models of conditional VEGF expression (Benjamin and Keshet, 1997). Bevacizumab (Avastin $\odot$, Genetech) is a recombinant humanized monoclonal antibody against all VEGF isoforms that inhibits receptor binding (Presta et al., 1997). In phase II trials against RCC in patients unresponsive to immunotherapy, time to progression was significantly longer in patients receiving bevacizumab than placebo (4.8 vs 2.5 months; Fig. 21; Yang et al., 2003). 


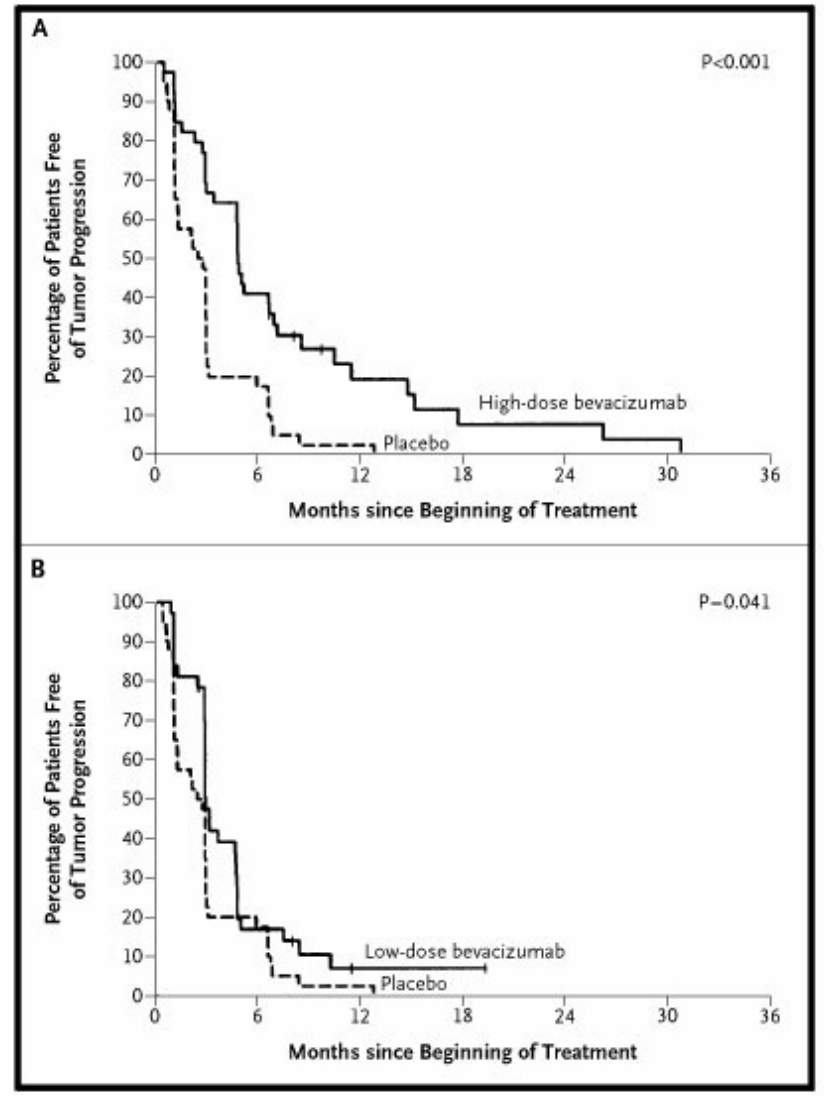

Fig. 21. Kaplan-Meier anaylsis of surivial free of tumor progression for patients receiving high dose bevazicumab $(\mathrm{A})$ or low dose bevazicumab $(\mathrm{B})$ as compared to placebo (Yang et al., 2003).

In addition to increased expression of angiogenesis factors, HIF binding also results in induction of anaerobic metabolic activity. Any tumor tissue greater than 100-200 $\mu \mathrm{m}$ from vasculature exists in hypoxic conditions, resulting in increased induction of HIF- $1 \alpha$. HIF- $1 \alpha$ acts as a metabolic switch enabling cells to survive anaerobically on glucose by induction of glycolysis genes and inhibition of genes leading to oxidative phosphorylation (Kim et al., 2006). Upregulated genes include aldolase A, enolase 1, lactate dehydrogenaes A, 
phosphofructokinase L, phosphofructokinase 1 , and pyruvate kinase 1 among others (Fig. 22; Dang and Semenza, 1999).

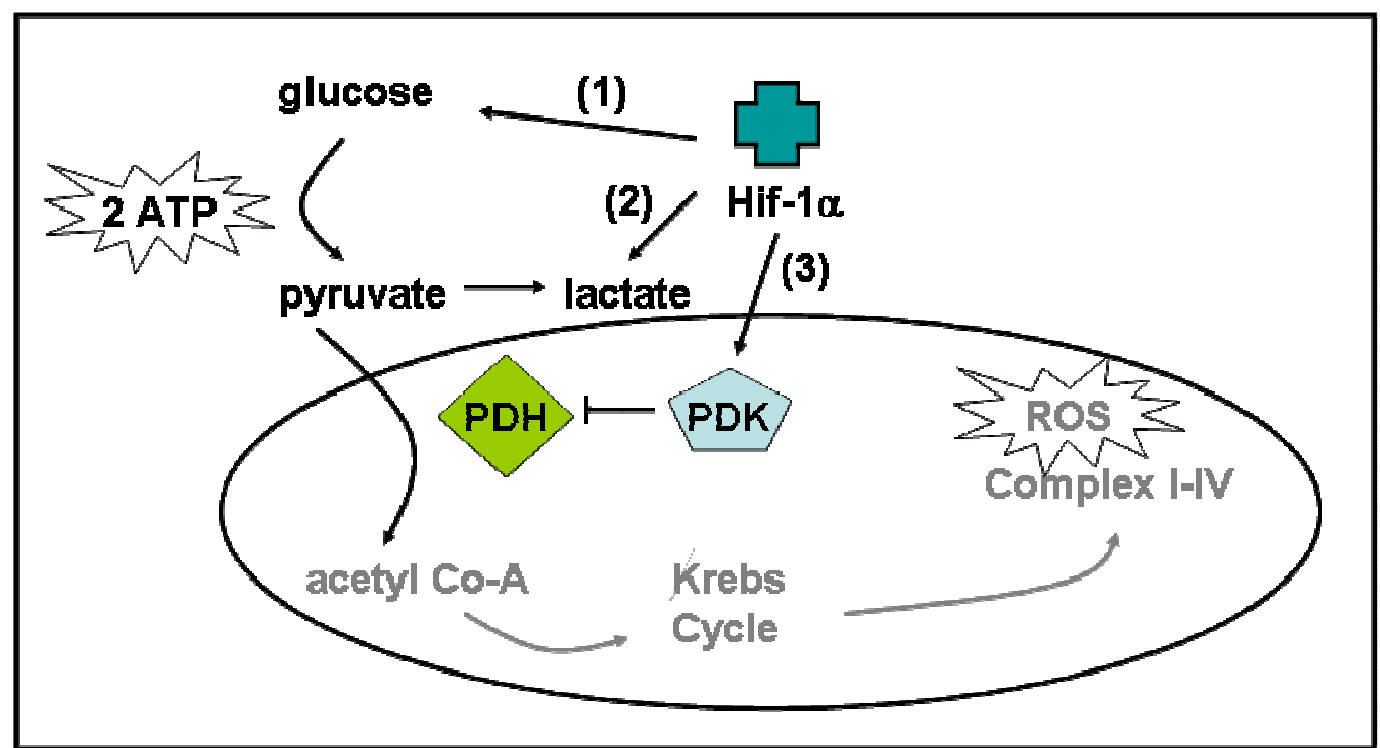

Fig. 22. Regulation of hypoxia induced metabolic switches by HIF-1 $\alpha$. In hypoxia HIF1 $\alpha$ induces genes involved in, (1) conversion of glucose to pyruvate through glycolysis, (2) reduction of pyruvate to lactate, and (3) induction of pyruvate dehydrogenase kinase (PDK) to block pyruvate progression into Krebs cycle and subsequent ROS generation. Modified from Kim et al., 2006.

Proliferative factors induced by HIF activity include transforming growth factor- $\alpha$ (TGF- $\alpha$ ) and epidermal growth factor receptor (EGFR). TGF- $\alpha$ has an unusual role in RCC in addition to an established role in angiogenesis since TGF- $\alpha$ acts as a mitogenic factor. Unusually, cell proliferation of both $\mathrm{VHL}+/+$ and $\mathrm{VHL}-/-$ RCC cells is suppressed by contact inhibition. The importance of the mitogenic action of TNF- $\alpha$ is underscored by the observation that in the absence of external growth factors, proliferation of RCC can be blocked by inhibition of 
TGF- $\alpha$ or it's receptor epidermal growth factor receptor (EGFR; Fig. 23; de Paulsen et al., 2001).

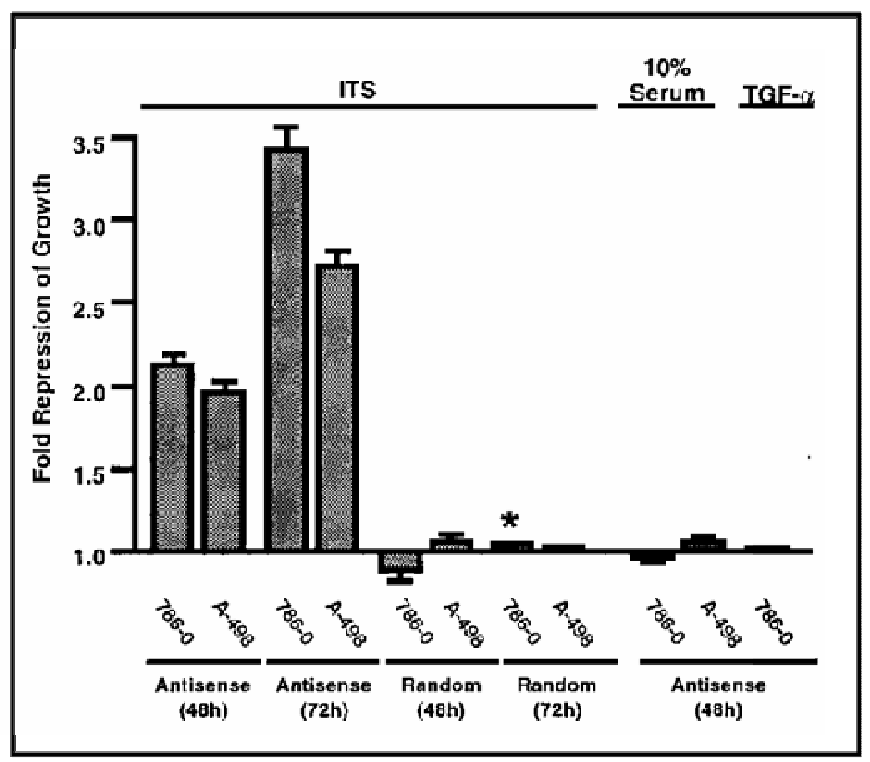

Fig. 23. Growth inhibitory effects of TFG- $\alpha$ antisense oligodeoxynucleotide on $\mathrm{VHL}^{-1-}$ RCC cells. Cells were grown in media containing either $10 \%$ serum or ITS (insulin, transferin and selenium) in the presence of TFG- $\alpha$ antisense nucleotide. Inhibition of TFG- $\alpha$ in the presence of ITS resulted in 2.2 and 1.8 fold decreases in cell proliferation that could be abolished by the addition of $10 \%$ serum or the addition of purified TFG- $\alpha$ (de Paulsen et al., 2001).

Both EGF and TGF- $\alpha$ can bind EGFR $\alpha$ and downstream effectors include Ras that constitutively activates the Raf/MEK/ERK pathway. Raf controls the expression of over 120 genes involved in promotion of cell transformation, proliferation, invasion and adhesion (Staehler et al., 2005). Tyrosine kinase inhibitors directly targeted against the EGFR have been studied in phase III trials and have delayed time to progression by only 4 weeks ( 15.1 weeks vs. 11.1 
weeks) indicating that action of EGFR/TGF- $\alpha$ feedback loop is more complicated in vivo (Vogelzang and Sternberg, 2007).

Peroxisome Proliferator-Activated Receptor- $\boldsymbol{\gamma}$. Many molecular targets are being explored outside of the VHL gatekeeper pathway including activation of peroxisome proliferator-activated receptors- $\gamma$ (PPAR $\gamma)$. PPAR $\gamma$ is a member of the nuclear hormone receptor superfamily (Isseman and Green, 1990). Upon ligand binding PPAR $\gamma$ heterodimerizes with retinoid $X$ receptor $(R X R)$ and binds to PPAR $\gamma$ response elements (PPRE) within the genome (Palmer et al., 1995). PPAR $\gamma$ activity has been correlated with antineoplastic and anti-inflammatory responses in tumor cell lines including lung, breast, colon, prostate, osteosarcomas, and acute myelogenous leukemia. Although PPAR $\gamma$ activity has been linked to many of the above functions, PPAR $\gamma$ agonists also display many other surprising actions unrelated to PPAR $\gamma$ expression, the so-called PPAR $\gamma$ independent effects (Yuan et al., 2006). These PPAR $\gamma$ independent activities constitute many of the antineoplastic responses observed for diverse PPAR $\gamma$ agonists.

PPAR $\gamma$ and NSAID Activated Gene-1. In addition to antiproliferative actions, PPAR $\gamma$ ligands induce NSAID activated gene-1 (NAG-1), a protein implicated in apoptosis in various tumor cell lines (Chintharlapalli et al., 2005b). NAG-1 is a 
divergent member of the TGF- $\beta$ superfamily and has also been named macrophage inhibitory cytokine-1 (MIC-1), placental transformation factor (PDF), growth differentiation factor 15 (GD15), and placental bone morphogenic protein (PLAB) (Baek and Eling, 2006). NAG-1 is formed as a proprotein consisting of 167 amino acids and undergoes proteolytic cleavage to generate a 112 amino acid secretory product (Bauskin et al., 2000). Mature NAG-1 is expressed at high levels in the placenta and at lower levels in the kidney, colon, and prostate (Paralkar et al., 1998). Many structurally diverse compounds can induce NAG-1 including COX inhibitors, dietary agents, PPAR $\gamma$ agonists and anti-cancer drugs (Table 3; Eling et al., 2006).

Table 3: Select NAG-1 inducers. Modified from Eling et al., 2006.

\begin{tabular}{|lc|}
\hline \multicolumn{1}{|c|}{ Concentration (uM) } \\
\hline Cyclooxygenase Inhibitors & $1,000-10,000$ \\
Aspirin & $1-50$ \\
Sulindac Sulfide & $50-200$ \\
Diclofenac & $100-1,000$ \\
ibuprofen & \\
Dietary Agents & $10-100$ \\
Resveratrol & $10-100$ \\
Caspsaicin & 50 \\
Indol 3-carbinol & $10-100$ \\
Genesitein & $10-100$ \\
Lycopene & \\
PPARg agonists & 5 \\
Troglitazone & 20 \\
DIM & $5-10$ \\
C-DIM & \\
Anti-Cancer Drugs & $.01-5$ \\
2F-203 & \\
\hline
\end{tabular}

Interestingly, NAG-1 induction by COX inhibitors appears to be COXindependent. For example, in the COX negative HCT-116 cell line induction of 
NAG and it's proapoptotic effects are observed (Eling et al., 2006). The biological functions of NAG-1 are still widely unknown but are thought to emulate those of other TGF- $\beta$ family members. NAG -1 has shown potential both as an anti-inflammatory and antiproliferative agent. Ectopic expression of NAG-1 can result in cancer cell growth arrest in soft agar and retroviral expression inhibits MCF-7 breast cancer cell growth (Baek et al., 2001; Li and Jee, 2000). Heterozygous C57BL/6J-Apc ${ }^{\mathrm{Min} /+}$ mice are prone to develop tumors of the stomach, colorectal axis and esophagus and were crossed with LOX-P-NAG-1 transgenic mice. When these mice are crossed with Protamine-Cre mice, NAG1 is overexpressed in all tissues Upon treatment with the colon carcinogen azoxymethane (AOM), $\mathrm{Apc}^{\mathrm{Min} /+} / \mathrm{NAG}^{+/-}$mice showed a $58 \%$ reduction in numbers of small intestinal polyps and a $60 \%$ reduction in tumor load (Fig. 24; Baek et al., 2006). 


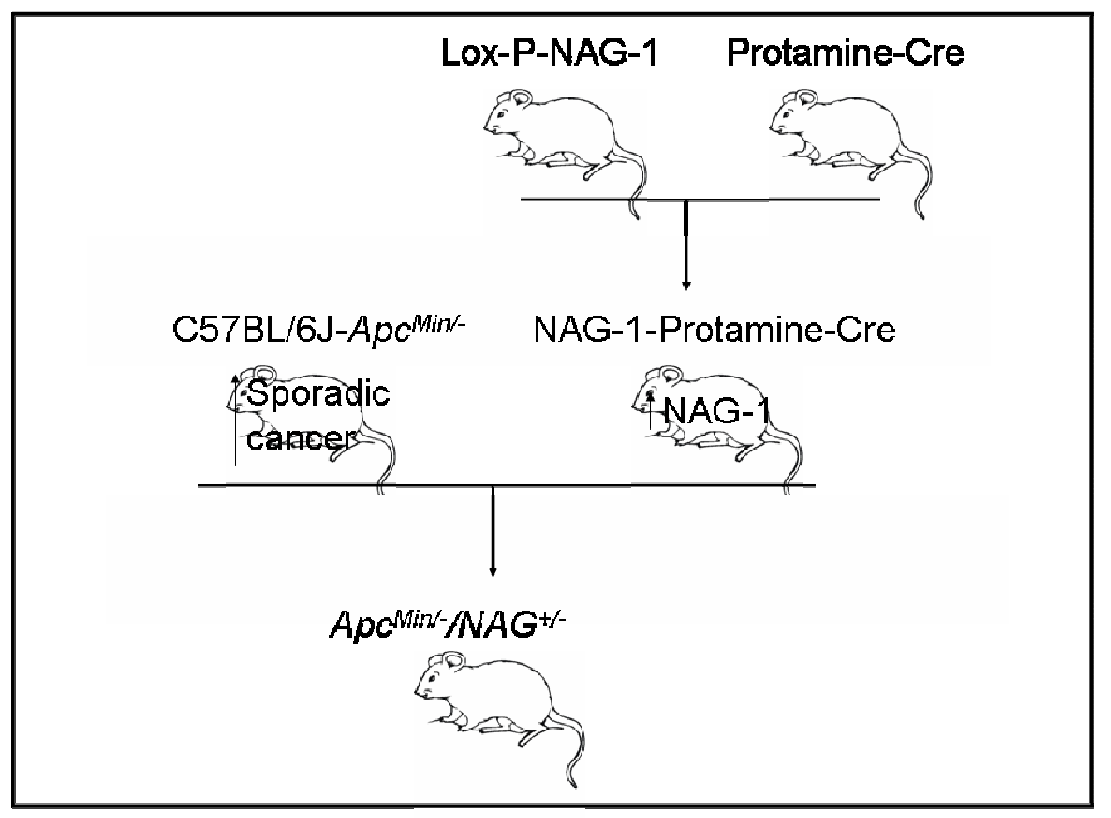

Fig. 24. Production of NAG-1 transgenic mice. Modified from Baek et al., 2006.

The NAG-1 promoter is regulated by diverse elements including p53, early growth response-1 (EGR-1), chicken ovalbumin upstream promoter-transcription factors (COUP-TF1), specificity protein 1 (Sp1), and activating transcription factor 3 (ATF3) (Baek et al., 2001). Interestingly, EGR-1 and Sp1 share the same binding site and in the presence of NAG-1 inducers, EGR-1 is also induced and preferentially binds the NAG-1 promoter (Chintharlapalli et al., 2005b). In addition to transcriptional regulation, NAG-1 is subject to posttranscriptional modifications for example, the NAG-1 inducer retinoid 6-[3-(1adamantyl)-4-hydroxyphenyl]-2-napthalene carboxylic acid (AHPN) increases NAG-1 RNA stability (Newman et al., 2003). ATF3 is a member of the ATF/CREB (cAMP response element binding protein) subfamily of the basicregion leucine zipper (bZIP) family of transcription factors (Hai and Hartman, 
2001). ATF3 regulation of the NAG-1 promoter element has been shown in a study in which the transfection of ATF3 can increase NAG-1 induction by 3-fold. The potential ATF3 binding sequence on the NAG-1 promoter is TGACGTCA, a sequence which is identical to the CRE consensus sequence (Lee et al., 2006).

PPAR $\gamma$ and Caveolin-1. PPAR $\gamma$ agonists have been shown to induce caveolin1 expression in prostate cancer cells (Chintharlapalliet al., 2006). Caveolin-1 is a membrane scaffolding protein and a major structural and functional component of lipid microdomains in the plasma membrane called caveolae (Razani et al., 2002). In the kidney, caveolae are found in the basolateral membrane of the distal collecting tubule, collecting duct, parietal cells of Bowman's capsule, endothelial cells and smooth muscle cells (Breton et al., 1998). Caveolae compartmentalize signal transduction receptors like EGFR, PDGFR and Gprotein, Ha-Ras to facilitate crosstalk (Carrion et al., 2003). In tumors, caveolin has been linked to both tumor suppressive and oncogenic functions. As a tumor suppressor, expression of recombinant caveolin-1 inhibits growth in breast, lung, and ovarian cancer cells and the caveolin gene located on $7 q 31.1$ is often lost in many human cancers including RCC (Campbell et al., 2003; Engelman et al., 1999). However, caveolin acts as an oncogene in prostate cancer in which expression of caveolin-1 was found to be sufficient for growth and survival (Tahir et al., 2001). Oncogenic activities are mechanistically explained by the fact that caveolin-1 activates MMP action to stimulate plasminogen synthesis of plasmin, 
a molecule linked to extracellular matrix degradation (Campbell et al., 2003). In RCC, studies confirm that caveolin acts as a mediator of metastasis and increased levels are linked with poor prognosis (Carrion et al., 2003).

PPAR $\gamma$ and Cell Cycle Regulation. The cell cycle progresses through distinct phases of growth; G1 phase allows growth in preparation for the $S$ (synthesis) phase during which the DNA is replicated. The S phase leads into the G2 phase allowing time for cell growth before the M (Mitosis) stage and the restart of the cell cycle at G1. Cell cycle checkpoints allow the cell to exert control over the cell cycle and arrest at G1 if the cellular mass is too little or if DNA damage has occurred. Most mutations involved in tumorigenesis affect the restriction point which occurs mid-G1 after this checkpoint cells are independent of growth factors and are commited to cell division (Pardee, 1974). Ninety percent of human cancers have mutations affecting the coordinated regulation of retinoblastoma $(\mathrm{Rb})$ protein by cyclin $\mathrm{D} 1, \mathrm{D} 2$, and $\mathrm{D} 3$ and cyclin $\mathrm{E} 1$ and $\mathrm{E} 2$ which partner with cyclin dependent kinases (cdks) (Malumbres and Barbacid, 2001). In normal cells, cyclin D binds and activates cdk 4 and 6 while cyclin $E$ binds to activate cdk2. Cdk protein concentrations are stable throughout the cell cycle and activities are inhibited by phosphorylation on threonine and tyrosine residues. The $\mathrm{p} 21^{\mathrm{cip} 1}$ family regulates $\mathrm{Cdk}$ phosphorylation for inhibition of kinase activity and consists of three different members, p2 $1^{\text {cip } 1}, \mathrm{p} 27^{\mathrm{kip} 1}$ and p5 $7^{\text {kip2 }}$. In cancer both p21 and p27 actions are described as both oncogenic 
and tumor suppressive depending on the cellular location (Swanton, 2004). In colon cancer, patients with low or nondetectable p27 have 50\% less survival time than patients with high p27 expression, in addition low p27 expression is correlated to poor cellular differentiation and prognosis in breast cancer (Loda et al., 1997; Catzavelos et al., 1997). However, deletion of p27 is a rare event in cancer indicating that sometimes this protein can have oncogenic actions. For example, in breast cancer cell lines, phosphorylation of p27 resulting in cytoplasmic localization, a condition associated with direct anti-apoptotic functions by binding of p27 to caspase 3 leading to inhibition of apoptosis (Swanton, 2004). Passage by the restriction point is coordinated by hyperphosphorylation of $\mathrm{Rb}$ leading to the cessation of its replication suppressive actions. Rb protein suppresses replication by the recruitment of histone deacetylase to E2F sites resulting in tighter association between DNA and nucleosomes and recruitment of SWI/SWF complexes. Cyclin D1 interacts with cdk 4 and 6 to phosphorylate and inactivate $\mathrm{Rb}$ protein allowing replication to proceed (Swanton, 2004). Cyclin D1 is negatively regulated by GSK-3 $\beta$ phosphorylation that marks cyclin D1 for cytoplasmic localization and ubiquitin mediated degradation and p21 and p27 inhibit nuclear translocation of the cyclin D1/cdk4 complex (Fig. 25; Lin et al., 2000). 


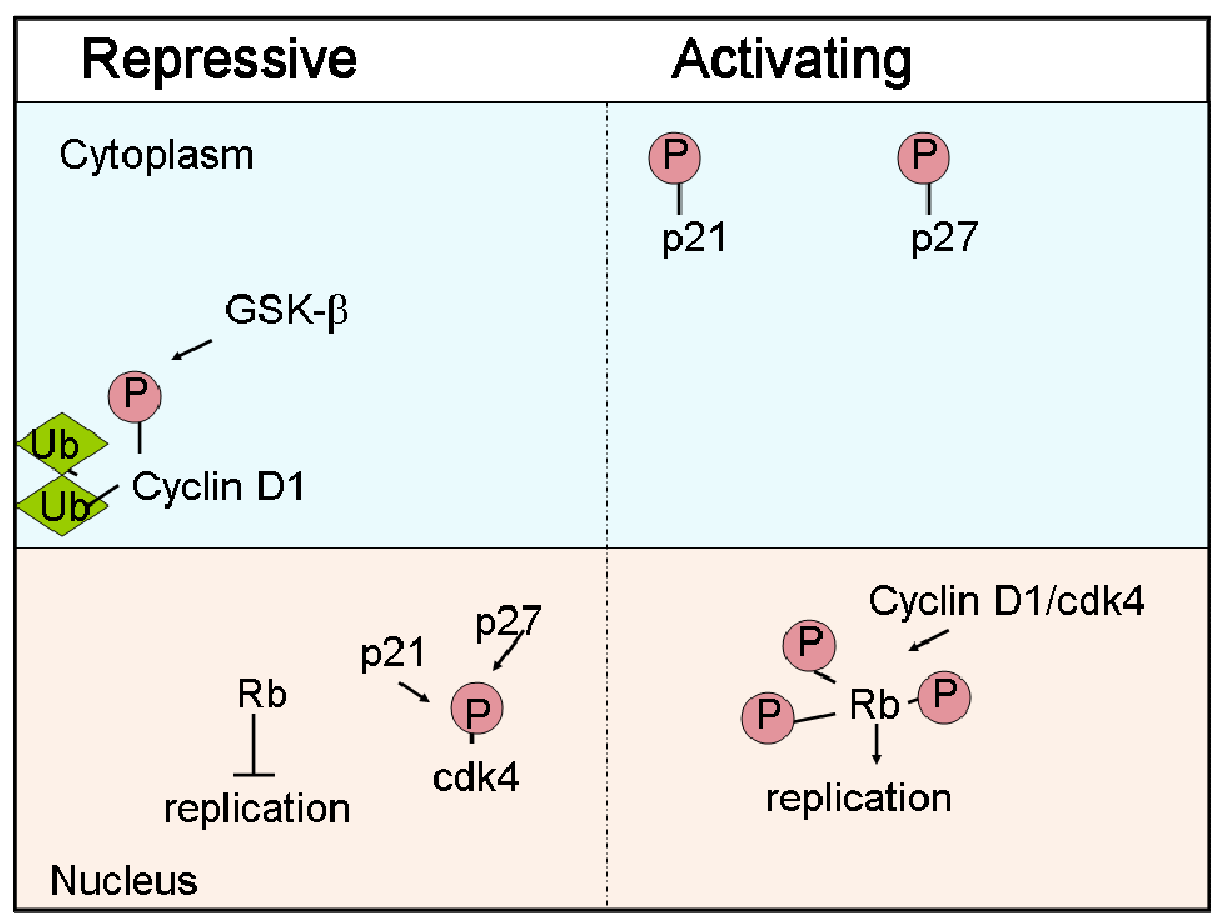

Fig. 25. Cell cycle regulation. In repressive conditions, cyclin D1 is inhibited by phosphorylation by GSK-3 $\beta$ which enhances ubiquitin-mediated degradation and activity by p21 and p27. In replication activating conditions, p21 and p27 are phosphorylated and translocated to the cytoplasm. Nuclear cyclin D1 hyperphosphorylates $\mathrm{Rb}$ protein to activate replication.

Treatment of RCC cell lines with PPAR $r$ agonists (pioglitazone and troglitazone) can increase growth arrest in $\mathrm{G} 1$ phase and repress expression of Rb, cyclin D, and cdk4 while inducing p21 and p27 (Yang et al., 2005).

PPAR $\gamma$ and ER Stress-Dependent Apoptosis. HIF-1 $\alpha$ regulation of metabolism allows tumor cells to grow in hypoxic conditions but the metabolic switch from oxidative phosphorylation to glycolysis results in a deficit of 34 ATP Iglucose molecule. Consequently, many tumors including those found in the breast, lung, gastric system and prostate suffer from severe depletion of glucose 
and oxygen leading to constitutive induction of HIF- $1 \alpha$ independent unfolded protein response (UPR) pathway also called the ER stress response (Li et al., 2006).

The UPR proceeds in 2 main phases generating first a protective response and then upon acute stimuli ER stress-dependent apoptosis (Koumenis, 2006). Induction of ER-stress dependent glucose regulated protein -78 (GRP78) results in decreased translational activity coupled with selective translation of ER chaperone proteins and induction of ER-associated degradation pathways (Li et al., 2006). GRP78 is a member of the HSP70 family of proteins and is overexpressed in many tumor types due to higher glucose utilization rates of cancer cells compounded by hypoxia (Koong et al., 1994; Dong et al., 2004). A secondary, ER stress-dependent apoptotic pathway is induced in response to acute ER stress stimuli. CHOP, also known as growth arrest and DNA damageinducible gene (GADD153) is a member of the CCAAT/enhancer binding proteins (C/EBPs). ER stress dependent induction of CHOP leads to cell cycle arrest and/or apoptosis and serves as a marker for induction of ER stressdependent apoptosis (Oyadomari and Mori, 2004).

Several models have been proposed for ER stress-dependent apoptosis. In apoptosome deficient cells, release of $\mathrm{Ca}^{2+}$ is essential for downstream apoptosis in response to the classical ER stress inducer tunicamycin (Sano et 
al., 2006). In one model, release of $\mathrm{Ca}^{2+}$ from the $\mathrm{ER}$ leads to mitochondrial uptake of $\mathrm{Ca}^{2+}$ and release of cytochrome $\mathrm{c}$. It is not known if the release of cytochrome c from the mitochondria is essential for ER stress however, it is known that certain types of ER stress can be blocked by bcl-2 indicating that mitochondrial depolarization plays a large role in this ER stress induced apoptosis.

In this laboratory it has been shown that ER stress is induced in cancer cells treated with both classical UPR activators and peroxisome proliferator activated receptor- $\gamma$ (PPAR $\gamma)$ agonists called C-substituted dindolylmethane (DIM)s. This reponse results in the induction of $\mathrm{CHOP}$ and it's binding as a transcription factor to the DR5 promoter causing an upregulation of the DR5 gene. It is hypothesized that overexpression of the death receptor induces dimerization and subsequent activation of caspase 8 dependent apoptosis (Fig. 26; Abdelrahim et al., 2006). 


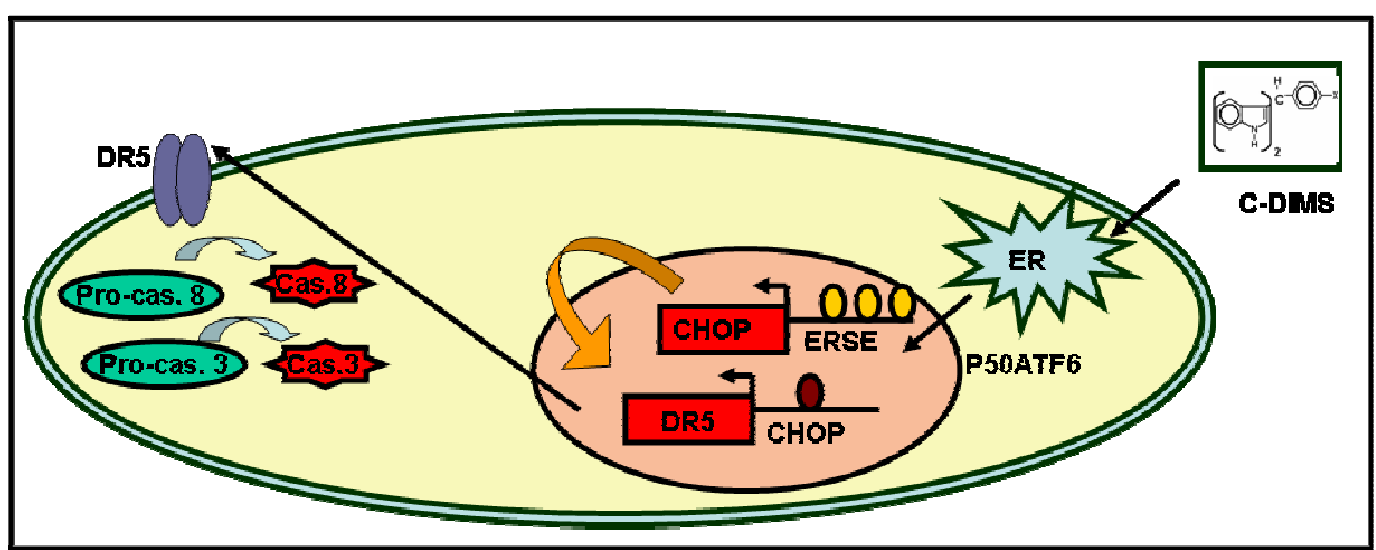

Fig. 26. ER stress-dependent apoptosis. C-DIM treatment results in ER-stressdependent apoptosis through the induction of CHOP and it's subsequent induction of DR5. Increased expression of DR5 results in autodimerization and binding of procaspase 8 and the caspase cascade. Modified from Abdelrahim et al., 2006.

The overexpression of the UPR protective response by cancer cells is an interesting new molecular target for cancer therapy. Researchers are now attempting to facilitate the switch from protective UPR to ER-stress dependent apoptosis either by inhibition of protective UPR genes (GRP78) and downstream effectors or new cancer treatments that impose acute ER stress and thus bypass the UPR response (Fig. 27; Abdelrahim et al., 2006; Li et al., 2006).

Although PPAR $y$ agonists show great promise for treatment of many diverse cancer cell types, until late 2005 no group had pursued research on the treatment of kidney cancer by PPAR $\gamma$ agonists. In select renal cancer cells, it has been shown that PPAR $\gamma$ agonists inhibit cell proliferation, induce apoptosis, and induce anti-angiogenic effects in vitro (Yuan et al., 2005). Recently, PPAR has been identified as a potential tumor suppressor gene in RCC as was 
downregulated in tissue samples from 47 RCC patients (Yuan et al., 2006). A rationale for PPAR $\gamma$ downregulation in RCC is unknown but the gene resides in chromosome 3p25 in which heterozygocity is commonly lost in RCC (Yuan et al., 2006). Interestingly in RCC cells in culture, PPAR $\gamma$ expression does not correlate with growth inhibitory or proapoptotic effects induced by PPAR $\gamma$ agonists in renal cell lines indicating that PPAR $\gamma$-independent responses may play an important role the activities of PPAR $\gamma$ agonists.

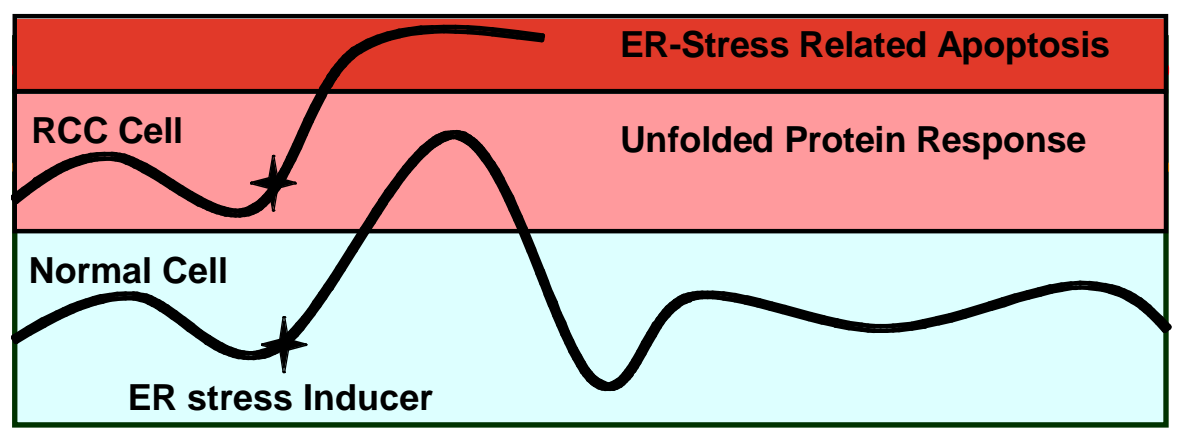

Fig. 27. Rational for the targeting of ER stress-related apoptosis. RCC cells exist in Unfolded Protein Response conditions while normal cells exist under decreased metabolic and oxygen burden. Upon addition of ER stress inducers, normal cells can compensate with induction of the unfolded protein response however, cancer cells will be overwhelmed and will enter ER-stress related apoptosis.

PPAR $\gamma$ agonists including thiazolidinediones and 15-deoxy- $\Delta 12,14-$ prostaglandin J2 (PGJ2) induce cell cycle arrest and apoptosis in human renal cell carcinoma cell lines (Yang et al., 2005, Yuan et al., 2005, Yuan et al., 2006). Recent studies in this laboratory have identified a series of 1,1-bis(3'indolyl)-1( $\rho$-substitutedphenyl)methanes [PPAR $\gamma$ active C-substituted DIMs] that inhibit growth and induce apoptosis in various cancer cell lines (Fig. 28; Chintharlapalli 
et al., 2006; Chintharlapalli et al., 2005b; Lei et al., 2006; Chintharlapalli et al., 2006; Kassouf W et al., 2006).

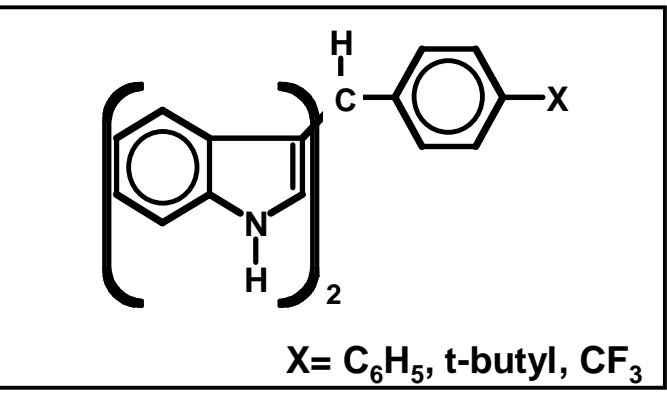

Fig. 28. Structures of PPAR $\gamma$-active C-substituted DIMs.

PPAR $\gamma$-active C-DIMs: Effects on RCC. Peroxisome proliferator-activated receptor $\gamma$ (PPAR $\gamma$ ) is a member of the nuclear receptor superfamily of ligandactivated transcription factors (Berger and Moller, 2002; Mangelsdorf et al., 1995). PPARs are involved in an increasing number of physiological functions including regulation of lipid metabolism and homeostasis and they also play a role in metabolic diseases, atherosclerosis and cancer (Lee et al., 2003, Desvergne and Wahli, 1999; Escher and Wahli, 2000; Rosem and Piegelman, 2001; Wilson et al, 2001; Fajas et al, 2001). Fatty acids, prostaglandins and related compounds bind PPARs; however, the endogenous ligands for these receptors are not well defined (Corton et al, 2000). PPAR $\gamma$ agonists such as the thiazolidinediones rosiglitazone and pioglitazone have been developed for treatment of type II diabetes due to their activity as insulin-sensitizing agent (Wilson et al., 2000; Moller, 2001) 
PPAR $\gamma$ is highly expressed in many tumor samples and cancer cell lines derived from hematopoietic and non-hematopoietic tumors and PPAR been extensively investigated as potential antitumor drugs (Ikezoe et al., 2001; Gupta et al., 2003; Brockman et al., 1998; Kato et al., 2004, Place et al., 2003; Qin et al., 2003; Gupta et al.,2001; Kitamura et al., 1999; Takahashi et al., 1999; Motomura et al., 2000; Chang et al., 2000, Elstner et al., 1998).

Thiazolidinediones such as rosiglitazone, troglitazone and 15-deoxy$\Delta^{12,14}$ prostaglandin J2 (PGJ2) typically inhibit cancer cell growth. This is accompanied by inhibition of $G_{0} / G_{1}$ to $S$ phase progression, downregulation of cyclin D1, and induction of p21 and/or p27. These compounds and other classes of PPAR $\gamma$ agonists such as 2-cyano-3,12-dioxoolean-1,9-dien-28-oic acid (CDDO) and related triterpenoids, and 1,1-bis(3'-indolyl)-1-( $p$ substitutedphenyl)methanes [methylene-substituted diindolylmethanes (CDIMs)] also induce apoptotic pathways in cancer cell lines and inhibit tumor growth in in vivo models. Research in this laboratory has focused on PPAR $\gamma$ active C-DIM compounds containing p-substituted trifluoromethyl (DIM-C$\mathrm{pPhCF}_{3}$ ), $t$-butyl (DIM-C-pPhtBu), and phenyl (DIM-C-pPhC ${ }_{6} \mathrm{H}_{5}$ ) groups (Hong et al., 2004; Contractor et al., 2005; Chintharlapalli et al., 2005a; Chintharlapalli et al., 2005b; Abdelrahim et al., 2006; Lei et al., 2006; Chintharlapalli et al., 2007; Chintharlapalli et al., 2006). These compounds induce PPAR $\gamma$-dependent p21 and caveolin-1 expression in pancreatic and colon cancer cell lines, respectively. 
However, many of the induced responses are PPAR $\gamma$-independent. For example, C-DIMs induce endoplasmic reticulum (ER) stress in pancreatic and ovarian cancer cells, and this leads to constitutive activation of death receptor 5 (DR5) and caspase 8-mediated apoptosis (Abdelraim et al., 2006). In addition, C-DIMs induce receptor-independent downregulation of cyclin D1, increased expression of nonsteroidal anti-inflammatory drug induced gene 1 (NAG-1) and activating transcription factor 3 (ATF3; Chintharlapalli et al., 2005b).

Previous studies have reported that PGJ2 and thiazolidinediones induce cell cycle arrest and apoptosis in human renal cell carcinoma (RCC) cell lines, and this study investigates the effects of PPAR $\gamma$-active C-DIMs in ACHN and 786-0 renal cell carcinoma cells (Yang et al., 2005; Yuan et al., 2005; Yuan et al., 2006). 


\section{MATERIALS AND METHODS}

\section{Cell Culture}

Human renal clear cell carcinoma cell lines $A C H N$ and $786-0$ were obtained from the American Type Culture Collection (Manassas, VA). ACHN cells were maintained in MEM (Sigma, St. Louis, MO) supplemented with $10 \%$ fetal bovine serum (FBS) and $10 \mathrm{ml} / \mathrm{L}$ of $100 \mathrm{X}$ antibiotic/antimycotic solution (Sigma-Aldrich, St Louis, Mo). 786-0 cells were maintained in RPMI 1640 (Sigma) supplemented with $10 \% \mathrm{FBS}$, and $10 \mathrm{ml} / \mathrm{L}$ of $100 \mathrm{X}$ antibiotic/antimycotic solution. Cells were maintained at $37^{\circ} \mathrm{C}$ in the presence of $5 \% \mathrm{CO}_{2}$.

\section{$\underline{\text { Reagents }}$}

Antibodies for DR5, cleaved PARP, cleaved caspases 3 and 8 were purchased from Cell Signaling (Beverly, MA). Antibodies CHOP, GRP78, PPAR $\gamma$, Cyclin D1, p27, caveolin and $\beta$-tubulin were purchased from Santa Cruz Biotechnology (Santa Cruz, CA), and NAG-1 antibody was obtained from Upstate (Charlottesville, VA). p21 antibody was obtained from BD Pharmingen (San Diego, CA), and monoclonal $\beta$-actin was obtained from Sigma-Aldrich (St. Louis Mo). Reporter lysis buffer and luciferase reagent for luciferase studies were supplied by Promega (Madison, $\mathrm{WI})$. $\beta$-Galactosidase ( $\beta$-Gal) reagent was obtained from Tropix (Bedford, MA), and Lipofectamine 2000 reagent was purchased from Invitrogen (Carlsbad, CA). Western Lightning 
Chemiluminescence reagent was from PerkinElmer Life and Analytical Sciences (Boston, MA). MG132 was obtained from Sigma. Z-VAD-FMK and Z-IETDFMK were obtained from BD Bioscience (San Diego, CA), and the C-substituted DIMs (C-DIMs) and T007 were prepared in this laboratory as described previously (2830).

\section{Plasmids}

The Gal4 reporter containing 5x Gal4 response elements (pGal4) was kindly provided by Dr. Marty Mayo (University of North Carolina, Chapel Hill, NC). Gal4DBD-PPAR $\gamma$ construct (gPPAR $\gamma$ ) was a gift from Jennifer L. Oberfield (GlaxoSmithKline Research and Development, Research Triangle Park, NC). The GRP-78 promoter-luciferase construct contains $374 \mathrm{bp}$ from the promoter and was provided by Dr. K. Park, Center for Molecular Medicine, Sungkyunkwan University (Seoul, Korea). Human CHOP promoter constructs were provided by Dr. Pierre Fafournoux (Saint Genes, Champarelle, France).

\section{Cell Proliferation Assay}

ACHN $\left(3 \times 10^{4}\right.$ cells $\left./ \mathrm{mL}\right)$ and $786-0$ cells $\left(1.5 \times 10^{4}\right.$ cells $/ \mathrm{mL}$ were plated in 12 well plates. After cell attachment for $24 \mathrm{hr}$, the medium was changed to DMEM/Ham's F12 media containing 2.5\% charcoal-stripped FBS and either vehicle (DMSO) or the indicated compound. Fresh media and compound were added every $48 \mathrm{hr}$, and representative samples were trypsinized and counted 
using the Coulter Z1 cell counter (Beckman Coulter, Fullerton, CA). Each experiment was done in triplicate and results are expressed as means \pm S.E. for each determination.

\section{Western Blot Analysis}

Cell lysates were prepared using lysis buffer [50 mM HEPES, $0.5 \mathrm{M} \mathrm{NaCl}, 1.5$ $\mathrm{mM} \mathrm{MgCl}_{2}, 1 \mathrm{mM}$ EGTA, $10 \%(\mathrm{v} / \mathrm{v})$ glycerol, $1 \%(\mathrm{v} / \mathrm{v})$ Triton X-100, and $5 \mu \mathrm{l} / \mathrm{ml}$ Protease Inhibitor Cocktail (Sigma Aldrich)]. The lysates were incubated on ice for $1 \mathrm{hr}$ with intermittent vortexing followed by centrifugation at $20,000 \mathrm{~g}$ for 10 $\min$ at $4^{\circ} \mathrm{C}$. Protein samples $(60-100 \mu \mathrm{g})$ were size-separated by electrophoresis on sodium dodecylsulfate-polyacrylamide gels under nonreducing conditions. Separated proteins were electroblotted onto polyvinylidene membranes (polyvinylidene diflouride; Bio-Rad, Hercules, CA). The blot was blocked by incubating in blocking buffer (5\% skim milk, $10 \mathrm{mM}$ Tris-HCL, 150 $\mathrm{mM} \mathrm{NaCl}, \mathrm{pH} 8$ and $0.1 \%$ Tween 20 ) for $1 \mathrm{hr}$ at $20^{\circ} \mathrm{C}$, and then incubated with the primary antibody overnight at $4^{\circ} \mathrm{C}$. Incubation with a horseradish peroxidase (HRP)-conjugated anti-mouse or rabbit secondary antibody was then carried out at $37^{\circ} \mathrm{C}$ for $1 \mathrm{hr}$, and antibody-bound proteins were detected by the ECL western blotting analysis system. 


\section{$\underline{\text { Transfection and Luciferase Assay }}$}

Cells were cultured in 12-well plates DMEM/Ham's F12 media containing 2.5\% charcoal-stripped FBS. After $16-20 \mathrm{hr}$, when cells were $50-60 \%$ confluent, reporter gene constructs were transfected using Lipofectamine 2000 (Invitrogen, Carlsbad, CA). The effects of different treatments on transactivation were investigated on $\mathrm{ACHN}$ and $786-0$ cells. Cells were transfected with either 500 ng of pGRP78, pCHOP, Gal4Luc and/or PPAR $\gamma$-GAL4 constructs in the presence of $40 \mathrm{ng} \beta$-Gal according to the manufacturers protocol. Five hr after transfection, the transfection mix was replaced with complete media containing either vehicle (DMSO) or the indicated ligand for $24 \mathrm{hr}$. Cells were then lysed with $100 \mu \mathrm{l}$ of $1 \mathrm{X}$ reporter lysis buffer, and $30 \mu \mathrm{l}$ of cell extract was used for luciferase and $\beta$-Gal assays. A lumicount luminometer (PerkinElmer Life and Analytical Sciences) was used to quantitate luciferase and $\beta$-Gal activities. Luciferase activities were then normalized to $\beta$-Gal activity.

\section{Animals and Orthotopic Implantation of Tumor Cells}

Male athymic nude mice $(\mathrm{NCl}-\mathrm{nu})$ were purchased from the Animal Production Area of the National Cancer Institute Frederick Cancer Research and Development Center (Frederick, MD). The mice were housed and maintained under specific pathogen-free conditions in facilities approved by the American Association for Accreditation of Laboratory Animal Care and in accordance with current regulations and standards of the United States Department of 
Agriculture, United States Department of Health and Human Services, and the $\mathrm{NIH}$. The mice were used in accordance with institutional guidelines when they were 8 - 12 wk old.

To produce tumors, ACHN cells were harvested from subconfluent cultures by a brief exposure to $0.25 \%$ trypsin and $0.02 \%$ EDTA. Trypsinization was stopped with medium containing $10 \%$ fetal bovine serum, and the cells were washed once in serum-free medium and resuspended in HBSS. Only suspensions consisting of single cells with $>90 \%$ viability were used for the injections. Injection of cells into the kidney subcapsule was performed. Briefly, mice were anesthetized and placed in the left lateral decubitus position. A vertical incision was made in the right flank through the skin and peritoneum, exposing the lateral aspect of the kidney. The kidney was lifted gently and stabilized. A 27gauge needle was inserted into the renal parenchyma from the lower pole of the kidney and advanced until its point reached just below the renal capsule. At this time, the mice were injected with one million viable tumor cells in $50 \mu \mathrm{L}$ HBSS. After injection, the kidney was returned to the abdominal cavity, and the wound was closed in one layer with wound clips.

The mice were killed 5 wks after injection, normal and the injected kidneys were removed and fixed in $10 \%$ buffered formalin solution after measuring the weight. 
Tumors usually grow in kidney subcapsules and invade into the kidneys cortex and medulla.

\section{TUNEL Assay and Histological Studies}

For H\&E staining and TUNEL assay, tumor tissue was fixed in formalin and embedded in paraffin, one section was processed for H\&E staining and the others were used for the TUNEL assay. TUNEL staining was carried out using DeadEnd Colorimetric TUNEL System (Promega, Madison, WI). Paraffinembedded sections (4-6 $\mu \mathrm{M}$ thick) were processed per manufacturer protocol. Briefly, sections were deparaffinized in xylene and then treated with a graded series of alcohol $\left[100,95,85,70\right.$ and $50 \%$ ethanol $(\mathrm{v} / \mathrm{v})$ in double distilled $\mathrm{H}_{2} \mathrm{O}$ ] and rehydrated in PBS $(\mathrm{pH}$ 7.5). Tissues were then treated Proteinase K solution for permeabilization and then refixed with $4 \%$ paraformaldehyde solution. Slides were then treated with $\mathrm{rTdT}$ reaction mix and incubated at $37^{\circ} \mathrm{C}$ for $1 \mathrm{hr}$. Reaction was terminated by immersing the slides in 2 X SSC solutions for $15 \mathrm{~min}$ at room temperature. After blocking the endogenous peroxidases activity (by $0.3 \%$ hydrogen peroxide) slides were washed with PBS and then incubated with Streptavidin HRP solution for $30 \mathrm{~min}$ at room temp. After washing, slides were incubated with DAB (substrate) solution until a light brown background appeared (10 $\mathrm{min}$ ) and then rinsed several times in deionized water. After mounting, slides were observed by light microscopy. 


\section{$\underline{\text { Statistical Analysis }}$}

Statistical significance of protein expression and promoter activation was assessed using Student's t-test. A value of $P<0.05$ compared with solvent control was considered statistically significant. 


\section{RESULTS}

The growth inhibitory effects of PPAR $\gamma$-active C-DIMs were investigated in both 786-0 and $\mathrm{ACHN}$ renal carcinoma cell lines (Fig. 29). $\mathrm{IC}_{50}$ values for growth inhibition by DIM-C-pPhCF 3 , DIM-C-pPhtBu and DIM-C-pPhC $6 \mathrm{H}_{5}$ were in the 1 $5 \mu \mathrm{M}$ range in both cell lines. However, $\mathrm{ACHN}$ cells appeared to be slightly more sensitive to the C-DIM compounds than 786-0 cells since significant growth inhibition was observed in the former cell line after treatment with $1.0 \mu \mathrm{M}$ concentration. These results indicted that C-DIMs were more potent than pioglitazone or PGJ2 which exhibited $\mathrm{IC}_{50}$ values from $10-20 \mu \mathrm{M}$ in $\mathrm{ACHN}$ and Cak-1 cell lines (Yang et al., 2005; Yuan et al., 2005; Yuan et al., 2006) 


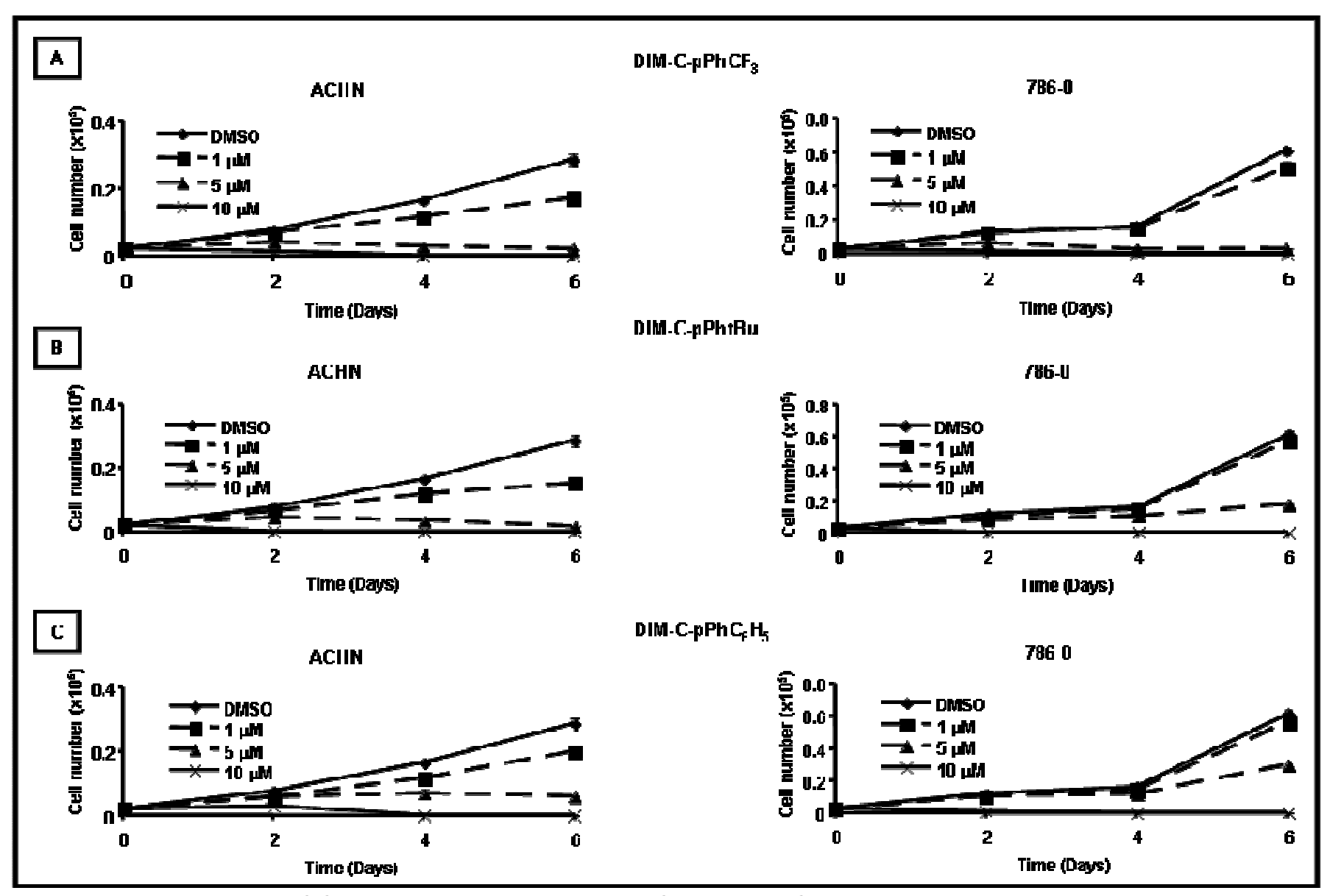

Fig. 29. Inhibition of RCC growth by PPARy-active C-DIMs. ACHN and 786-0 cells were treated with DMSO or 1,5 and 10 $\mu \mathrm{M}$ DIM-C-pPhCF $3(A)$, DIM-C-pPhtBu (B), and DIM-C-pPhC ${ }_{6} \mathrm{H}_{5}(\mathrm{C})$ for up to 6 days. The number of cells were determined on days 2, 4 and 6 as described in the Materials and Methods. Results are expressed as means \pm SE for three separate determinations for each treatment group. Significant $(p<0.05)$ inhibition of cell growth in ACHN and $786-0$ cells was observed at concentrations $\geq 1.0$ and $\geq 5.0 \mu \mathrm{M}$, respectively. 
Results in Figure 31A illustrated the effects of DIM-C-pPhtBu on activation of luciferase activity in ACHN and 786-0 cells transfected with the PPAR $\gamma$-GAL4 chimera and a reporter gene construct (pGAL4) containing five tandem yeast GAL4 response elements linked to a luciferase reporter gene. The PPAR $\gamma$ GAL4 chimera contains the ligand binding domain of PPAR $\gamma$ linked to the DNA binding domain of the yeast GAL4 protein. The results show that DIM-C-pPhtBu induced luciferase activity in both cell lines and induction was also observed for DIM-C-pPhCF 3 and DIM-C-pPhC $6 \mathrm{H}_{5}$ (data not shown). In contrast, Western blot analysis of whole cell lysates from 786-0 and ACHN cells shows that PPAR $\gamma$ is highly expressed in the latter cell line, whereas low to non-detectable levels of PPAR $\gamma$ protein were detected in 786-0 cells (Fig. 30A). Protein expression was not affected by treatment with $10 \mu \mathrm{M}$ DIM-C-pPhtBu. These data are consistent with a previous study showing highly variable expression of PPAR $\gamma$ in kidney cancer cell lines and tumors, and renal carcinoma is an example of a tumor type where decreased PPAR $\gamma$ expression in tumor vs. non-tumor tissue has been observed (Novick et al., 2002). 
Fig. 30. Activation of PPAR $\gamma$ and cell cycle proteins by C-DIMs. (A) Activation of PPAR $\gamma$-GAL4/GAL4-luc and PPAR $\gamma$ expression in ACHN and 786-0 cells. ACHN and 786-0 cells were transfected with PPAR $\gamma$-GAL4/GAL4-luc and treated with DMSO or C-DIMs. Luciferase (relative to $\beta$-galactosidase) activity was determined as described in the Materials and Methods. Results are expressed as means \pm SE for three separate determinations for each treatment group. Significant $(p<$ $0.05)$ induction is indicated by an asterisk. Western blot analysis of whole cell lysates was determined as described in the Materials and Methods. Analysis of p21, p27 and cyclin D1 in ACHN (B) and 786-0 (C) cells, and of cyclin D1 (D) in both cell lines. Cells were treated with different compounds and DMSO (control), and proteins were analyzed by Western blot analysis of whole cell lysates as described in the Materials and Methods. Results in B and C were quantitated from three separate experiments in which cyclin D1 levels (relative to $\beta$-tubulin) in the DMSO group were set at 1.0. Significant $(p<0.05)$ inhibition of cyclin D1 protein is indicated by an asterisk. 


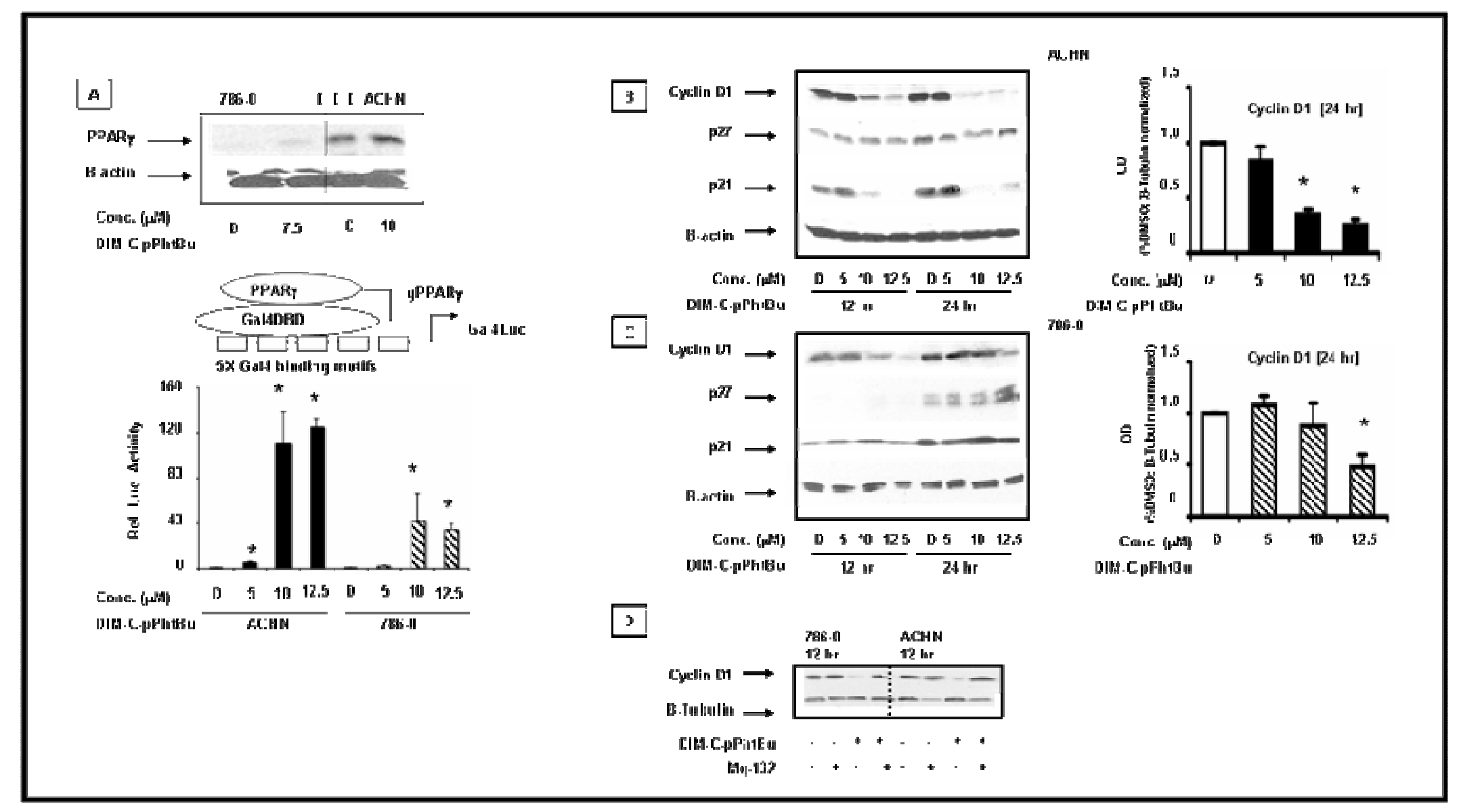


PPAR $\gamma$ agonists typically affect cell cycle proteins such as cyclin D1, p27 and p21, and results in Figures 31B and 31C summarize the concentration- and time-dependent effects of DIM-C-pPhtBu on these same proteins in ACHN and 786-0 cells, respectively. p27 is uniformly expressed after 12 or $24 \mathrm{hr}$ in ACHN cells and is unaffected by treatment with DIM-C-pPhtBu. In contrast, p21 expression is low after $12 \mathrm{hr}$ and enhanced after $24 \mathrm{hr}$. Some induction of p27 is observed only at the highest concentration $(12.5 \mu \mathrm{M})$ of DIM-C-pPhtBu. p21 is expressed in both cell lines and DIM-C-pPhtBu decreases expression of p21 in ACHN but not 786-0 cells. In contrast, DIM-C-pPhtBu induced a significant decrease in the expression of cyclin D1 protein as previously observed in other cancer cell lines treated with PPARy-active C-DIMs (Qin et al., 2004, Chintharlapalli et al., 2007; Chintharlapalli et al., 2006), and this response was reversed after cotreatment with the proteasome inhibitor MG132 (Fig. 30D).

Previous studies show that caveolin 1 is induced in colon but decreased in prostate cancer cells (Chintharlapalli et al., 2005c, Chintharlapalli et al., 2006). DIM-C-pPhtBu decreased caveolin-1 in 786-0 cells but did not affect expression in ACHN cells (Fig. 31A). Previous studies have also shown that the proapoptotic NAG-1 gene and ATF3 are induced by C-DIMs. Results in Figure 32B demonstrate that both proteins were induced by DIM-C-pPhtBu in ACHN and 786-0 cells, and up to a 4-fold induction response was observed (Fig. 31C). 


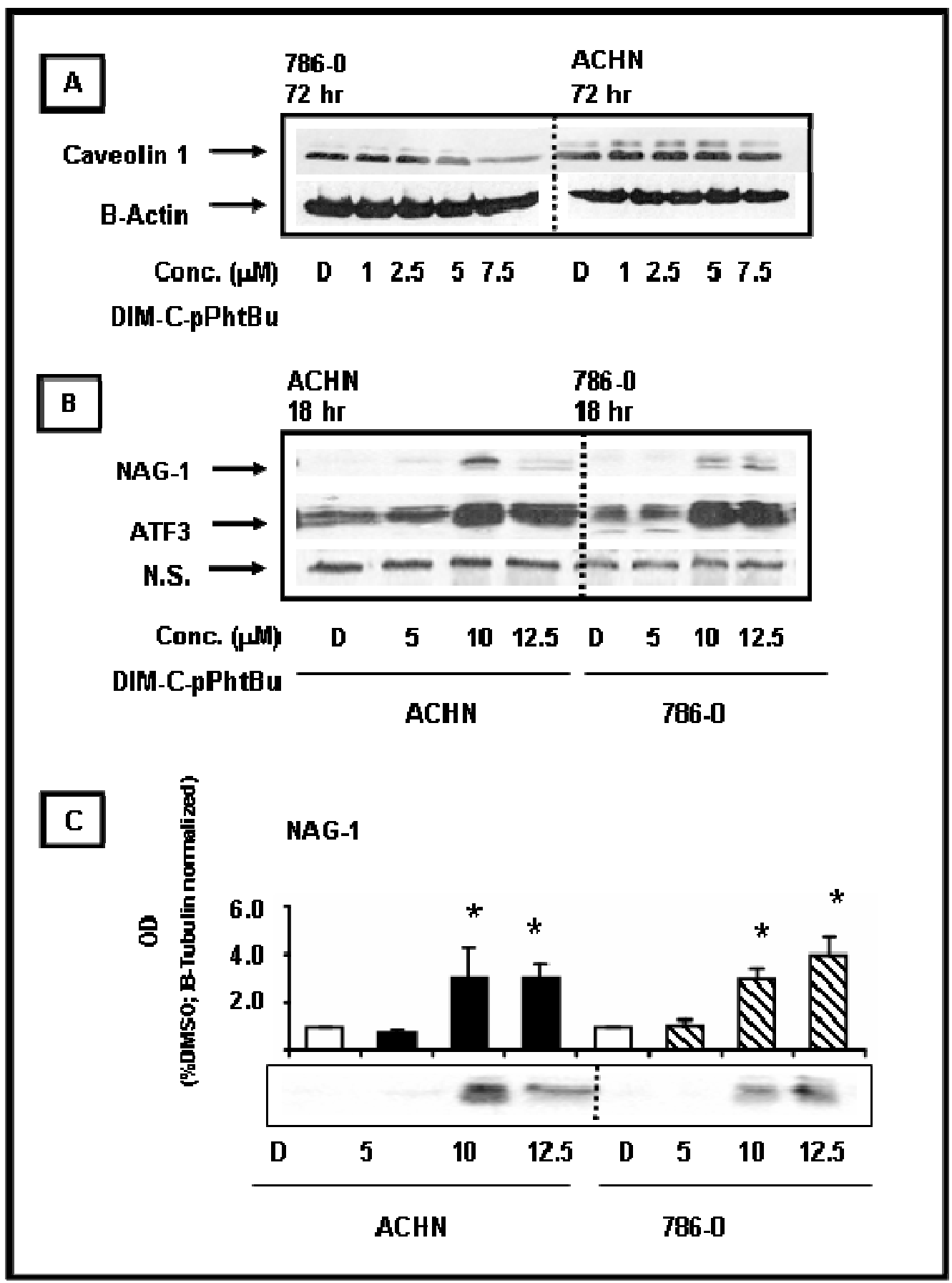

Fig. 31. Effects of C-DIM compounds on caveolin-1 (A), NAG-1 (B), and ATF-3 (C) expression in RCC cells. Cells were treated with DMSO or C-DIM compounds, and whole cell lysates were analyzed by Western blot analysis as described in the Materials and Methods. Quantitation of NAG-1 protein induction $(\mathrm{C})$ was determined in three separate experiments, and results are expressed as means \pm SE for NAG-1 (relative to $\beta$-tubulin) protein in the DMSO group (set at 1.0). Significant $(p<0.05)$ induction of NAG-1 is indicated by an asterisk. 
It has also been reported that C-DIM compounds activate receptor-independent ER stress and apoptosis in pancreatic and ovarian cancer cells (Abdelrahim et al., 2006; Lei et al., 2006). Results in Figure 33A summarize the effects of DIMC-pPhtBu on ER stress pathways in ACHN and 786-0 cells. Minimal induction of ER stress responses GRP78 and CHOP were observed after treatment of both cell lines for $6 \mathrm{hr}$ (data not shown), whereas both markers of ER stress were elevated after treatment with DIM-C-pPhtBu for 12 or $18 \mathrm{hr}$ and this persisted for up to $24 \mathrm{hr}$. Similar induction responses were also observed for DIM-C-pPhCF 3 and DIM-C-pPhC $6 \mathrm{H}_{5}$ (data not shown). In addition, a similar time-course was observed for induction of DR5 and cleaved caspase-8 which is indicative of activation of the extrinsic apoptotic pathway associated with induction of DR5. There were minimal differences in constitutive and inducible GRP78, CHOP, DR5 and caspase-3 cleavage in ACHN and 786-0 cells, except that higher constitutive levels of DR5 were expressed in the former cell line. Figure 33B directly compares and quantitates induction of GRP78 and CHOP proteins in ACHN and 786-0 cells after treatment with $5-12.5 \mu \mathrm{M}$ DIM-CpPhtBu for $18 \mathrm{hr}$. Significant induction was observed in both cell lines using 10 $\mu \mathrm{M}$ DIM-C-pPhtBu. 
Fig. 32. Activation of ER stress and apoptotic responses by C-DIMs in RCC cells. (A) Induction of ER stress responses by C-DIMs in ACHN and 786-0 cells. Cells were treated with DMSO or DIM-C-pPhtBu for 12 or $18 \mathrm{hr}$, and whole cell lysates were analyzed by Western blot analysis. Minimal protein expression was observed after treatment for $6 \mathrm{hr}$, whereas the blot obtained using lysates treated for $24 \mathrm{hr}$ was similar to that observed for the $18 \mathrm{hr}$ treatment group (data not shown). (B) Quantitation of GRP78 and CHOP expression. Cell lysates from three replicate experiments were analyzed as described in (A), and both GRP78 and CHOP proteins (relative to $\beta$-tubulin) in the DMSO group were assigned a relative value of 1.0. Significant $(p<0.05)$ induction of these proteins by DIM-C-pPhtBu is indicated by an asterisk. (C) Activation of pGRP78 and pCHOP constructs by C-DIMs. ACHN or 786-0 cells were transfected with pGRP78 or pCHOP and treated with DMSO or DIM-C$\mathrm{pPhtBu}$. Luciferase (relative to $\beta$-galactosidase) activity determined as described in the Materials and Methods. Results are expressed as means \pm SE for three separate experiments for each treatment group, and significant $(p<$ 0.05 ) induction is indicated by an asterisk. 


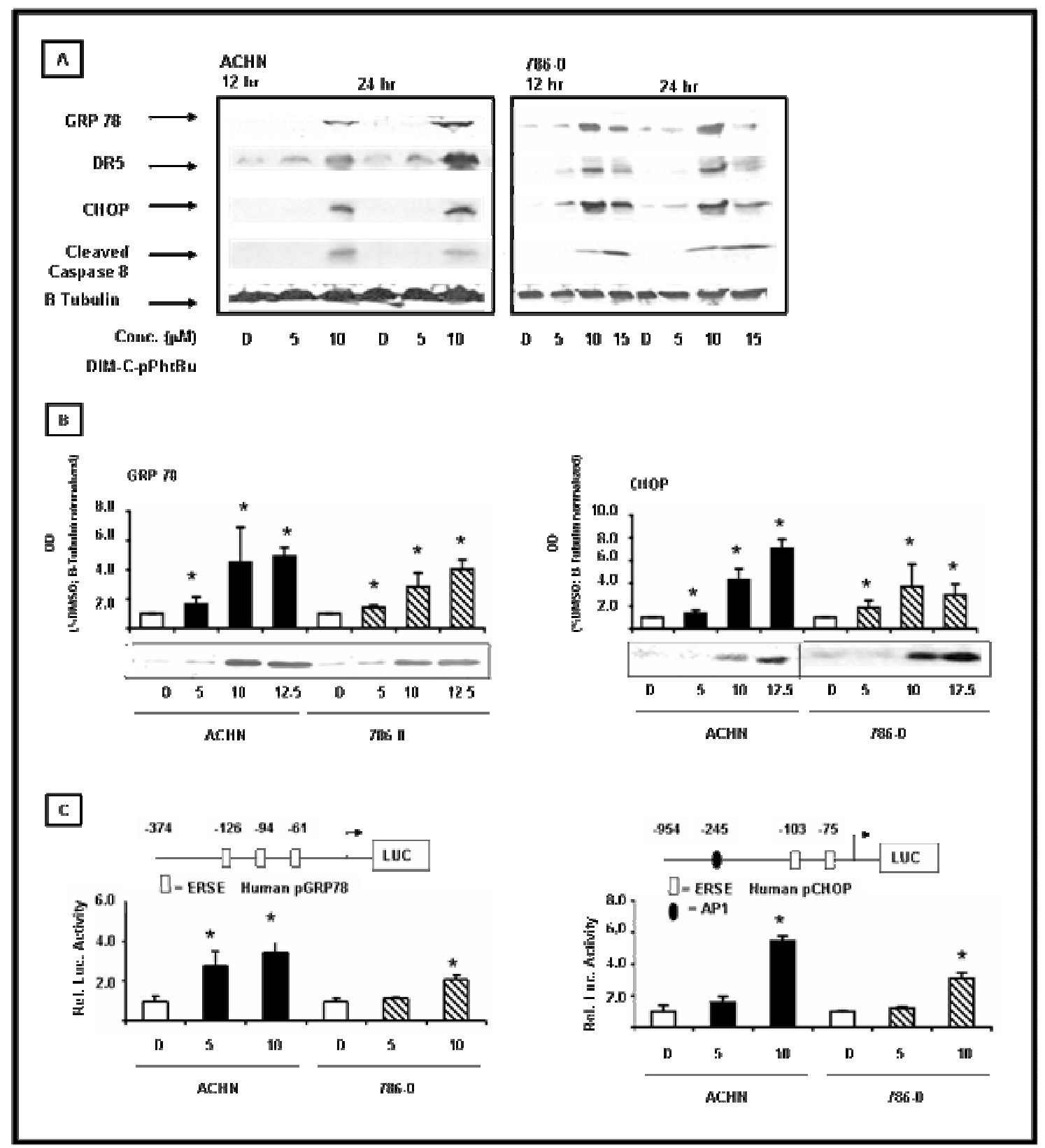


We also showed that $10 \mu \mathrm{M}$ DIM-C-pPhtBu induced transactivation in ACHN and $786-0$ cells transfected with pGRP78, a construct containing the -374 to +1 region of the GRP78 gene promoter which has an ER stress response element (ERSE; Fig. 32C). Similar induction of luciferase activity by DIM-C-pPhtBu was observed in cells transfected with pCHOP which contains the -954 to +1 region of the CHOP gene promoter.

Activation of ER stress pathways and the subsequent induction of DR5 and cleaved caspase 8 (Fig. 32A) is consistent with the induction of RCC cell death observed after treatment with the C-DIM compounds (Fig. 29). Results in Figure 5A confirm that DIM-C-pPhtBu induced a concentration- and time-dependent induction of cleaved (activated) caspase-3 and caspase-dependent PARP cleavage in $\mathrm{ACHN}$ and $786-0$ cells at concentrations of 5 and $7.5 \mu \mathrm{M}$ with the maximal effects observed after $72 \mathrm{hr}$. The role of PPAR $\gamma$ in mediating DIM-CpPhtBu-induced PARP cleavage, cyclin D1 downregulation, induction of NAG-1 and GRP78 was investigated in ACHN and 786-0 cells treated with the C-DIM compound alone or in combination with the PPAR $\gamma$ antagonist T007 (Fig. 33A). The results show that T007 did not affect any to the DIM-C-pPhtBu-induced responses, suggesting that these effects were PPAR $\gamma$-independent. Similar results were observed in previous studies with C-DIMs in other cancer cell lines (Abdelrahim et al., 2006; Lei et al., 2006; Chintharlapalli et al., 2007, Chintharlapalli et al., 2006). Results in Figures 34B and 34C also demonstrate 
(quantitatively) that DIM-C-pPhtBu induced PARP cleavage in 786-0 and ACHN cell lines, respectively. These responses were blocked after cotreatment with both a caspase-8 (Z-IETD-FMK) and a pancaspase (Z-VAD-FMK) inhibitor. These results confirm that DIM-C-pPhtBu induces caspase-8 and caspase-3dependent apoptosis in both $\mathrm{ACHN}$ and $786-0$ cells. This is consistent with activation of ER stress (Fig. 32) and other proapoptotic genes such as NAG-1 and ATF3.

We also investigated the effects of DIM-C-pPhtBu on renal adenocarcinoma development in an orthotopic model for kidney cancer in which ACHN and 786-0 cells were directly injected into the kidney. Preliminary studies showed that ACHN but not 786- 0 cells formed tumors in this model. Figure 6 illustrates the effects of DIM-C-pPhtBu (40 mg/kg/d) and corn oil vehicle control on normal kidney weights and kidney weights in tumor-bearing animals. Normal kidney weights in animals administered corn oil or DIM-C-pPhtBu were $0.262 \pm 0.047$ and $0.274 \pm 0.03$, respectively, and kidney weights in tumor-bearing animals were $0.752 \pm 0.08$ and $0.444 \pm 0.07$, respectively (Figs. 35A and 35B). 


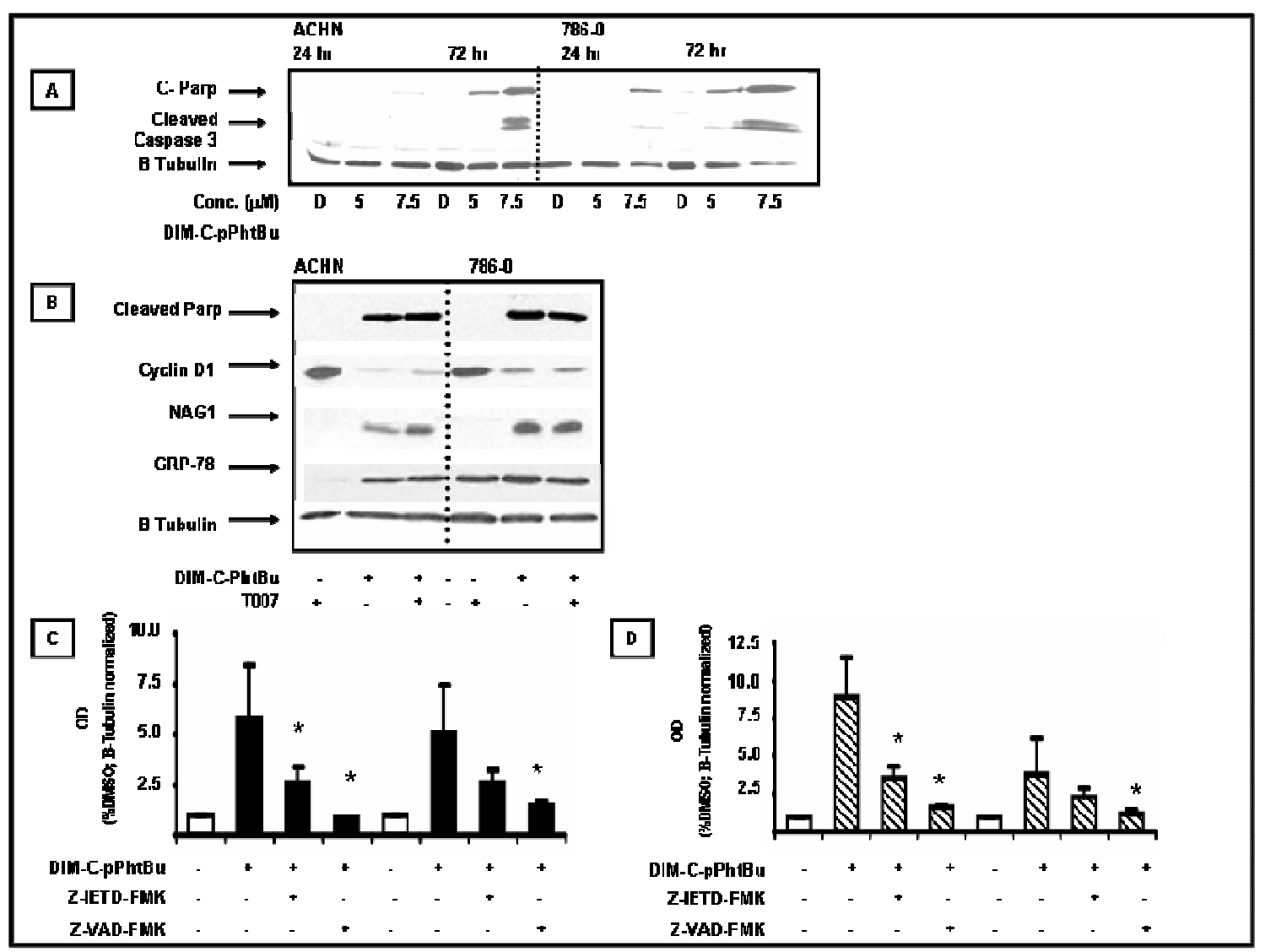

Fig. 33. Induction of apoptosis and role of PPAR in mediating effects of C-DIMs in RCC cells. (A) Induction of caspase 3 and PARP cleavage by C-DIMs. Cells were treated with DMSO and 5 or $7.5 \mu \mathrm{M}$ DIM-C-pPhtBu for 24 or $72 \mathrm{hr}$. Whole cell lysates were analyzed by Western blot analysis as described in the Materials and Methods. (B) Effects of T007 on C-DIM-induced responses. Cells were treated with DMSO, $12.5 \mu \mathrm{M}$ DIM-C-pPhtBu, and $10 \mu \mathrm{M} \mathrm{T007}$ alone or in combination for $24 \mathrm{hr}$. Whole cell lysates were analyzed by Western blot analysis as described in the Materials and Methods. Similar results were observed in duplicate experiments. Effects of caspase inhibitors on DIM-C-pPhtBu-induced PARP cleavage in ACHN (C) and 786-0 (D) cells. Cells were treated for $72 \mathrm{hr}$ as indicated in (A), and cleaved PARP in DMSO-treated cells (relative to $\beta$-tubulin) was set at 1.0. Treatment with DIM-C-pPhtBu significantly induced PARP cleavage in both cell lines. Results for all treatment groups are given as means \pm SE for three replicate experiments, and both caspase-8 (Z-IETD-FMK) and pancaspase (ZVAF-FMK) inhibitors significantly inhibited (*) DIM-C-pPhtBu-induced PARP cleavage. 


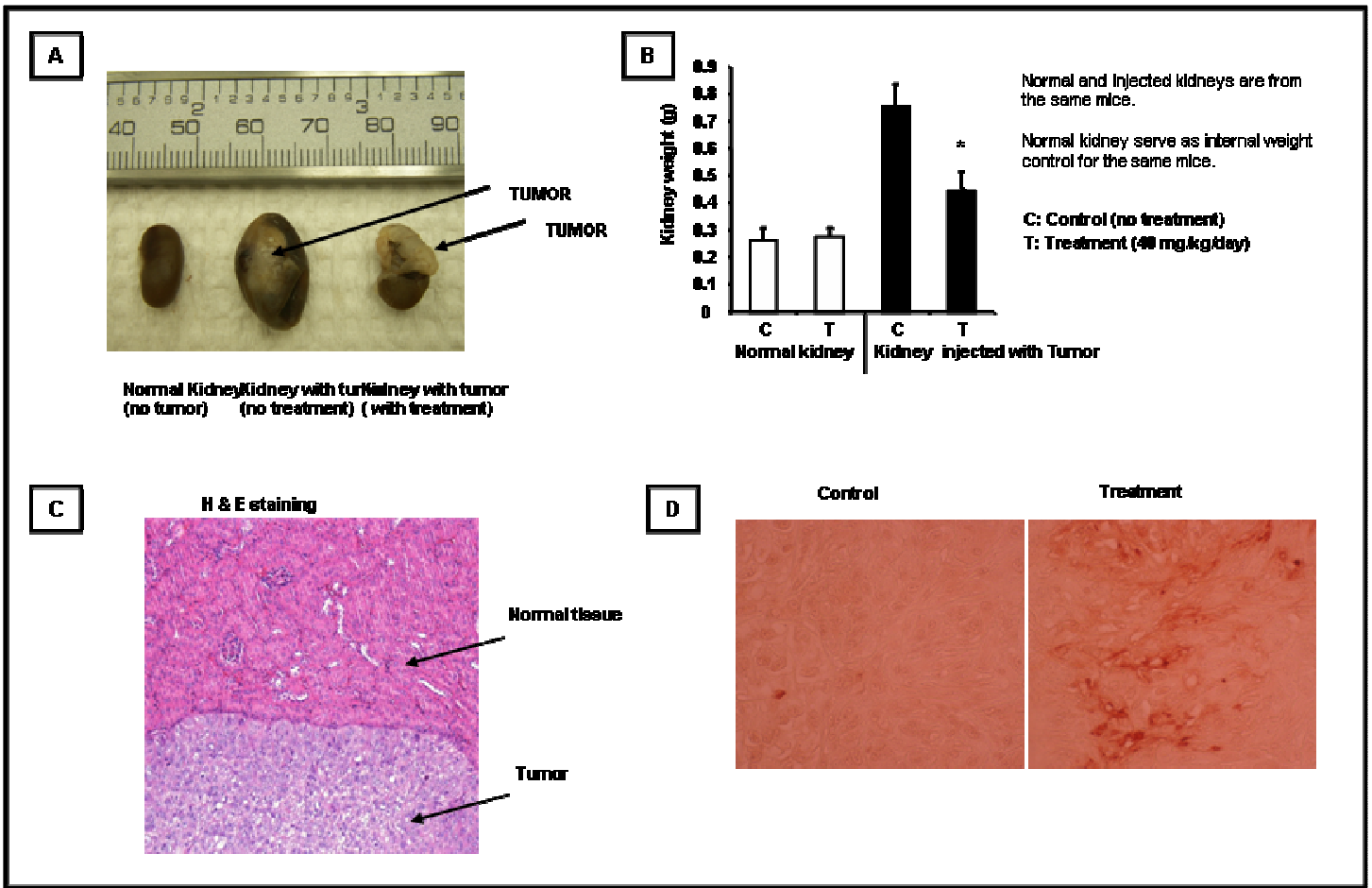

Fig. 34. DIM-C-pPhtBu inhibits tumor growth in an orthotopic model for renal adenocarcinoma. Representative kidney/tumors (A) and weights (B). Weights of kidneys and kidneys + tumors from mice treated with corn oil (controls) or DIM-C$\mathrm{pPhtBu}(40 \mathrm{mg} / \mathrm{kg} / \mathrm{d})$ were determined after sacrifice. A significant $(\mathrm{p}<0.05)$ decrease in kidney + tumor weight in animals treated with DIM-C-pPhtBu is indicated by an asterisk. Kidney ( \pm tumor) weights are means \pm SE for at least 5 animals per treatment group. Hematoxylin and eosin staining (C) and TUNEL staining (D) in kidneys/kidney tumors. Hematoxylin and eosin staining of tumor and non-tumor tissue from mice bearing human ACHN tumors and TUNEL staining of kidney tumors from corn oil and DIM-C-pPhtBu-treated mice was carried out as described in the Materials and Methods. Similar results were observed in replicate experiments.

Thus, DIM-C-pPhtBu had no affect on kidney weights but significantly decreased kidney tumor weights in animals bearing ACHN cells. Hematoxylin and eosin staining of kidney tumors and non-tumor tissue showed distinct differences. The normal kidney (Fig. 6C, upper) consists of low numbers of glomerulas surrounded by normal appearing tubular epithelium, whereas the appearance of tumor tissue contained neoplastic cells with atypical epithelium with variable 
malignant features (Fig. 34C, lower). In addition, using the TUNEL assay, it was apparent that DIM-C-pPhtBu induced massive staining in the tumors compared to corn oil (control) tumors demonstrating that apoptosis was induced in both ACHN tumors (Fig. 34D) and cells. This was a major pathway for the anticarcinogenic activity of DIM-C-pPhtBu in this kidney cancer model and is consistent with the PPAR $\gamma$-independent activation of apoptosis by C-DIMs in RCC cells (Figs. 33 and 34). 


\section{DISCUSSION AND CONCLUSIONS}

Renal cell carcinoma is a complex disease and the most predominant form is clear cell carcinoma which is highly metastatic and resistant to many chemotherapies. Interferon and interleukin-2 have been used for treatment of metastatic renal cell carcinoma; however, only $15-20 \%$ of patients benefit from these treatments (Novick et al., 2002). Renal cell carcinoma typically exhibits high expression of hypoxia-inducible factor $1 \alpha(\mathrm{HIF}-1 \alpha)$ and upregulation of vascular endothelial growth factor (VEGF) expression, and newer chemotherapies for treatment of renal cell carcinoma are targeting VEGF/VEGF receptor signaling using antibodies and kinase inhibitors (Motzer et al, 2006).

PPAR $\gamma$ is an orphan nuclear receptor that is overexpressed in many tumor types and different structural classes of PPAR $\gamma$ agonists show some promise for cancer chemotherapy (lkezoe et al., 2001, Fajas et al., 2001). For example, both thiazolidinediones and PGJ2 inhibit growth of renal cell carcinoma cells and typically affect cell cycle genes/proteins associated with $G_{0} / G_{1}$ to $S$ phase progression (Yang et al., 2005; Yuan et al., 2005). However, unlike many cancer cell lines and tumors, there is some suggestion that the overexpression of PPARy in renal cell carcinoma is somewhat variable (Yuan et al., 2006). For example, in a study of six renal cell carcinoma cell lines, the expression of PPAR $\gamma$ was lower in five of these cell lines compared to normal kidney tissue. 
Only ACHN cells expressed PPAR $\gamma$ mRNA levels higher than observed in normal kidney cells. Similar results were observed in the comparison of PPAR mRNA in renal cell carcinoma tumors vs. normal kidney tissue where the tumor samples frequently exhibited lower levels of this transcript.

Studies in our laboratory have identified a novel class of PPAR $\gamma$ agonists derived from DIM and, like many other ligands for PPAR $\gamma$, the C-DIM compounds inhibit cancer cell/tumor growth through receptor-dependent and independent pathways (Abdelrahim et al., 2006; Lei et al., 2006; Chintharlapalli et al., 2007; Chintharlapalli et al., 2006). Results of growth inhibitory studies in $\mathrm{ACHN}$ and 786-0 renal cell carcinoma cells showed that $\mathrm{IC}_{50}$ values for PPAR $\gamma$ active C-DIMs were between $1-5 \mu \mathrm{M}$ in both cell lines, and this was much lower than observed for pioglitazone or PGJ2 in other studies (Yuan et al., 2006). These results suggest that C-DIM compounds are potentially effective drugs for treatment of renal cell carcinoma. Moreover, due to the differential expression of PPAR $\gamma$ protein in ACHN (high) vs. 786-0 (low to non-detectable) (Fig. 30A), these cell lines are ideal for investigating activation of receptor-dependent and independent growth inhibitory/proapoptotic pathways by C-DIMs. In transactivation studies using a PPAR $\gamma$-GAL4 chimera, we observed induction responses by DIM-C-pPhtBu (Fig. 30) in ACHN and 786-0 cell lines, suggesting that the appropriate cofactors required for this response are expressed in both cell lines. The effects of PPAR $\gamma$-active C-DIMs on p27 and p21 were highly 
variable in ACHN and 786-0 cells (Figs. 31B and 31C). However, DIM-CpPhtBu induced proteasome-dependent degradation of cyclin D1 (Fig. 30) which was not inhibited after cotreatment with a PPAR $\gamma$ antagonist (Fig. 33B). These results are consistent with previous reports showing that C-DIMs induce receptor-independent degradation of cyclin D1 in other cancer cell lines (Qin et al., 2004; Chintharlapalli et al., 2007; Chintharlapalli et al., 2006). PPAR $\gamma$-active C-DIMs induce receptor-dependent expression of caveolin-1 in colon cancer cells, where this gene may exhibit tumor suppressor activity, but decrease caveolin-1 in prostate cancer cells, where it may have tumor-enhancing activity (Chintharlapalli et al, 2006; Bender et al., 2000; Chintharlapalli et al., 2007; Yang et al., 1998; Williams et al., 2005). Caveolin-1 overexpression in renal cell carcinoma patients predicts poor disease-free survival; however, the functional role of caveolin-1 in renal cell carcinoma has not been explored (Campbell et al., 2003). In our studies, 7.5 $\mu \mathrm{M}$ DIM-C-pPhtBu decreased caveolin-1 expression in 786-0 but not in ACHN (no change) cells (Fig. 31A), and resembled the responses observed in prostate cancer cells where PPAR $\gamma$-active C-DIMs decrease levels of caveolin-1 protein (Chintharlapalli et al., 2007). The function of this effect of DIM-C-pPhtBu (i.e. decreased caveolin-1 expression) in renal cell carcinoma cells is now being further investigated.

PPAR $\gamma$-active C-DIMs also induce NAG-1 and ER stress in colon and pancreatic cancer cells. These receptor-independent responses lead to apoptosis. Results 
summarized in Figures 32 - 34 show that DIM-C-pPhtBu also induced NAG-1 and ER stress proteins and DR5, and these responses are coupled with activation of caspase-dependent PARP cleavage. This suggests that DIM-CpPhtBu-induced apoptosis in renal cell carcinoma cells is similar to that observed in colon and pancreatic cells and these responses are PPAR $\gamma$ independent (Chintharlapalli et al., 2005b; Abdelrahim et al., 2006; Lei et al., 2006; Chintharlapalli et al., 2006) (Fig. 33B).

We also used an orthotopic model of renal cell carcinoma and directly injected human $\mathrm{ACHN}$ cells into the kidney of each athymic mouse. The results in Figures $35 \mathrm{~A}$ and 35B show that treatment with DIM-C-pPhtBu $(40 \mathrm{mg} / \mathrm{kg} / \mathrm{d})$ did not affect normal kidney weight but significantly decreased the weight of the tumor-bearing kidney. Hematoxylin and eosin staining of normal kidney and kidney tumors exhibited the expected differences in staining, and the TUNEL assay demonstrated extensive staining for apoptosis in the treated animals but not in the controls (Fig. 34C). These results demonstrate a parallel mode of action between the in vivo and in vitro studies where DIM-C-pPhtBu inhibits both RCC cell and tumor growth and this is due, in part, through activation of apoptosis. Thus, DIM-C-pPhtBu, a prototypical C-DIM compound represents a novel class of drugs for treatment of renal tumors through PPAR $\gamma$-independent activation of proapoptotic proteins (NAG-1) and pathways (ER stress). Current studies are focused on identifying the most active proapoptotic C-DIM analogs 
(among over 100 compounds) for potential clinical applications in treating renal cell carcinoma. 


\section{REFERENCES}

Abdelrahim M, Newman K, Vanderlaag K, Samudio I and Safe S (2006)

3,3'Dinindoloylmethan (DIM) and its derivatives induce apoptosis in pancreatic cancer cells through endoplasmic reticulum stress-dependent upregulation of DR5. Carcinogenesis 27:171-728.

Ahmed A and Anders M (1978) Metabolism of dihalomethanes to formaldehyde and inorganic halide. II. Studies on the mechanism of the reaction. Biochem Pharm 27:2021-2025.

Akhurst R and Derynck R (2001) TGF-beta signaling in cancer- a double edged sword. Trends Cell Biol 11:S44-51.

Alper S (2002) Genetic Diseases of acid-base transports. Ann Rev Physiol 64:899-923.

Anders M (1980) Metabolism of drugs by the kidney. Kidney Int 18:636-647.

Anders M (2004) Glutathione-dependent bioactivation of haloalkenes and haloalkanes. Drug Metab Rev 36:583-594.

Apiwattanakul N, Sekine T, Chairoungdua A, Kanai Y, Nakajima N, Sophasan S and Endou H (1999) Transport properties of nonsteroidal anti-inflamatory drugs by organic anion transport 1 expressed in Xenopous laevis oocytes. Mol Pharmacol 55:847-854.

Ashkenazi A and Dixit V (1998) Death receptors: signaling and modulation. Science 281:1305-1308. 
Baek S and Eling T (2006) Changes in gene expression contribute to cancer prevention by COX inhibitors. C Prog Lipid Res 45:1-16.

Baek S, Horowitz J and Eling T (2001) Molecular cloning and characterization of human non-steroidal anti-inflamatory drug -activated gene promoter. Basal transcription is mediated by Sp1 and Sp3. J Biol Chem 276:33383-33392.

Baek S, Okazaki R, Lee S, Martinez J, Kim J, Yamaguchi K, Mishina Y, Martin D, Schoieb A, McEntee M and Eling T (2006) Nonsteroidal anti-inflamatory drug activated gene-1 overexpression in transgenic mice suppresses intestinal neoplasi. Gastrointerology 131:1553-1560.

Bachschmid M, Schildknecht S and Ullrich V (2005) Redox regulation of vascular prostanoid synthesis by the nitric oxide-superoxide system. Biochem Biophys Res Commun 338:536-542.

Bauskin A, Brown D, Junankar S, Rsaih K, Eggleton S, Hunter M, Liu T, Smith D, Kuffner T and Pankhurst G et al. (2000) The propeptide of macrophage inhibitory citokine (MIC-1), a TGB-beta superfamily member, acts as a quality determinant for correctly folded MIC-1. Embo J 19:2212-2220.

Bender FC, Reymond MA, Bron C, Quest AF (2000) Caveolin-1 levels are downregulated in human colon tumors, and ectopic expression of caveolin-1 in colon carcinoma cell lines reduces cell tumorigenicity. Cancer Res 60:58705878. 
Benjamin L, Golijanin D, Itin A, Pode A and Keshet E (1999) Selective ablation of immature blood vessels in established human tumors follows vascular endothelial growth factor withdrawal. J Clin Invest 103:159-165.

Benjamin L and Keshet E (1997) Conditional switching of vascular endothelial growth factor (VEGF) expression in tumors: Induction of endothelial cell shedding and regression of hemangioblastoma-like vessels by VEGF withdrawal. Proc Natl Acad Sci 94:8761-8766.

Berger J and Moller DE (2002) The mechanisms of action of PPARs. Annu Rev Med 53:409-35.

Bergstrom A, Hsieh S, Lindblad P, Lu, C, Cook N and Wolk A (2001) Obesity and renal cell cancer- a quantitative review. Br J Cancer 85:984-990.

Bichler K and Wechsel H. (1999) The problematic nature of metastasized renal cell carcinoma. Anticancer Res 19:1462-1466.

Bleumer I, Oosterwijk E, de Mulder P and Mulders P (2003) Immunotherapy for renal cell carcinoma. Eur Urol 44:65-75.

Boogard P, Commandeur J, Mulder G, Vermeulen N, Nagelkerke J (1989) Toxicity of the cysteine-S-conjugates and mercapturic acids of four structurally related diflouroethylenes in isolated proximal tubular cells from rat kidney. Uptake of the conjugates and activation to toxic intermediates. Biochem Pharmacol 36: 654-663.

Bottinger E and Bitzer M (2001) TGF-beta signaling in renal disease. J Am Soc Nephrol 13:2600-2610. 
Brauch H, Weirich G, Klein B, Rabstein S, Bolt H and Bruning T (2004) VHL mutations in renal cell cancer: does occupational exposure to trichloroethylene make a difference. Toxicol Letters 151:301-310.

Brenner B (1976) Transport of molecules across renal glomerular capillaries. Physiol Rev 56:502-534.

Breton S, Lisanti M, Tyszkowski R, McLaughlin M, Brown D (1998) Basolateral distribution of caveolin-1 in the kidney. Absence from $\mathrm{H}+$-atpase-coated endocytic vesicles in intercalated cells. J Histochem Cytochem 46:205-214.

Brockman JA, Gupta RA and DuBois RN (1998) Activation of PPARg leads to inhibition of anchorage independent growth of human colorectal cancer cells. Gastroenterology 115:1049-1055.

Bui M, Seligson D, Han K, Pantuck A, Dorey F, Huang Y, Horvath S, Leibovich B, Chopra S, Liao S, Stanbridge E, Leman M, Palotie A, Figlin R, Belldegrun A (2003) Carbonic anhydrase IX is an independent predictor of survival in advanced renal clear cell carcinoma. Clin Cancer Res 9:802-811.

Bull H, Brickell P and Down P (1994) Src-related protein tyrosine kinases are phyosogically associated with the surface antigen CD36 in human dermal microvascular endothelial cells. FEBS lett 351:41-44.

Burlacu A (2003) Regulation of apoptosis by bcl-2 family proteins. J Cell Mol Med 7: 249-257. 
Campbell L, Gubleton M and Griffiths D (2003) Caveolin-1 overexpression predicts poor disease-free survival of patients with clinically confined renal cell carcinoma. Br J Cancer 89:1909-1913.

Campese V and Park J (2007) The kidney and hypertension:over 70 years of research. J Nephrol 19:691-698.

Cardillo M, Lazzereschi D, Gansini O, Di Solverio F and Colleta G. (2001) Transforming growth factor-beta pathway in human renal cell carcinoma and surrounding normal-appearing renal parenchyma. Anal Quant Cytol Histol 23:109-117.

Carrion R, Morgan B, Tannenbaum M, Salup R and Morgan M (2003) Caveolin expression in adult renal tumors. Urol Oncol 21:191-196.

Catzavelos C, Bhattacharya N, Ung Y, Wilson J, Roncari L, Sadnhu C, Shaw P, Yeger H, Morava-Protzner, Kaputsa L, Franssen E, Pritchard K, Slingerland J (1997) Decreased levels of the cell-cycle inhibitor p27/Kip1 protein: prognostic implications in primary breast cancer. Nat Med 3:227-230.

Chang TH and Szabo E (2000) Induction of differentiation and apoptosis by ligands of peroxisome proliferator-activated receptor $\mathrm{g}$ in non-small cell lung cancer. Cancer Res 60:1129-38.

Chintharlapalli S, Burghardt R, Papineni S, Ramaiah S, Yoon K and Safe S (2005a) Activation of Nur77 by selected 1,1-Bis(3'-indolyl)-1-(p-substituted phenyl)methanes induces apoptosis through nuclear pathways. J Biol Chem 280:24903-24914. 
Chintharlapalli S, Papineni S, Baek SJ, Liu S and Safe S (2005b) 1,1-Bis(3'indolyl)-1-(p-substitutedphenyl)methanes are peroxisome proliferatoractivated receptor gamma agonists but decrease HCT-116 colon cancer cell survival through receptor-independent activation of early growth response-1 and NAG-1. Mol Pharmacol 68:1782-92.

Chintharlapalli S, Papineni S, Konopleva M, Andreef M, Samudio I, Safe S (2005c) 2-Cyano-3,12-dioxoolean-1,9-dien-28-oic acid and related compounds inhibit growth of colon cancer cells through peroxisome proliferator-activated receptor g-dependent and -independent pathways. $\mathrm{Mol}$ Pharmacol 68:119-128.

Chintharlapalli S, Papineni S and Safe S (2006) 1,1-Bis(3'-indolyl)-1-(psubstitutedphenyl)methanes inhibit colon cancer cell and tumor growth through PPAR $\gamma$-dependent and PPAR $\gamma$-independent pathways. Mol Cancer Ther 5:1362-1370.

Chintharlapalli S, Papineni S, Safe S (2007) 1,1-Bis(3'-indolyl)-1-(psubstitutedphenyl)methanes inhibit growth, induce apoptosis, and decrease the androgen receptor in LNCaP prostate cancer cells through peroxisome proliferator-activated receptor gamma-independent pathways. Mol Pharmacol 71:558-569.

Christiansen C, Christiansen M, Melson F, Rodbro P and Deluca H (1981) Mineral metabolism in chronic renal failure with special reference to serum concentrations of $1,25(\mathrm{OH})_{2} \mathrm{D}$ and $24,25(\mathrm{OH})_{2} \mathrm{D}$. Clin Nephrol 15:18-22. 
Christoph F, Kempkensteffen C, Weikert S, Krause H, Schostak M, Schrader M and Miller K (2006) Methylation of tumor suppressor genes APAF-1 and DAPK-1 and in vitro effects of demethylating agents in bladder and kidney cancer. Br J Cancer 95: 1701-1707.

Clevers H, Alarcon B, Wileman T and Terhorst C (1988) The T-cell receptor/CD3 complex: a dynamic protein ensemble. Am Rev Immunol 6: 629-662.

Cole S, Bhardwag G, Gerlach J, Mackie J, Grant C, Almquist K, Stewart A, Kurz E, Duncan A and Deeley R (1992) Overexpression of a transporter gene in a multidrug-resistant human lung cancer cell line. Science 258:1650-1654.

Commandeur J, de Kanter F and Vermeulen N (1989) Bioactivation of cysteineS-conjugate and mercapturic acid of tetraflouroethylene to acylating reactive intermediates in the rat. Dependence of activation and deactivation activities on acetyl coenzyme A availability. Mol Pharmacol 36: 654-663.

Commandeur J and Vermeulen N (1990) Molecular and biochemical mechanisms of chemically induced nephrotoxicity: A Review. Chem Res Toxicol 3:171-189.

Contractor R, Samudio I, Estrov Z, Harris D, McCubrey J, Safe S, Adreeff M, Konopleva M (2005) A novel ring-substituted diindolylmethane 1,1-bis[3'-(5methoxyindolyl)]-1-(p-t-butylphenyl)methane inhibits ERK activation and induces apoptosis in acute myeloid leukemia. Cancer Res 65:2890-2898. 
Cooper A, Bruschi S and Anders M (2002) Toxic, halogenated cysteine Sconjugates and targeting of mitochondrial enzymes of energy metabolism. Biochem Pharmacol 64: 553-564.

Copland J, Luxon B, Ajani L, Maity, Campagnaro E, Guo H, LeGrand S, Tamboli P and Wood C (2003) Genomic profiling identifies alterations in TGF-beta signaling through loss of TGF-beta recptor expression in human renal cell carcinogenesis and progression. Oncogene 22: 8053-8062.

Cordon-Cardo C, and Prives C (1999) At the crossroads of inflammation and tumorigenesis. J Exp Med 190: 1367-1370.

Coresh J, Byrd-Holt D, Astor B, Briggs J, Eggers P, Lacher D and Hostetter T (2005) Chronic kidney disease awareness, prevention, and trends in US adults, 1999 to 2000. J Am Soc Nephrol 16:180-188.

Corton JC, Anderson SP and Stauber A (2000) Central role of peroxisome proliferator-activated receptors in the actions of peroxisome proliferators. Annu Rev Pharmacol Toxicol 40:491-518.

Dang C and Semenza G (1999) Oncogenic alterations of metabolism. Trends in Biochem Sci. 24:68-72.

Dekant W and Vamvakas S (1996) Biotransformation and membrane transport in nephrotoxicity. Crit Dev Toxicol 26:309-334.

Dembic Z, Haas W, Weiss S, McCubrey J, Keifer H, von Beohmer H and Steinmetz M (1986) Transfer of specificity by murine alpha and beta T-cell receptor genes. Nature 320:232-238. 
de Paulsen N, Brychzy A, Fournier M, Kluasner R, Gnarra J, Pause A and Lee S (2001) Role of transforming growth factor-alpha in von-Hippel Lindau (VHL)(-/) clear cell renal carcinoma cell proliferation: a possible mechanism coupling VHL tumor suppressor inactivation and tumorigenesis. PNAS 98:1387-1392.

Deryugina E and Quigley J (2006) Matrix metalloproteinases and tumor metastasis. Cancer Metastasis Rev 25:9-34.

Desvergne B and Wahli W (1999) Peroxisome proliferator-activated receptors: nuclear control of metabolism. Endocr Rev 20:649-88.

Dillon R, White D and Muller W (2007) The phosphatidyl inositol 3-kinase signaling network: implications for human breast cancer. Oncogene 26:13381345.

Dinour D, Chang M, Satoh J, Smith BL, Angle N, Knecht A, Serban I, Holtzman E and Romero M (2004) A novl missense mutation in the sodium bicarbonate cotransporter (NBCe1/SLC4A4) causes proximal tubular acidosis and glaucoma through ion transport defects. J Biol Chem 279:52238-52246.

Dische F, Weston M and Parsons V (1985) Abnormally thin glomerular basement membranes associated with hematuria, proteinuria or renal failure in adults. Am J Nephrol 5:103-109.

Doll R and Peto R (1981) the causes of cancer: quantitative estimates of avoidable risks of cancer in the US today. $J$ Natl Cancer Inst 66:1191-1308. Dong D, Dubeau L, Bading J, Nguyen K, Luna M, Yu H and Gazit-Bornstein (2004) Spontaneous and controllable activation of suicide gene expression 
driven by the stress-inducible grp78 promoter resulting in eradication of sizable human tumors. Hum Gene Ther 15:553-561.

Dunham M, Neumann A, Fasching C and Reddel R (2000) Telomere maintenance by recombination in human cells. Nat Genet 26: 447-450.

Dunn G, Bruce A, Ikeda H, Old L and Schrieber R (2002) Cancer immunoediting: from immunosurveilance to tumor escape. Nat Immunol 3:991-998.

Duriez P and Shah G (1997) Cleavage of poly(ADP-ribose) polymerase: a sensitive parameter to study cell death. Biochem Cell Biol 75: 337-349.

Dvorak H (2002) Vascular permeability factor/vascular endothelial growth factor: a critical cytokine in tumor angiogenesis and a potential target for diagnosis and therapy. J Clin Oncol 20:4368-4380.

Dvorak H, Senger D, Dvorak A, Harvey V and McDonagh J (1985) Regulation of extravascular coagulation by microvascular permeabiltiy. Science 227:10591061.

Edgington T, Glassock R and Dixon F (1968) Autologous immune complex nephritis induced with renal tubular antigen. Identification and isolation of the pathogenetic antigen. J Exp Med 127:555-572.

Eling T, Baek S, Shim M and Lee C (2006) NSAID activated gene (NAG-1), a modulator of tumorigenesis. J Biochem Mol Bio/ 39: 649-655.

Elnemr A, Ohta T, Iwata K, Ninomia L, Fushida S, Nishimura G, Kitagawa H, Kayahara M, Yammoto M, Terada T and Miwa K (2000) PPARy ligand 
(thiazolidinedione) induces growth arrest and differentiation markers of human pancreatic cancer cells. Int J Oncol 17:1157-1164.

Elstner E, Muller C, Koshizuka K, Williamson E, Park D, Asou H, Shintaku P, Said J, Heber D, Koeffler H (1998) Ligands for peroxisome proliferatoractivated receptor gamma and retinoic acid receptor inhibit growth and induce apoptosis of human breast cancer cells in vitro and in BNX mice. Proc Natl Acad Sci U S A 95:8806-8811.

Engelman J, Zang X, Galbiati F and Lisanti M (1999) Genes encoding human caveolin-1 and 2 are located to the D7S522 locus (7q31.1) a known fragile site that is frequently deleted in human cancers. FEBS Lett 436:403-410.

Escher P and Wahli W (2000) Peroxisome proliferator-activated receptors: insight into multiple cellular functions. Mutat Res 448:121-138.

Esteban M, Tran M, Harten S, Hill P, Castellanos M, Chandra A, Raval R, O'brien T, Maxwell P (2006) Regulation of E-daherin expression by VHL and Hypoxia-inducible factor. Cancer Res 66:3567-3575.

Evans W and Relling M (1999) Pharmacogenomics: translating functional genomics into rational therapeutics. Science 286:487-491.

Fajas L, Debril MB and Auwerx J (2001) Peroxisome proliferator-activated receptor-g: from adipogenesis to carcinogenesis. J Mol Endocrinol 27:1-9.

Fan Y, Liu Z, Fang X, Ge Z, Ge N, Jia Y, Sun O, Lou F, Bjorkholm M, Gruber A, Ekman P and Xu D (2005) Differential expression of full-length reverse 
transcriptase mRNA and telomerase activity between normal and malignant renal tissues. Clin Cancer Res 11:4331-4337.

Farber J and el Mofty S (1975) The biochemical pathology of liver cell necrosis. Am J Pathol 81:237-250.

Folkman J (1971) Tumor angiogenesis: therapeutic implications. N Eng J Med 285:1182-1186.

Fujiwara T, Verbalis, J and Nielson S (1995) Molecular biology of diabetes insipidus. Annu Rev Med 46:331-343.

Gazit G, Lu J and Lee A (1999) De-regulation of GRP stress protein expression in human breast cancer cell lines. Breast Cancer Res Treat 54:135-146.

Giancotti F and Ruoshlahti E (1999) Integrin signaling. Science 285:1028-1032.

Giehl K (2005) Ocogenic Ras in tumour progression and metastasis. Biol Cheml 386:193-205.

Grommes C, Landreth G and Heneka M (2004) Antineoplastic effects of Peroxisome proliferator-activated receptor y agonists. Lancet Oncol 5:419429.

Griffith J, Comeau L, Rosenfield S, Stansel R, Bianchi A, Moss H and de Lange T (1999) Mammalian telomeres end in a large duplex loop. Cell 97:503-514. Gudjonsson T and Magnusson M (2005) Stem cell biology and the cellular pathways of carcinogenesis. APMIS 113:922-929. 
Gudjonsson T, Villadsen R, Nielson H, Ronnov-Jessen L, Bissel M and Peterson O (2002) Isolation, immortalization and characterization of a human breast epithelial cell line with stem cell properties. Genes Dev 16:693-706.

Gupta RA, Brockman JA, Sarraf P, Willson TM and DuBois RN (2001). Target genes of peroxisome proliferator-activated receptor $\mathrm{g}$ in colorectal cancer cells. J Biol Chem 276:29681-2967.

Gupta RA, Sarraf P, Mueller E, Brockman J, Prusakiewicz J, Eng C, Wilson T and DuBois R (2003) Peroxisome proliferator-activated receptor g-mediated differentiation: a mutation in colon cancer cells reveals divergent and cell type-specific mechanisms. J Biol Chem 278:22669-22677.

Gurova K, Hill J, Razorenova O, Chumakov P and Gudkov A (2004) p53 pathway in Renal cell carcinoma is repressed by a dominant mechanism. Cancer Res 64:1951-1958.

Hai T and Hartman M (2001) The molecular biology and nomenclature of the activating transcription factor/cAMP responsive element binding family of transcription factors: activating transcription factor proteins and homeostasts. Gene 273:1-11.

Hanahan D and Weinberg R (2000) The hallmarks of cancer. Cell 100:57-70. Harris C (1996) p53 tumor suppressor gene: from the basic research laboratory to the clinic- an abridged historical perspective. Carcinogenesis 17:11871198. 
Hart I and Fidler I (1980) Role of organ selectivity in the determination of metastatic patterns of B16 melanoma. Cancer Res 40:2281-2287.

Hayflick L (1964) The limited in vitro lifetime of human diploid cell strains. Exp Cell Res 37:614-636.

Hecht S, Carmela S, Mori H and Hoffman D (1981) A study of tobacco carcinogenesis XX. Role of catechol as a major cocarcinogen in the weakly acidic fraction of smoke condensate. J Natl Cancer Inst 66:163-169.

Hedberg Y, Ljungberg B, Roos G and Landberg G (2004) Retinoblastoma protein in human renal cell carcinoma in relation to alterations in G1/S regulatory protiens. Int J Cancer 109:189-193.

Hegele A, Varga Z, von Knobloch, Heidenreich A. Olbert P, Kropf J, Hofmann R (2003) Cellular fibronectin in patients with transitional cell carcinoma of the bladder. Urol Res 301:126-129.

Hemminki K and Xinjun L (2002) Cancer risks in second-generation immigrants to Sweden. Int J Cancer 99:229-237.

Herrera M, Ortiz P and Garvin J (2006) Regulation of the thick ascending limb transport: role of nitric oxide. Am J Physiol Renal Physiol 290:F1279-F1284. Hoenderop J, Nilius B and Bindels R (2005) Calcium absorption across epithelia. Physiol Rev 85:373-422.

Holick M (2003) Vitamin D: a millinium perspective. J Cell Biochem 62:301-313. 
Holick M (2004) Sunlight and vitamin D for bone health and prevention of autoimmune diseases, cancers, and cardiovascular disease. Am J Clin Nutr 80:1678S-1688S.

Holmberg C, Antikainen M, Ronnholm K, Ala-Louhala M and Jalenko H (1995) Management of congenital nephritic syndrom of the Finnish type. Pediatr Nephro/ 9:87-93.

Hong J, Samudio I, Liu S, Abdelrahim M and Safe S (2004) Peroxisome proliferator-activated receptor g-dependent activation of p21 in Panc-28 pancreatic cancer cells involves Sp1 and Sp4 proteins. Endocrinology 145:5774-5785.

Hunt J, van der Hel, O, McMilliam G, Boffeta P and Brennan P (2005) Renal cell carcinoma in relation to cigarette smoking: meta-analysis of 24 studies. Int $J$ Cancer 114:101-108.

Hursting S, Slaga T, Fishcer S, DiGiovanni J, Phang J (1999) Mechanism-based cancer prevention approaches: targets, examples, and the use of transgenic mice. J Natl Cancer Inst 91:215-225.

Ikezoe T, Miller CW, Kawano S, Heaney A, Williamson F, Histake J, Green E, Hofmann W, Taguchi H and Koeffler H (2001) Mutational analysis of the peroxisome proliferator-activated receptor $\mathrm{g}$ gene in human malignancies. Cancer Res 61:5307-5310.

Inui K, Satohiro M and Saito H (2000) Cellular and molecular aspects of drug transport in the kidney Kidney Int 58:944-958. 
Isseman I and Green S (1990) Activation of a member of the steroid hormone receptor superfamily by peroxisome proliferators. Nature 347:645-650.

Jalanko H, Patrakka J, Tryggvason K and Holmberg C (2001) Genetic kidney diseases disclose the pathogenesis of proteinusia. Ann Med 33:526-533.

Jaradat M and Molitoris B (2002) Cardiovascular disease in patients with chronic kidney disease. Sem Nephrol 59:615-627.

Jemal A, Siegal R, Ward E, Murray T, Xu J, Smigal C and Thun M (2006) Cancer Statistics, 2006. CA Cancer J Clin. 56:106-130.

Kalluri R, Shield C, Todd P, Hudson B and Neilson E (1997) Isoform switching of type IV collagen is developmentally arrested in X-linked Alport syndrome leading to increased susceptibility of renal basement membranes to endoproteolysis. J Clin Invest 98:2470-2478.

Kanwar Y (1984) Biology of disease: biophysiology of glomerular filtration and proteinuria. Lab Invest 51:7-21.

Karlsseder J, Smogorzesska A, de Lange T (2002) Senescence induced by altered telomere state, not telomere loss. Science 295:2446-2449.

Kassouf W, Chintharlapalli S, Abdelrahim M, Nelkin G, Safe S and Kamat A. (2006) Inhibition of bladder tumor growth by 1,1-Bis(3'-indolyl)-1-(psubstitutedphenyl)methanes: a new class of peroxisome proliferatoractivated receptor gamma agonists. Cancer Res 66:412-418.

Kato M, Kusumi T, Tsuchida S, Tanaka M, Sasaki M and Kudo H (2004) Induction of differentiation and peroxisome proliferator-activated receptor $\mathrm{g}$ 
expression in colon cancer cell lines by troglitazone. J Cancer Res Clin Oncol 130:73-79.

Kestila M, Lenkkeri U, Mannikko M, Lamerdin J, McCready P, Putaala H, Ruotsalainen V, Morita T, Nissinen M, Herva R, Kashtan C, Peltnonen L, Holmberg C, Olsen A and Tryggvason K (1998) Positionally cloned gene for a novel glomerular protein-nephrin is mutated in congenital nephritic syndrome. Mol Cell 1:575-582.

Khosla S (2001) The OPG/RANKL/RANK system. Endocrinology 142:50505055.

Kim J, Tchernshyov, Semenza G and Dang C (2006) HIF-1-mediated expression of pyruvate dehydrogenase kinase: A metabolic switch required for cellular adaptation to hypoxia. Cell Metabo/ 3:177-185.

Kimura K, Hirata T, Nanba S, Tojo A, Matuoka H and Sugimoto T (1990) Effects of atrial natriuretic peptide on renal arterioles: morphometric analysis using microvascular casts. Am J Physiol 259:F936-944.

Kinne R (1975) Polarity of the proximal tubular cell: function and enzyme pattern of the isolated plasma membranes. Med Clin North Am 59:615-627.

Kitamura S, Miyazaki Y, Shinomura Y, Kondo S, Kanayama S and Matsuzawa Y (1999). Peroxisome proliferator-activated receptor $g$ induces growth arrest and differentiation markers of human colon cancer cells. Jpn J Cancer Res 90:75-80. 
Knepper M and Inoue T (1997) Regulation of aquaporin-2 water channel trafficking by vasopressin. Curr Opin Cell Bio/ 9:560-564.

Knight D and Stadler W (2007) Prognostic factors in localized renal cell cancer. BJU Int 99:1212-1216.

Koide A, Fuwa K, Furukawa F, Hirose M, Nishikawa A and Mori Y (1999) Effect of cigarette smoke on the mutagenic activation of environmental carcinogens by rodent liver. Mutat Res 428:165-176.

Koong A, Chen E, Lee A, Brown J and Giaccia A (1994) Increased cytotoxicity of chronic hypoxic cells by molecular inhibition of GRP78 induction. Int $J$ Radiat Oncol Biol Phys 1:661-616.

Kopper L and Timar J (2006) Genomics of renal cell cancer-does it provide breakthrough. Pathol Oncol Res 12:5-11.

Koumenis C (2006) ER stress, hypoxia tolerance and tumor progression. Curr Mol Med 6:55-69.

Kubic V and Anders M (1978) Metabolism of dihalomethanes to carbon monoxide-III. Studies in the mechanism of the reaction. Biochem Pharmacol 27:2349-2355.

Lash L and Anders M (1989) Uptake of nephrotoxic S-conjugates by isolated rat renal proximal tubular cells. J Pharmacol Exp Ther. 248:531-537.

Lee $\mathrm{CH}$, Olson P and Evans RM (2003) Minireview: lipid metabolism, metabolic diseases, and peroxisome proliferator-activated receptors. Endocrinology 144:2201-2207. 
Lee S, Yamaguchi K, Kim J, Eling T, Safe S, Park Y and Baek S (2006) Conjugated linoleic acid stimulates an anti-tumorgenic protein NAG-1 in an isomer specific manner. Carcinogenesis 27:972-981.

Lei P, Abdelrahim M and Safe S (2006) 1,1-Bis(3'-indolyl)-1-( $p$-substituted phenyl)methanes inhibit ovarian cancer cell growth through peroxisome proliferator-activated receptor-dependent and independent pathways. Mol Cancer Ther 5:2324-2336.

Lemmink H, Schroder C, Monnens L and Smeets H (1997) The clinical spectrum of type IV collagen mutations. Hum Mutat 9:477-499.

Leung S and Ohh M (2002) Playing tag with HIF: the VHL story. J Biomed Biotechnol 2:131-135.

Levin A (2006) Kidneys, hearts, hormones and immunomodulators: integrated understandings. Blood Purif 24:46-50.

Li B, Gao B, ye L, Han X, Wang W, Kong L, Fang X, Zheng H, Li S, Wu Z, Ye L (2007) Adaptation to ER stress is mediated by differential stabilities of prosurvival and pro-apoptotic mRNAs and proteins. PLoS Biol 4:e374.

Li J and Lee A (2006) Stress induction of GRP78/BiP and its role in cancer. Curr Mol Med 6:5987-5993.

Lin X, Nelson PP, Gelman H (2000) SSeCKS, a makor protein kianse C substrate with tumor suppressor activity, regulates G1-S compartmentalization of cyclin D. Mol Cell Bioll 18:7259-7272. 
Li P, Wong J, Ayed A, Ngo D, Brade A, Arrowsmith C, Austin R and Klamut H (2000) Placental transforming growth factor-beta is a downstream mediator of the growth arrest and apoptotic response of tumor cells to DNA damage and p53 overexpression. J Biol Chem 275:20127-20135.

Lipworth L, Tarone R and McLaughlin J (2006) The epidemiology of renal cell carcinoma. J Urol 176:2353-2358.

Liotta L, Kleinerman J and Saidel G (1974) Quantitative relationships of intravascular tumor cells: tumor vessels and pulmonary metastases following tumor implantation. Cancer Res 34:997-1003.

Liu X, Zou H, Slaughter C and Wang X (1997) DFF, a heterodimeric protein that functions downstream of caspase-3 to trigger DNA fragmentation during apoptosis. Cell 89:175-184.

Loda M, Cukor B, Tam S, Lavin P, Fiorentino M, Draetta G, Jessup J, Pagano M (1997) Increased proteasome-dependent degredation of the cyclin-dependent kinase inhibitor p27 in aggressive colorectal carcinomas. Nat Med 3:231-234. Lola P and Graham C (1990) Mechanisms of trophoblast invasiveness and their control: the role of the proteases and protease inhibitors. Cancer Metastasis $\operatorname{Rev}$ 9:396-380.

Macklin K, Maus A, Pererira E, Albuquerque B, Conti-Fine B (1998) Human vascular endothelial cells express functional nicotinic acetylcholine receptors. J Pharmaco Exp Ther 287:435-439. 
Malabanan A, Turner A and Holick M (1998) Severe generalized bone pain and osteoporosis in premenopausal black female: effect of vitamin D replacement. J Clin Densitometr 1:201-204.

Malumbres M and Barbacid M (2001) To cycle or not to cycle: a critical decision in cancer. Nat Rev Cancer 1:222-231.

Mangelsdorf DJ, Thummel C, Beato M, Herrlich P, Schutz G, Umesono K, Blumberg B, Kastner P, Mark M, Chambon P and Evans R (1995) The nuclear receptor superfamily: the second decade. Cell 83:835-839.

Mannervik B and Danielson U (1988) Glutathione transferases - structure and catalytic activity. Crit Rev. Biochem 283:283-337.

Marin E and Sessa W (2007) Role of endothelial-derived nitric oxide synthase in hypertension and renal disease. Curr Opin Nephrol Hypertens 16:105-110.

Markowitz S, Wang J, Myeroff L, Parsons R, Sun L, Lutterbaugh J, Fan R, Zborowska E, Kinzler K, Vogelstein et al. (1995) Inactivation of the type II TGF-beta receptor in colon cancer cells with microsatellite instability. Science 268:1336-1338.

Mariotto A, Rowland J, Ries L, Scoppa S and Fauer E (2007) Multiple cancer prevalence: a growing challenge in long-term survivorship. Cancer Epidemiol Biomarkers Prev 16:566-571.

Mashima T, Najito M, Fujita N, Noguchi K and Tsurou T (1995) Identification of actin as a substrate of ICE and an ICE-like protease and involvement of an 
ICE-like protease but not ICE in VP-16-induced U937 apoptosis. Biochem Biophys Res Commun 217:1185-1192.

Mathew A, Devesa S, Fraumeni J and Chow A (2002) Global increases in kidney cancer incidence. 1973-1992. Eur J Cancer Prev 11:171-178.

Maustakas A, Souchelnytksi S and Heldin C (2001) Smad regulation in TGFbeta signal transduction. J Cell Sci 114:4359-4369.

McCredie M, Pommer W, McLaughlin J, Stewart J, Lindblad P and Mandel J (1995) International renal cell cancer study II. Analgesics. Int J Cancer 60:345-349.

McDermott D and Rini B (2007) Immunotherapy for metastatic renal cell carcinoma. BJU Int 99:1282-1288.

McLaughlin J and Lipworth L (2000) Epidemiologic aspects of renal cell cancer. Semin Oncol 27:115-123.

McLaughlin J, Lindblad P, Mellemgaard A, McCredie M, Mandel, Schlehofer B, Pommer W and Adami H (1995) International renal-cell cancer study. I. Tobacco use. Int J Cancer 60:194-198.

Medema R and Bos J (1993) The role of p21-ras in receptor tyrosine kinase signaling. Crit Rev Oncog 4:254-256.

Melendez-Colon V, Luch A, Seidel A and Bair W (1999) Cancer initiation by polycyclic aromatic hydrocarbons results from formation of stable DNA adducts rather than apurinic sites. Carcinogenesis 20:1885-1891. 
Michael A and Pandha H (2003) Renal-cell carcinoma: tumour markers, T-cell epitopes, and potential for new therapies. Lancet Oncol 4:215-223.

Miller D (1995) Daunomycin secretion by killifish renal proximal tubules. Am J Physiol 269:R370-R379.

Mita M, Mita A and Rowinsky E (2003) The molecular target of rapamycin (mTOR) as a therapeutic target against cancer. Cancer Biol Ther 24:S169177.

Moller DE (2001) New drug targets for type 2 diabetes and the metabolic syndrome. Nature 414:821-827.

Monks T, Anders M, Dekant W, Stevens J, Lau S and van Bladeren P (1990) Glutathione conjugate mediated toxicities. Toxicol Appl Pharmacol 106:1-19. Morrison R and Farmer S (1999) Role of PPARgamma in regulating a cascade expression of cyclin-dependent kinase inhibitors, p18(INK4c) and p21(Waf1/Cip1), during adipogenesis. J Biol Chem 274:17088-17097.

Motomura W, Okumura T, Takahashi N, Obara T and Kohgo Y (2000) Activation of peroxisome proliferator-activated receptor gamma by troglitazone inhibits cell growth through the increase of $\mathrm{p} 27^{\mathrm{KiP} 1}$ in human pancreatic carcinoma cells. Cancer Res 60:5558-5564.

Motzer RJ and Bukowski RM (2006) Targeted therapy for metastatic renal cell carcinoma. J Clin Oncol 2:5601-5608.

Moustakas A, Souchelnytksyi S and Heldin C (2001) Smad regulationin TGFbeta signal transduction. J Cell Sci 114:4359-4359. 
Mukhopadhyay D, Knebelmann B, Cohen H, Ananth S and Sukhatme V (1997) The von Hippel-Lindau tumor suppressor gene product interacts with Sp1 to repress vascular endothelial growth promoter activity. Mol Cell Biol 17:56295639.

Nagata S (1997) Apoptosis by death factor. Cell 88:355-365.

Nagi A, Alexander F and Barabas A (1971) Gold nephropathy in rats-light and electron microscope studies. Exp Mol Pathol 15:354-362.

Nakamura S (2004) Glucose activates H(+)-ATPase in kidney epithelial cells. Am J Physiol Cell Physiol 287:C97-C105.

Nangaku M and Couser W (2005) Mechanisms of immune-deposit formation and the mediation of immune renal injury. Clin Ex Neprol 9:183-191.

Nash K, Hafeez A and Hou S (2002) Hospital aquired renal insufficiency. Am J Kidney Dis 39:930-936.

Nebert D and Dalton T (2006) The role of cytochrome p450 enzymes in endogenous signaling pathways and environmental carcinogenesis. Nat Rev Cancer 6:947-960.

Newman S, Sakaue M, Koo J, Kim K, Baek S, Eling T and Jetten A (2003) Differential regulation of nonsteroidal anti-inflammatory drug-activated gene in normal human tracheobronchial epitheial and lung carcinoma cells by retinoids. Mol Pharmacol 63:557-564.

Nicholson D and Thornberry N (1997) Caspases: killer proteases. Trends Biochem Sci 22: 1312-1316. 
Novick A and Campbell S (2002) Campbells Urology (Walsh P, Retik AB, and Vaughan E, eds) pp 2672-2731, W.B. Saunders, Philadelphia.

Nykjaer A, Dragun D, Wlather D, Vorum H, Jacobsen C, Herz J, Meslson F, Christensen E and Willnow T (1999) An endocytic pathway essential for renal uptake and activation of the steroid $25-(\mathrm{OH})$ vitamin $\mathrm{D}_{3}$. Cell 96:507-515 O'Conner P (2006) Renal Oxygen Delivery: Matching delivery to metabolic demand. Clin Exp Pharmacol Physiol 33:961-967.

Olovnikov A (1973) A theory of marginotomy. The incomplete copying of template margin in enzymic synthesis of polynucleotides and biological significance of the phenominon. J Theor Biol 41:181-190.

Oyadomari S and Mori M (2004) Roles of CHOP/GADD153 in endoplasmic reticulum stress. Cell Death Differ 11:381-389.

Palmer C, Hsu M, Griffin H, Johnson E (1995) Novel sequence determinants in peroxisome proliferator signaling. J Biol Chem 270:16114-16121 .

Panigrahy D, Singer S, Shen L, Butterfield C, Freedman D, Chan E, Moses M, Kilroy S, Duensing S, Fletcher C, Fletcher J, Hlatky L, Hahnfeldt P, Folkman J and Kaipainen A (1999) PPARy ligands inhibit primary-tumor growth and metastisis by inhibiting angiogenesis. J Clin Invest 110: 923-932.

Paralkar V, Vail A, Grassner W, Brown T, Xu H, Vukicevic S, Ke H, Qi H, Owen T, Thompon D (1998) Cloning and characterization of a novel member of the transforming growth factor-beta/bone morphogenetic protein family. J Biol Chem 273:13760-13767. 
Pardee A (1974) A restriction point for control of normal cell proliferation. Proc Natl Acad Sci USA 71:1286-1290.

Parhami F, Bostrom K, Watson K and Demer L (1996) Role of molecular regulation in vascular calcification. $J$ Atheroscler Thromb 3:90-94.

Petrella B and Brinckerhoff C (2006) Tumor cell invasion of von-Hippel Lindau renal cell carcinoma cells is mediated by membrane type- 1 matrix metalloproteinase. Mol Cancer 5:66.

Pilot H (1989) Progression: the terminal stage in carcinogenesis. Jpn J Cancer Res 80:599-607.

Place AE, Suh N, Williams CR, Risingsong R, Honda T, Honda Y, Gribble G, Lessnitzer L, Stimmel J, Wilson T, Rosen E and Spom M (2003) The novel synthetic triterpenoid, CDDO-imidazolide, inhibits inflammatory response and tumor growth in vivo. Clin Cancer Res 9:2798-2806.

Portale A, Booth B, Halloran B and Morris R (1984) Effect of dietary phosphorus on circulating concentrations of 1,25-dihydroxyvitamin D and immunoreactive parathyroid hormone in children with moderate renal insufficiency. $J$ Clin Invest 73:1580-1589.

Presta L, Chen H, O'Conner S, Chisholm V, Men Y, Krummen L, Winkler M and Ferrera N (1997) Humanization of an anti-vascular endothelial growth factor monoclonal antibody for the therapy of solid tumors and other disorders. Cancer Res 57:4593-4599. 
Presta M, Dell'Era P, Mitola S, Moroni E, Ronca R and Rusnati M (2005) Fibroblast growth factor/fibroblast growth factor receptor system in angiogenesis. Cytokine Growth Factor Rev 29:305-317.

Qin C, Burghardt R, Smith R, Wormke M, Stewart J, Safe S (2003) Peroxisome proliferator-activated receptor g (PPARg) agonists induce proteasomedependent degradation of cyclin D1 and estrogen receptor a in MCF-7 breast cancer cells. Cancer Res 63:958-964.

Qin C, Morrow D, Stewart J, Spencer K, Porter W, Smith R, Phillips T, Abdelrahim M, Samudio L and Safe S (2004). A new class of peroxisome proliferator-activated receptor $\mathrm{g}$ (PPARg) agonists that inhibit growth of breast cancer cells: 1,1-bis(3'-indolyl)-1-(p-substitutedphenyl)methanes. Mol Cancer Therap. 3:247-59.

Rahn K, Heidenreich S and Bruckner D (1999) How to assess glomerular function and damage in humans. J. Hypertens 17:309-317.

Rashidkhani B, Lindblad P and Wolk A (2005) Fruits, vegetables and risk of renal cell carcinomas: a prospective study of Swedish women. Int J Cancer 113:451-455.

Razani M, Woodman S and Lisanti M (2002) Caveolae: from cell biology to animal physiology. Pharmacol Rev 54:431-467.

Renan M (1993) How many mutations are required for tumorigenesis? Implications from human cancer data. Mol Carcinogenesis 7:139-146. 
Reitz R, Medrala A and Guengerich F (1989) In vitro metabolism of methylene chloride in human and animal tissue: use in physiologically based pharmacokinetic models. Toxicol Appl Pharmacol 97:230-246.

Rini B and Rathmell K (2007) Biological Aspects and Binding strategies of vascular endothelial growth factor in renal cell carcinoma. Clin Cancer Res 13(suppl): 741S-764S.

Robertson G (1983) Thirst and vasopressin function in normal and disorders states of water balance. J Lab Clin Med 101:35-371.

Robertson E and Rankin G (2006) Human renal organic anion transporters: characteristics and contributions to drug and drug metabolite excretion. Pharm Ther 109:399-412.

Roe J, Kim H, Lee S, Kim S, Cho E and Youn H (2006) p53 stabilization and transactivation by a von-Hippel-Lindau protein. Mol Cell 22:385-405.

Rosenberg S, Mule J, Spiess P, Reichert C and Schwarz S (1985) Regression of established pulmonary metastases and subcutaneous tumor mediated by the systemic administration of high dose recombinant interleukin 2. J Exp Med 161: 1169-1188.

Rosen E and Spiegelman BM (2001) PPARg: a nuclear regulator of metabolism, differentiation, and cell growth. J Biol Chem 276:37731-37334. Rubin H (2002) Selective clonal expansion and microenvironmental permissiveness in tobacco carcinogenesis. Oncogene 21:7392-7411. 
Ruggeri B, DiRado M, Zhang S, Bauer B, Goodrow T and Klein-Szanto A (1993) Benzo[a]pyrene-induced murine skin tumors exhibit frequent and characteristic $\mathrm{G}$ to $\mathrm{T}$ mutations in the p53 gene. Proc Natl Acad Sci USA 90:1013-1017.

Ruth J and Wassner S (2006) Body composition: salt and water. Pediatr Rev 27:181-187.

Sabo E, Miselevich I, Bejar J, Segenreich M, Wald M, Moskovitz B and Nativ O (1997) The role of vimentin expression in predicting the long-term outcome of patients with localized renal cell carcinoma. $\mathrm{Br} J$ Uro/ 80: 864-868.

Sainsbury J, Anderson T and Morgan D (2000) ABC of breast disease: breast cancer. BMJ 321:745-750.

Sakahira H, Enari M and Nagata S (1998) Cleavage of CAD inhibitor in CAD activation and DNA degredation during apoptosis. Cell 89: 96-99.

Sano F, Elisabetta F, Tufi R, Achsel T, Piacentini M and Cecconi F (2006) Endoplasmic reticulum stress induced apoptosis by an apoptososmedependent but caspase 12-independent mechanism. J Biol Chem 281: 26932700.

Sarnak M and Levey A (2000) Epidemiology, diagnosis, and management of cardiac disease in chronic renal disease J Thromb Thrombolysis 10:169-180.

Schaller m, Hildebrand J, Shannon J, Fox J, Vines R and Parsons J (1994) Autophosphorylation of the focal adhesion kinase pp125FAK, direscts SH2dependent binding of pp60src Mol Cell Bio 14:1660-1668. 
Schlaepfer D, Hanks S, Hunter T and van der Geer P (1994) Integrin-mediated signal transduction linked to Ras pathway by Grb2 binding to focal adhesion kinase. Nature 372:786-791.

Sejima T, Isoyama T, Miyagawa I (2003) Alteration of apoptotic regulatory molecules expression during carcinogenesis and tumor progression of renal cell carcinoma. Int $J$ Urol 10:476-484.

Sell S (2004) Stem cell origin of cancer and differentiation therapy. Crit Rev Oncol Hematol 51:1-28.

Senger D, Galli S, Dvorak A, Perruzzi C, Harvey V and Dvorak H (1997) Tumor cells secrete a vascular permeability factor that promotes accumulation of ascites fluid. Science 219:983-985.

Shack S, Wang X, Kokkonen G, Gorospe M, Longo D and Holbrook N (2003) Caveolin-induced activation of phophatidylinositol 3-kinase/Akt pathway increases arsenite cytotoxicity. Moll Cell Bio 23:2407-2414.

Shay J and Wright W (2005a) Senescence and immortalization: role of telomeres and telomerase. Carcinogenesis 26:867-874.

Shay J, Wright W and Werbin H (1991) Defining the molecular mechanisms of human cell immortalization. Biochim Biophys Acta 1072:1-7.

Smith K and Gunaratnum et al. (2005) Silencing of epidermal growth factor receptor suppresses hypoxia-inducible factor-2 driven VHL -/- renal cancer. Cancer Res 65:5221-5230

Sporn M (1996) War on cancer. Lancet 347:1377-1381. 
Stanton B and Koeppen B (2001) Renal Physiology $3^{\text {rd }}$ edition. Mosby, Missouri. Starry H (2000) Natural history of calcium deposits in the atherosclerosis progression and regression. $Z$ Kardiol 89:28-35.

Staeler M, Rohrmann N, Haseke C, Stief C and Siebels M (2005) Targeted agents for the treatment of advanced renal cell carcinoma. Curr Drug Targets 6: 835-846.

Stevens J and Jakoby W (1983) Cysteine conjugate $\beta$-lysase. Mol Pharmacol 23:761-765.

Stewart A and Weinberg R (2006) Telomeres: cancer to human aging. Annu rev Cell Dev Biol 22:531-557.

Strand S, Hoffman W and Hug H et al. (1996) Lymphocyte apoptosis induced by CD95 (APO-1/Fas) ligand-expressing tumour cells: a mechanism of immune evasion. Nature Med 2: 1361-1366.

Suki W (1979) Calcium transport in the nephron. Am J Physiol 237:F1-F6.

Suzuki Y, Ruiz Ortega M, Gomez-Guerrero C, Tomino Y and Egido J (2003) Angiotensin II, the immune system and renal diseases, another road for RAS? Nephrol Dial Transplant 18:1423-1426.

Swanton C (2004) Cell-cycle targeted therapies. Lancet Oncol 5:27-36.

Sweeney C and Farrow D (2000) Differential survival related to smoking among patients with renal cell carcinoma Epidemiology 11:344-346.

Tahir S, Yang G, Ebara S, Timme T, Satoh T, Li L, Goltsoc A, Itmann M, Morrisett J, Thompson T (2001) Secreted caveolin-1 stimulates cell 
survival/clonal growth and contributes to metastasis in androgen-insensitive prostate cancer. Cancer Res 61:3882-3885.

Takahashi N, Okumura T, Motomura W, Fujimoto Y, Kawabata I and Kohgo Y (1999) Activation of PPARg inhibits cell growth and induces apoptosis in human gastric cancer cells. FEBS Lett 455:135-9.

Takamoto S, Onishi T, Morimoto S, Imanaka S, Tsuchiya S, Seino Y, Yokokawa T, lida N and Kumahara Y (1985) Serum phosphate, parathyroid hormone and vitamin D metabolites in patients with chronic renal failure: effect of aluminum hydroxide administration. Nephron 40:286-291.

Takeyama K, Kitanaka S, Sato T, Kobori M, Yanagisawa J and Kato S (1997) 25-hydroxyvitamin $D_{3}, 1 \alpha$-hydroxylase and vitamin $D$ synthesis. Science 277:1827-1830.

Talhouk R, Bisell M and Werb Z (1992) Coordinated expression of extracellular matrix proteinases and their inhibitors regulates mammary epithelial function during involution. J Cell Biol 118:1271-1282.

Tareen N, Martins D, Nagami G, Levine B and Norris K (2005) Sodium disorders in the elderly. J Natl Med Assoc 97:217-224.

Thompson C, Bland J, Burd J and Baylis P (1986) The osmotic thresholds for thirst and vasopressin release are similar in healthy man. Clin Sci 71:651-656. Tomita Y (2006) Early renal cell cancer. Int J Clin Oncol 11:22-27. 
Trachtman H (1991) Cell volume regulation: a review of cerebral adaptive mechanisms and implications for clinical treatment of osmolal disturbances. Pediatr Nephrol 5:743-750.

Tsui K, Shvarts O, Smith R, Figlin R, deKernion J and Belledegrun A (2000) Renal cell carcinoma prognostic significance of incidentally detected tumors. J Urol 163:426-430.

Uwai Y, Okuda M, Takami K, Hashimoto Y and Inui K (1998) Functional characterization of the rat multispecific organic anion transporter OAT1 mediating basolateral uptake of anionic drugs in the kidney. FEBS letters 438:321-324.

Van Duuren B and Goldschmidt B (1976) Cocarcinogenic and tumor-promoting agents in tobacco carcinogenesis. J Natl Cancer Inst 56:1237-1242.

Verbalis J (2003) Disorders of body water homeostasis. Best Pract Res Clin Endocrinol Metab 17:471-503.

Vermeulen K, Bockstacle D and Berneman Z (2005) Apoptosis: mechanisms and relevance in cancer. Ann Hematol 84:627-639.

Virtanen I and Lehto V (2004) Progression of malignancy in clear cell renal cell carcinomas. Scand J Surg 93:112-117.

Vogelzang N and Sternberg C (2007) Signal-transduction inhibitors in renal cell carcinoma. BJU Int 99:1289-1295.

Volkel W and Dekant W (1998) Chlorothioketene, the ultimate reactive intermediate formed by cysteine conjugate beta-lyase-mediated cleavage of 
the trichloroethene metabolite S-(1,2-Dichlorovinyl)-L-cysteine, forms cytosine adducts in organic solvents, but not in aqueous solution. Chem Res Toxicol 11:1082-1088.

Volpe A and Jewett M. (2005) The natural history of small renal masses. Nat Clin Pract Urol 2: 384-390.

Wagner A, Kovacikova J, Stehberger P, Winter C, Banabbas C and Mohebbi N (2006) Renal acid-base transport: old and new players. Nephron Physiol 103:1-6.

Watson J (1974) Origin of concatemeric T7 DNA. Nat New Biol 239:197-201. Weinberg R, Masson S and Grose A (2007) The biology of cancer. Garland Science, Taylor and Francis group, New York.

Weinstein I (1988) The origins of human cancer: molecular mechanisms of carcinogenesis and their implications for cancer prevention and treatmenttwenty-seventh G.H.A. Clowes memorial award lecture. Cancer Res 48:41354143.

Wheeler J, Stourman N, Their R, Dommermouth A, Vuilleumier S, Rose, Armstrong R, Guengerich F (2002) Conjugation of haloalkanes by bacterial and mammalian glutathione transferases: mono- and dihalomethances. Chem Res Toxicol 14:1118-1127.

Williams R (1971) The metabolism of certain drugs and food chemicals in man. Ann N Y Acad Sci 179:141-154. 
Williams TM, Hassan GS, Li J, Cohen A, Medina F, Frank P, Pestell R, Di Vizio D, Loda M and Lisanti M (2005) Caveolin-1 promotes tumor progression in an autochthonous mouse model of prostate cancer: genetic ablation of Cav-1 delays advanced prostate tumor development in tramp mice. J Biol Chem 280:25134-25145.

Willson TM, Brown PJ, Sternbach DD and Henke BR (2000) The PPARs: from orphan receptors to drug discovery. J Med Chem 43:527-50.

Willson TM, Lambert MH and Kliewer SA (2001) Peroxisome proliferatoractivated receptor g and metabolic disease. Annu Rev Biochem 70:341-67.

Woodhouse E, Chuaqui R and Liotta L (1997) General mechanisms of metastasis. Cancer 80:1529-1537.

Wotkowicz C and Libertino J (2007) Renal cell cancer: radical nephrectomy. BJU 99:1231-1238.

Wright S (2005) Role of organic cation transporters in the renal handling of therapeutic agents and therapeutics. Toxicol Appl Pharmacol 204:309-319.

Wright S, Zhong J and Larrick J (1994) Inhibition of apoptosis as a mechanism of tumor promotion. FASEB J 8:654-660.

Yang G, Truong L, Timme T, Ren C, Wheeler T, Park S, Nasu Y, Bangma C, Katan M, Scardino P, Thompson T (1998) Elevated expression of caveolin is associated with prostate and breast cancer. Clin Cancer Res 4:1873-1880. 
Yang F, Zhang Z, Xin D, Shi C, Wu J, Guo Y and Guan Y (2005) Peroxisome proliferator-activated recpetor gamma ligands induce cell cycle arrest and apoptosis in human renal cell carcinoma. Urology 26:753-761.

Yang J, Haworth L, Sherry R, Hwu P, Shwartzentruber D, Topalian S, Steinberg S, Chen H, Rosenberg S (2003) A randomized trial of bevacizumab, an antivascular endothelial growth factor antibody, for metastatic renal cancer. $N$ Engl J Med 349:427-434.

Yarden Y and Ullrich A (1988) EGF and erbB2 receptor overexpression in human tumors. Growth factor receptor tyrosine kinases. Annu Rev Biochem $57: 443-478$.

Young R (1998) Metastatic renal cell carcinoma: what causes occaisional dramatic regressions? New Engl J Med 19:1649-1657.

Yuan J, Castelao J, Gago-Dominguez M, Ross R, and Yu M (1998) Hypertension, obesity and their medications in relation to renal cell carcinoma. Br J Cancer 77:1508-1513.

Yuan J, Takahashi A, Masumori N, Itoh N, Kitamura I and Tsukamoto T (2006) Peroxisome proliferator-activated receptor gamma is frequently underexpressed in renal cell carcinoma. Int J Urol 13:265-270.

Yuan, J, Takahashi A, Masumori N, Uchida K, Hisasue S, Kitamura I and Tsukamoto T (2005) Ligands for Peroxisome Proliferator-activated receptor gamma have potent antitumor effect against human renal cell carcinoma. Urology 65:594-599. 
Zander T, Kraus J, Grommes C, Schlegel U, Feinstein D, Klockgether T, Landreth Gm Koenisknect J, Heneka M (2000) Induction of apoptosis in human and rat gliomaby agonists of nuclear receptor PPARgamma. $J$ Neurosci Res 62:67-74.

Zhang T, Heng L, Shang X, Tian Y, Zheng C, Wang S, Cheng H and Zhou R (2006) Nicotine prevents the apoptosis induced by menadione in human lung cancer cells. Biochem Piophys Res Commun 342:928-934.

Zhang T, Wang L, Hashmi M, Anders M, Thorpe C and Ridge D (1995) Fouriertransform ion cyclotron resonance mass spectrometric evidence for the formation of a $\alpha$-chloroethenethiolates and thioketenes from chloroalkenederived cytotoxic 4-thiaalkanoates. Chem Res Toxicol 8:907-910.

Zeng H, Dvorak H and Mukhopadyay D (2001) Vascular permeability factor (VPF)/ vascular endothelail growth factor (VEGF) receptor-1 down-modulates VPF/VEGF receptor-2-mediated endothelial cell proliferation, but not migration, through phosphatidylinositol 3-kinase-dependent pathways. J Biol Chem 276:26969-26979. 


\section{VITA}

Name:

Professional title:

Mailing Address:

Toxicology Program Completion:

E-mail Address:
Melissa Dawn York

Graduate Assistant Research

2121 W. Holcombe Blvd. Rm 413

Houston TX 77030

3.0 years

myork2004@gmail.com

\section{Personal Information:}

Education: $\quad$ Present (Master of Science in Toxicology)

Texas A\&M University, College Station, TX (GPA 3.87/4.0) 2000-2004 BS Biology

Texas A\&M University, College Station, TX (GPA 3.77/4.0)

Internships: $\quad 2003$ Research Experience for Undergraduates

Awards: $\quad$ 2004-2006 Graduate Fellowship

Association of Former Students

\section{Published Articles}

York, M., Abdelrahim M, Chintharlapalli S and Safe, S. (2007) 1,1-Bis(3'Indolyl)-1-( $\rho$-substitutedphenyl)methanes induce apoptosis and inhibit renal cell carcinoma growth. Submitted to Clinical Cancer Research.

\section{Poster and Oral Presentations:}

York, M., Abdelrahim M, Chintharlapalli S and Safe, S. (2006) 1,1-Bis(3'Indolyl)-1-( $\rho$-substitutedphenyl)methanes induce apoptosis and inhibit renal cell carcinoma growth. Student Research Week. Texas A\&M University, College Station, Texas.

York, $\mathbf{M}$ and Safe, S. (2006) 1,1-Bis(3'-Indolyl)-1-( $\rho$-substitutedphenyl)methanes are Peroxsisome Proliferator-Activated Receptor $\gamma$ Agonists that Decrease Clear Cell Renal Carinoma Cell Survival Through Growth Inhibition, Induction of ER Stress and Increased Expression of NAG-1. Toxicology Symposium. College of Veterinary Medicine and Biomedical Sciences, Texas A\&M University, College Station, Texas.

York M, Reese E.D, Autenreith R.L. and Donnelly, K.C. (2003) Mutagenicity of PAHs in Binary Mixtures. Texas A\&M Research Symposium. Texas A\&M Universitiy, College Station, Texas. 